III) Nordic Council of Ministers

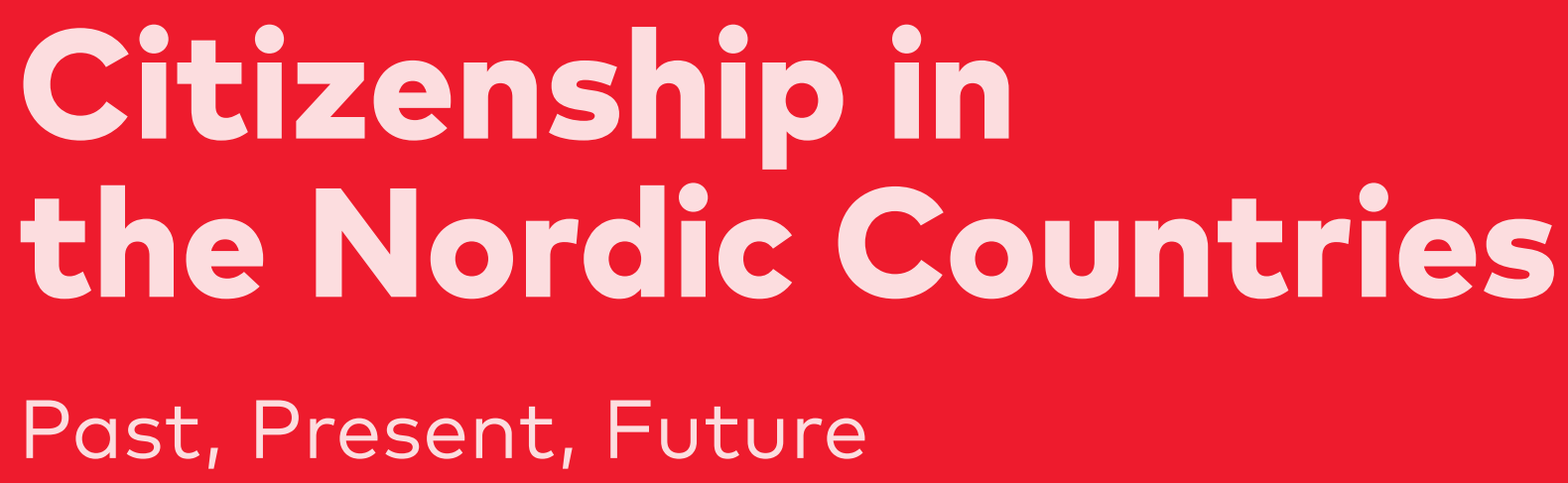





\section{Citizenship in the Nordic Countries}

Past, Present, Future

Arnfinn H. Midtbøen, Simon Roland Birkvad and Marta Bivand Erdal

TemaNord 2018:522 


\section{Citizenship in the Nordic Countries}

Past, Present, Future

Arnfinn H. Midtbøen, Simon Roland Birkvad and Marta Bivand Erdal

ISBN 978-92-893-5523-0 (PRINT)

ISBN 978-92-893-5524-7 (PDF)

ISBN 978-92-893-5525-4 (EPUB)

http://dx.doi.org/10.6027/TN2018-522

TemaNord 2018:522

ISSN 0.908-6692

Standard: PDF/UA-1

ISO 14289-1

(c) Nordic Council of Ministers 2018

Print: Rosendahls

Printed in Denmark

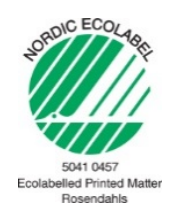

\section{Disclaimer}

This publication was funded by the Nordic Council of Ministers. However, the content does not necessarily reflect the Nordic Council of Ministers' views, opinions, attitudes or recommendations.

\section{Rights and permissions}

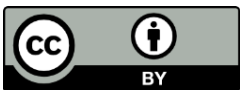

This work is made available under the Creative Commons Attribution 4.0 International license (CC BY 4.0) https://creativecommons.org/licenses/by/4.0

Translations: If you translate this work, please include the following disclaimer: This translation was not produced by the Nordic Council of Ministers and should not be construed as official. The Nordic Council of Ministers cannot be held responsible for the translation or any errors in it.

Adaptations: If you adapt this work, please include the following disclaimer along with the attribution: This is an adaptation of an original work by the Nordic Council of Ministers. Responsibility for the views and opinions expressed in the adaptation rests solely with its author(s). The views and opinions in this adaptation have not been approved by the Nordic Council of Ministers. 
Third-party content: The Nordic Council of Ministers does not necessarily own every single part of this work. The Nordic Council of Ministers cannot, therefore, guarantee that the reuse of third-party content does not infringe the copyright of the third party. If you wish to reuse any third-party content, you bear the risks associated with any such rights violations. You are responsible for determining whether there is a need to obtain permission for the use of third-party content, and if so, for obtaining the relevant permission from the copyright holder. Examples of third-party content may include, but are not limited to, tables, figures or images.

Photo rights (further permission required for reuse):

Any queries regarding rights and licences should be addressed to:

Nordic Council of Ministers/Publication Unit

Ved Stranden 18

DK-1061 Copenhagen K

Denmark

Phone +4533960200

pub@norden.org

\section{Nordic co-operation}

Nordic co-operation is one of the world's most extensive forms of regional collaboration, involving Denmark, Finland, Iceland, Norway, Sweden, and the Faroe Islands, Greenland and Åland.

Nordic co-operation has firm traditions in politics, economics and culture and plays an important role in European and international forums. The Nordic community strives for a strong Nordic Region in a strong Europe.

Nordic co-operation promotes regional interests and values in a global world. The values shared by the Nordic countries help make the region one of the most innovative and competitive in the world.

The Nordic Council of Ministers

Nordens Hus

Ved Stranden 18

DK-1061 Copenhagen K, Denmark

Tel.: +4533960200 www.norden.org

Download Nordic publications at www.norden.org/nordpub 



\section{Contents}

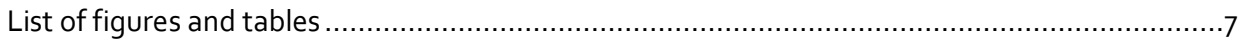

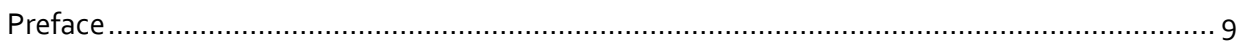

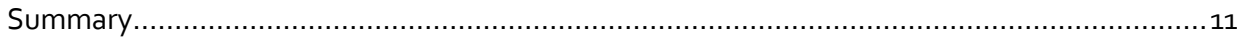

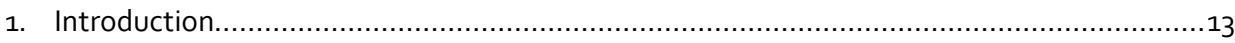

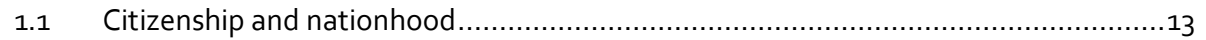

1.2 Immigration to the Nordic countries ......................................................... 15

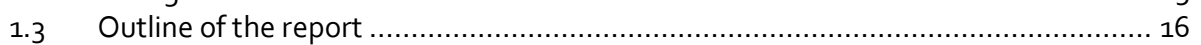

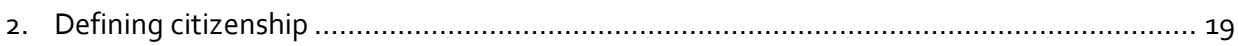

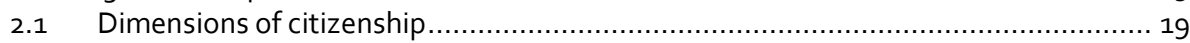

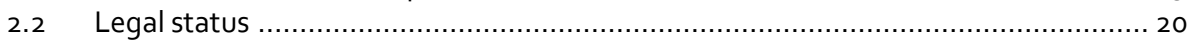

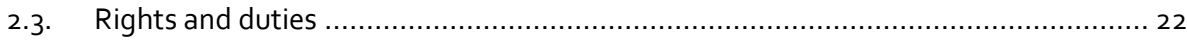

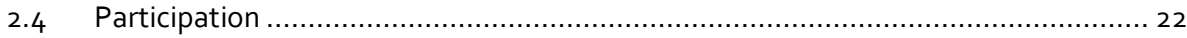

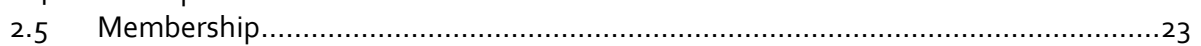

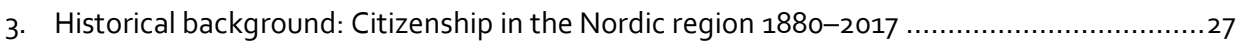

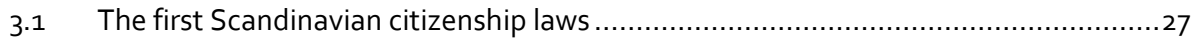

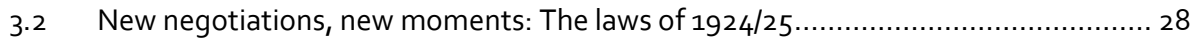

3.3 The postwar years: A uniform citizenship in the Nordic region? ............................ 29

3.4 From the postwar era to the end of the 2oth century .................................... 30

3.5 The 2000s: Revisions, amendments, divergence ............................................ 32

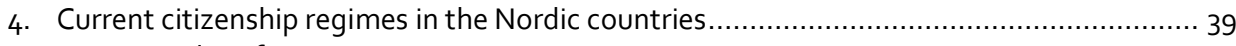

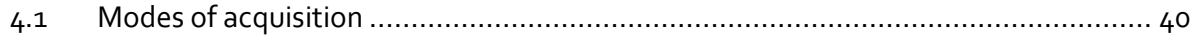

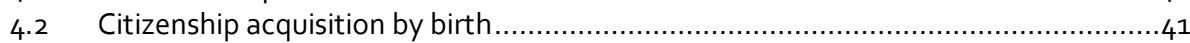

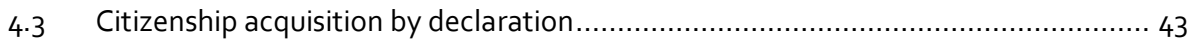

4.4 Citizenship acquisition by application .......................................................... 47

4.5 Citizenship acquisition by application: A cross-country comparison ........................57

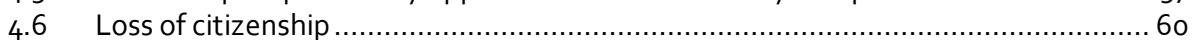

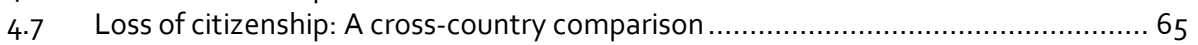

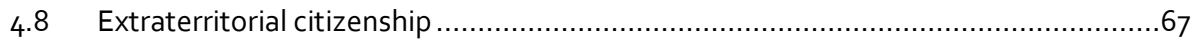

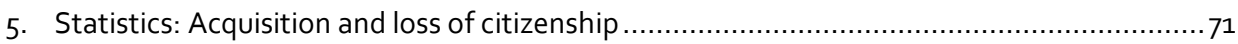

5.1 Acquisition of citizenship by declaration ...................................................... 72

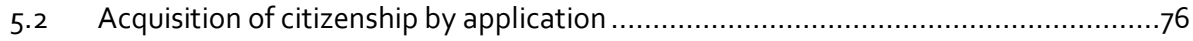

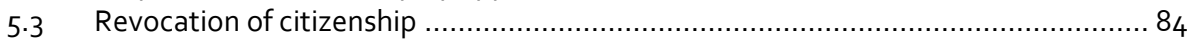

5.4 Naturalization in the Nordic countries: A cross-country comparison ....................... 86

6. Development of Nordic citizenship law in the 21st century - a comparative analysis.......... 89

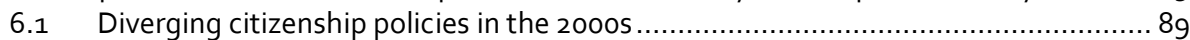

6.2 Immigration, membership and the re-emergence of citizenship as a policy tool...... 91

6.3 Immigrant integration and social cohesion .................................................. 92

7. The future of citizenship in the Nordic countries ................................................ 93

7.1 Consequences of different citizenship regimes in the Nordic region...................... 93

7.2 A Nordic citizenship in the making? Reflections and recommendations .................96

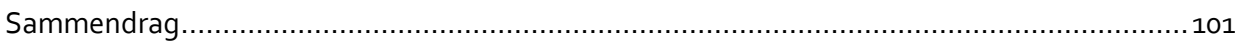

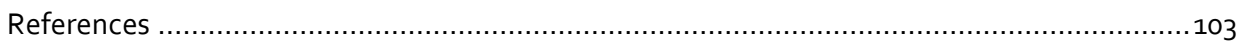




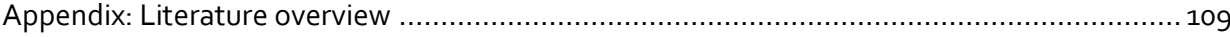

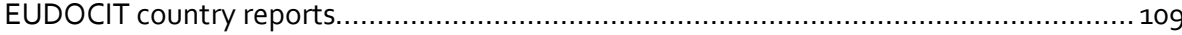

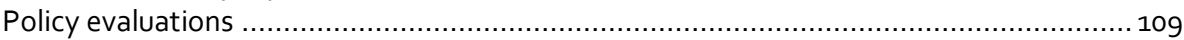

Master's and doctoral theses .......................................................................... 110

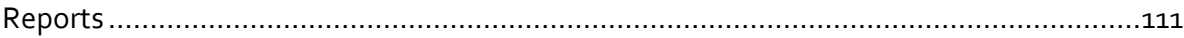

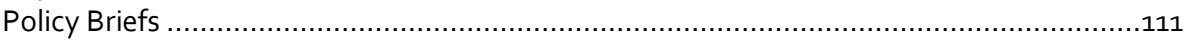

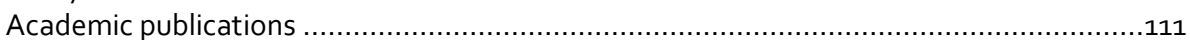




\section{List of figures and tables}

\section{Figures}

Figure 1: Number of immigrants in the Nordic countries, 1990-2016 ................................ 16

Figure 2: Decisions on declarations for Swedish citizenship, 2000-2017 .............................. 71

Figure 3: Decisions on declarations for Norwegian citizenship, 2005-2017 .........................73

Figure 4: Granted declarations for Danish citizenship, 2001-2015 …..............................74

Figure 5: Decisions on declarations for Finnish citizenship ............................................ 75

Figure 6: Decisions on applications for Swedish citizenship, 2000-2017 …........................76

Figure 7: Grounds for rejection of applications for Swedish citizenship, 2005-2017 ….............77

Figure 8: Decisions on applications for Norwegian citizenship, 2005-2017 ...........................78

Figure 9: Grounds for rejection of applications for Norwegian citizenship, 2007-2015.............79

Figure 10: Decisions on applications for Danish citizenship, 2001-2015 ............................ 80

Figure 11: Acquisitions of Icelandic citizenship, 2000-2015 ..........................................

Figure 12: Parliament decisions on applications for Icelandic citizenship, 2000-2017 ............. 82

Figure 13: Decisions on applications for Finnish citizenship, 2009-2017 ........................... 83

Figure 14: Grounds for rejection of applications for Finnish citizenship, 2011-2017 ............... 84

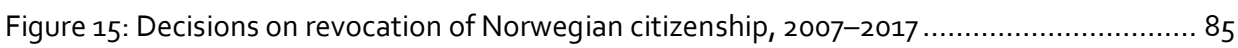

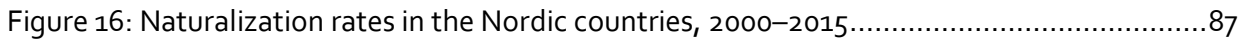

\section{Tables}

Table 1: Naturalization requirements in the Nordic countries ......................................... 58

Table 2: Provisions on loss of citizenship in the Nordic countries ....................................... 65 



\section{Preface}

This report reviews the historical development of citizenship law and the current citizenship regime in the five Nordic countries. It also presents statistics on the acquisition and loss of citizenship in each country over the past 10-15 years, provides a comparative analysis of the divergent development of citizenship policies in the Nordic region in the 2000s, and offers some reflections and recommendations on the future of citizenship in the Nordic region. The report was commissioned by The Nordic Council of Ministers and the project has been headed by the Institute for Social Research (ISF), in cooperation with the Peace Research Institute Oslo (PRIO).

We thank The Nordic Council of Ministers for the financial support and the Norwegian Ministry of Justice and Public Security for their administrative efforts. We also thank the Swedish Migration Agency, the Norwegian Directorate of Immigration, the Icelandic Ministry of Justice, the Icelandic Directorate of Immigration and the Finnish Immigration Service for providing statistics on the acquisition and loss of citizenship in the respective countries. Finally, we thank Liza Reisel, research director at ISF, for valuable comments on a previous version of the report, and Jon Haakon Hustad, librarian at ISF, for helpful assistance in conducting the literature review.

The report is a joint effort. It was written by the head of the project and senior researcher at ISF, Arnfinn H. Midtbøen, in close collaboration with Simon Roland Birkvad at ISF and Marta Bivand Erdal at PRIO. Midtbøen was responsible for writing Chapters 1 and 6, Birkvad for Chapters 4 and 5, and Erdal for Chapter 2 as well as the section on extraterritorial citizenship in Chapter 4. Chapter 3 was written in collaboration between Midtbøen and Birkvad and the concluding chapter in collaboration between Midtbøen and Erdal.

Oslo, March 5, 2018

Arnfinn H. Midtbøen

Simon Roland Birkvad

Marta Bivand Erdal 



\section{Summary}

The Nordic countries have a century-long tradition of cooperation within the area of citizenship law. As late as 1945 there was an explicit desire to establish the Nordic region as a citizenship unit. Since the mid-1970s, however, the Nordic countries have gradually moved in different directions, a process of divergence that accelerated with the law revisions in all countries in the 2000s. Today, the Nordic countries represent the entire continuum of European citizenship policies - from liberal Sweden to restrictive Denmark, with the other Nordic neighbors in intermediate positions.

This report discusses the concept of citizenship, distinguishing between legal status, rights and obligations, participation and membership; it reviews the historical development and current citizenship regimes in the five Nordic countries; it provides statistics on the acquisition and loss of citizenship over the past 10-15 years; and it offers comparative analysis of the divergent development of citizenship law in the 2000s. In the conclusion, we discuss possible consequences of the different citizenship regimes that have developed in the previous decades, and reflect on the prospects for strengthened cooperation between the Nordic countries in the field of citizenship law.

Strengthened cooperation on citizenship issues - perhaps even the realization of the idea of establishing the region as a citizenship unit - would require a strong engagement on behalf of the Nordic Council and the political leadership in the different countries. It would also require the Nordic countries to be willing and able to harmonize how citizenship is defined and legalized. Finally, strengthened cooperation would require that data on the acquisition and loss of citizenship are gathered, systematized and analyzed, with the explicit goal of understanding the impact of the various citizenship regimes on both citizenship acquisition patterns and the social, economic and political integration of new citizens across the Nordic countries.

Despite the merits of a closer cooperation between the Nordic countries within the area of citizenship, the report concludes that the vision of a Nordic citizenship unit will be hard to realize in practice. This pessimism is based on the fact that citizenship policies increasingly have become an important part of the countries' broader approach to immigration and integration. Since the early 2000s, the Nordic countries have turned inwards and been far more interested in finding their own solutions than submitting to the will of others. Even in the context of a hypothetical restrictive convergence in citizenship laws in the Nordic region, this would hardly be the result of, nor lead to, strengthened cooperation in this area of law. 



\section{Introduction}

\subsection{Citizenship and nationhood}

Citizenship defines the boundaries between insiders and outsiders in the nation state; between those that formally belong (citizens) and those that do not (aliens). Not surprisingly, then, have citizenship law and naturalization policies in Europe historically been characterized by striking national dissimilarities (Brubaker 1989). In the research literature, this variation has been explained by referral to the close coupling of citizenship and the conceptions of nationhood that are embedded in the political and cultural history of a country (Brubaker 1992). Citizenship law is the institutional expression of the sovereign right of a state to determine the terms under which new members shall be included in the national community (Hansen \& Weil 2001). ${ }^{1}$ Hence, different ideas of nationhood are manifested in rules for the acquisition of citizenship, as these rules signal a nation state's willingness to include newcomers in the national community (Brubaker 1992; see also Brochmann 2002; Favell 1998).

Against this backdrop, the Nordic region represents a peculiar case with regard to citizenship law. On one hand, the countries share a long tradition of cooperation: Ever since Norway, Sweden and Denmark adopted their first citizenship legislations in the late 19th century, they sought to achieve parity in their legislative regulations, and as late as 1945 there was an explicit desire to establish the entire Nordic region (including Finland and Iceland) as a citizenship unit with identical rules and free movement across the borders for citizens (Ersbøll 2003; Midtbøen 2009a; Nordhaug 2000). The main driver of the Scandinavian and later Nordic cooperation was probably the strong 19th century "pan-Scandinavianism", which rested on the idea of a common Scandinavian culture and community, and that was continued and expanded upon with the "Nordism" of the postwar era (Wickström 2017). The fact that Nordic citizens still have easier access to citizenship in another Nordic country than non-Nordic citizens reflects this historical tradition.

On the other hand, the Nordic countries gradually moved in different directions with regard to citizenship issues from the mid-1970s onward and have since the early 2000 been characterized by striking differences (Brochmann \& Seland 2010; Jensen, Fernández \& Brochmann 2017; Midtbøen 2009b, 2015). In 2001, Sweden adopted a new, liberal citizenship act that reduced the required time of residence and - as the first Nordic country - accepted dual citizenship (Bernitz 2012; Bernitz \& Bernitz 2006). Denmark, by contrast, has since 2002 implemented a series of highly restrictive

\footnotetext{
1 "Citizenship law" and "Nationality law" are often used interchangeably in the scholarly literature, reflecting the close relation between citizenship and nationhood. In this report, we use "citizenship law" when we refer to the rules for acquisition and loss of citizenship. However, we use the words "citizen" and "national" interchangeably throughout the report.
} 
changes in its naturalization requirements, making the country one of the most restrictive in Europe in the area of citizenship policies (Ersbøll 2006, 2015a; Midtbøen 2015). Iceland, Finland and Norway also revised their citizenship laws (Iceland) or adopted new nationality acts (Finland and Norway) in the early 2000 s (Brochmann 2013; Jóhannesson, Pétursson \& Björnsson 2013; Fagerlund \& Brander 2013). The changes in these countries embodied liberal as well as restrictive tendencies and positioned Iceland, Finland and Norway between Sweden and Denmark.

Nationhood, and normative conceptions thereof, has followed different historical trajectories in the Nordic region. Historically, Norway was in a union with Denmark till 1815 and subsequently with Sweden till 1905, and Iceland gained independence from Denmark in 1918, and fully as a republic in 1944; Finland declared independence in 1917, from Russia, after centuries under both Swedish and later Russian rule. However, across the Nordic region, as elsewhere in Europe, nationalist (and independence) movements gained traction in the 19th century, articulating national mythologies that shaped thinking on national membership as this emerged in early iterations of citizenship laws. Meanwhile, looking back, Jensen et al. (2017: 606) argue that "different conceptions of nationhood have mattered [for the development of citizenship law in Scandinavia], but that the national differences [today] have less to do with the normative content of nationhood than with how politicians tend to conceive of the integration process that newcomers must commit to in order to develop a strong sense of national belonging".

Whether citizenship is regarded as an important tool for nation states to distinguish between insiders and outsiders has varied over the course of history and is intrinsically linked to the strength and legitimacy of nationalism in a given era. It is no coincidence that most European countries developed their first citizenship laws in the 19th century, a period during which the modern idea of the nation state - either seen as an ethnic or a political unit - was established (Brubaker 1992). In the decades following World War II, the idea of the nation as a community that defines sharp boundaries between insiders and outsiders lost legitimacy, and many countries chose to liberalize their naturalization policies, thereby easing the access to national membership for foreigners (Hansen \& Weil 2001).

In contrast to the postwar years, however, citizenship is today a highly politicized area (Perchinig \& Bauböck 2006). Citizenship policies have in many national contexts become an important part of the broader approach to immigration and integration, exactly because of the role of regulating access to national membership. This makes citizenship law a contested political realm with great symbolic value, where changes tend to come about quickly - and often in relation to other changes in countries' immigration and integration policies (Bloemraad \& Sheares 2017; Goodman 2014). Iceland, Finland, Denmark and Norway have made a series of amendments in their citizenship laws over the past decade. Denmark, most notably, chose to accept dual citizenship in 2015, making Norway the last country in the Nordic region that (at least for a while longer) holds onto the principle of unitary citizenship. Even Sweden - the only Nordic country which has had a stable, liberal approach to citizenship since the new nationality act came into force in 2001 - is currently discussing ways of making Swedish citizenship a more effective tool for fostering a shared national identity 
(SOU 2013:29). These changes suggest that citizenship still plays a significant role for nation states in their efforts to define a common ground for membership in increasingly diverse societies.

This report reviews the historical development and the current citizenship regime in the five Nordic countries; it provides statistics on the acquisition and loss of citizenship in the Nordic countries over the past 10-15 years, and it offers a comparative analysis of the divergent development of citizenship law in the 2000s. We return to all of these issues in the subsequent chapters in the report. Before we proceed, however, it is useful to provide a broad picture of the key demographic transformation that underlies the changes in Nordic citizenship policies in the 2000s: the rise of immigration.

\subsection{Immigration to the Nordic countries}

The gradual increase of immigration from outside Europe to the Nordic countries since the late 1960 s (to Sweden even earlier), and especially in the 1990 s and 2000s, has transformed the Nordic societies in crucial ways and is the most important background for the changing citizenship policies in the 2000s. When Sweden adopted its new liberal nationality act in 2001, for example, this was a direct response to the fact that Sweden had become a multicultural society and reflected a wish to modernize Swedish citizenship policies in accordance with this reality (Bernitz \& Bernitz 2006; Brochmann \& Seland 2010; Midtbøen 2009b, 2015). Similarly, the rise of immigration, ongoing debates about integration and the so-called "backlash against multiculturalism" (Vertovec \& Wessendorf 2010) formed an important backdrop for the Norwegian law revision in 2005 and the changes in Danish naturalization requirements in 2002 and 2006 - although these countries, and especially Denmark, chose a more restrictive approach (Midtbøen 2015). The law revisions in Iceland and Finland in the early 2000 and especially the fact that both countries chose to follow Sweden and accepted dual citizenship in 2003 - are testament to a similar need for changes in their citizenship policies in the "age of migration" (Castles \& Miller 2009).

To illustrate this development, Figure 1 shows the number of immigrants in each of the Nordic countries from 1990 to 2016. The most striking feature of the figure is the large differences between the countries: In 2016, Sweden had close to 1.8 million residents born in another country, while Iceland had about 36,000. Absolute numbers are, however, not very useful in understanding the demographic impact of immigration on the various Nordic populations. When looking at the share of immigrants of the population in each country, a more similar pattern emerges: Sweden is the country with the largest share of immigrants in 2016 (about 18\%), while immigrants constituted about $13.5 \%$ of the population in Norway, 9.5\% in Denmark, $10.5 \%$ in Iceland and $6.5 \%$ in Finland. These figures suggest that immigration has changed the composition of the population in all the Nordic countries and that the transformation has come about rather quickly. 
Figure 1: Number of immigrants in the Nordic countries, 1990-2016

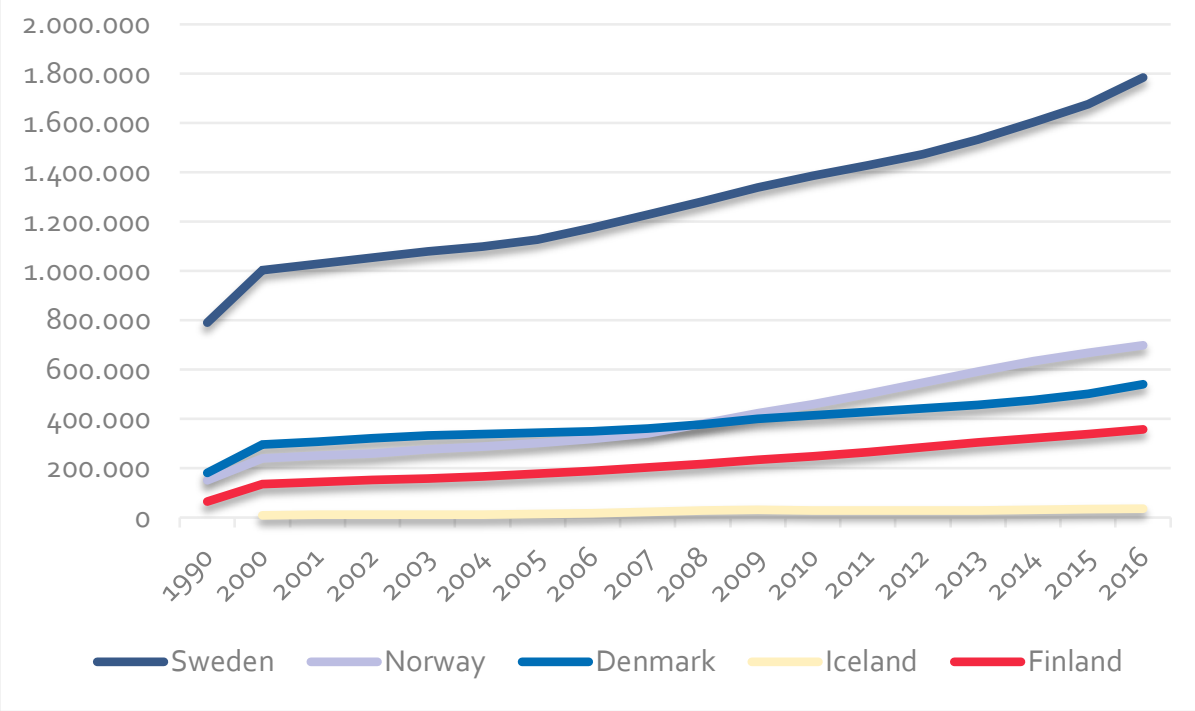

Source: Statistics Sweden, Statistics Norway, Statistics Denmark, Statistics Iceland, Statistics Finland.

Although the share of immigrants provides a better picture of the ways in which immigration has had an impact on the demographic composition of the Nordic countries, absolute numbers of immigrants are important in at least one aspect of this report: statistics on the acquisition of citizenship. As will become evident in Chapter 5, the numbers of acquired citizenships each year vary greatly between the Nordic countries, with Sweden and Iceland on each side of the spectrum. The large differences in the number of immigrants in each country explain much of the differences in absolute numbers of citizenship acquisitions. As we will return to in Chapter 5, naturalization rates - the share of foreign residents who actually acquire citizenship in a given year is a better way of measuring the effects of citizenship policies.

\subsection{Outline of the report}

This report describes and analyzes the development of citizenship policies in the Nordic countries, and it provides key statistics on the acquisition and loss of citizenship since the mid-2000s. In the next chapter, we discuss the concept of citizenship, distinguishing between its core dimensions: legal status, rights and obligations, participation and membership. In Chapter 3, we provide the historical background for the current situation by briefly presenting the development of citizenship law in the Nordic region in the period from 1880 to 2017 . In Chapter 4, we describe in detail and compare the current citizenship regimes in each of the Nordic countries. In Chapter 5, we present statistics on the acquisition and loss of citizenship in the Nordic countries over the past 10-15 years. In Chapter 6, we provide a comparative analysis of the divergent development of citizenship laws, by taking a step back and asking two fundamental 
questions: Why did citizenship re-emerge as an important policy tool in the 2000 after decades in hibernation? And why have the Nordic countries chosen such divergent paths in their citizenship policies? In the concluding chapter, we reflect on the future of citizenship in the Nordic region and the ways in which citizenship still plays a part in regulating membership in the increasingly diverse Nordic countries. 



\section{Defining citizenship}

This chapter presents key conceptual perspectives on citizenship of relevance to a review of citizenship law developments in the Nordic countries. We set out by defining citizenship, foregrounding the relationship between citizenship as legal status and as nation state membership. This dialectical relationship, and its implications, runs through the remainder of the chapter, as we consider citizenship in term of legal status; rights and duties; participation; and membership.

\subsection{Dimensions of citizenship}

Citizenship is inherently both a legal and a social construct (Isin \& Wood 1999), reflecting a vertical relationship between the state and the individual citizen and a horizontal relationship between citizens within the state (Brochmann 2002). The two dimensions are mutually constitutive as the collective of citizens provides the population base on which the state relies for its legitimate support, not least in liberal democracies (Brubaker 1992; Vink \& Bauböck 2013). Thus, citizenship is a foundational institution for both states and for citizens, regulating individual and collective relationships in societies.

In Norwegian and Danish, different words are used to capture the two dimensions of citizenship, the more legal and the more sociological: Statsborgerskap points to the legal status as a citizen, while medborgerskap relates to the horizontal dimension and the social relations between members in society. Notably, for the latter, their legal status may not be decisive as members in society may not have the legal status as citizens (Brochmann 2002: 58-59). In Swedish, the term medborgarskap is used synonymously with citizenship and the Swedish language does not distinguish between the vertical and the horizontal dimensions of the word, as in Norwegian and Danish. In Icelandic, rikisborgararétt is the only term used for citizenship. In Finnish the term for citizen, as a national subject, is kansalainen, whereas the term yhteisö is used in reference to societal membership. The divergence in linguistic terms in the Nordic countries points to some differences in legislation but perhaps also to differences in the vernacular understanding of citizenship across the region.

Citizenship as a concept, involves mutually overlapping dimensions, which can be summarized as: legal status, rights and duties, participation and membership (Staeheli 2010; Stokke 2017; van Bochove \& Rusinovic 2008). In the tradition of T. H. Marshall (1992 [1950]), in the context of post-war Europe, citizenship refers to the civil, political, and social rights individuals have qua citizens of a state. These citizenship dimensions became increasingly salient with the development of welfare states and reflect the contextual ways in which particular dimensions of citizenship become important over 
time. Today, citizenship is strongly overlapping with denizenship (Hammar 1990), and with other variants of quasi-citizenship, where there are different constellations of what types of rights (and duties) are granted to the individual (Knott 2017). This includes situations where individuals do not posit citizenship as a legal status within a given state, yet in some senses are members, and thus denizens. Simultaneously, identity dimensions of citizenship are also receiving increasing attention today (e.g., Joppke 2007. This is connected with the roles of citizenship in regulating national membership, an issue of critical importance to contemporary citizenship law developments (Bloemraad \& Sheares 2017).

In colloquial terms, however, citizenship is very often equated simply with "passport". This is related to the crucial mobility resource that citizenship constitutes in the contemporary world (Torpey 2000). Indeed, in the context of crossing national borders, the question of which citizenship an individual holds becomes critical for whether or not a border may be crossed in a legal manner. This is powerfully illustrated through the "visa restrictions index", which ranks the world's passports according to their strength in granting their holders access to enter other countries. ${ }^{2}$ Thus, citizenship also remains crucial precisely because of the globalization and international migration characterizing the 21st century, with the increasing prevalence of dual citizenship as one of the features set to affect future citizenship legislation developments.

In this chapter we go on to discuss citizenship as legal status, and the ways in which citizenship may be acquired. We then discuss the rights and duties that citizenship entails before foregrounding the role of participation. The final section discusses citizenship as membership and connects the discussion both with citizenship as an inclusive/exclusive institution, separating insiders from outsiders, and citizenship's intimate relationship with nationality and national belonging.

\subsection{Legal status}

The ius soli and ius sanguinis principles of citizenship acquisition, based on where you are born geographically, or to whom you are born in terms of blood ties, have traditionally described the key modes of citizenship acquisition at birth (Brubaker 1992). While it is now widely recognized that citizenship legislation is a multilayered conceptual construction of membership, these two main principles underpinning modes of citizenship acquisition remain as salient discursive realities in public imaginaries (Erdal \& Sagmo 2017; Mouritsen 2013; Vink \& Bauböck 2013).

The two principles have been connected with particular types of nationalism - ius soli to a civic nationalism and ius sanguinis to an ethnic nationalism. However, there

\footnotetext{
2 https://henleyglobal.com/files/download/hvri/HP_Visa_Restrictions_Index_170301.pdf, Sweden is ranked as the second "strongest" citizenship with regard to accessing other countries, with (or without) visas, whereas Denmark and Finland are listed as third, Norway fourth, and Iceland eight. The Nordic countries thus are all among those whose citizenship provides relatively easy access to entry to other countries, making citizenship in a Nordic country a significant mobility asset in a global comparative perspective.
} 
appears to be little empirical basis for such a clear-cut vision: nationhood is more often than not composed of ethnic dimensions related to questions of ancestry, of history, and of race but simultaneously also of civic dimensions related to political institutions and belonging to a territorially bounded nation state (Brubaker 1999; Bloemraad \& Sheares 2017; Reeskens \& Hooghe 2010). As nationhood develops over time, so do the philosophies underlying citizenship itself and thus also approaches to citizenship acquisition (Kaufman 2017).

Today, most European countries have citizenship legislation that draws in part on ius soli and/or ius sanguinis and is often combined with ius domicili, the right to citizenship based on place of residence (Austin \& Bauder 2010; Erdal \& Sagmo 2017), and to a lesser degree also ius matrimonii, the right to citizenship by marriage. As Vink and Bauböck (2013) describe, these combinations of principles may be seen as "citizenship configurations". Such citizenship configurations not only build on a blend of different "ideal type" philosophies of citizenship, but also serve a mix of different purposes simultaneously. This is a key characteristic of European citizenship legislation today, which is relevant in particular for assessing the foreseen and unforeseen policy outcomes and how these relate to one another in different citizenship policy areas (Erdal \& Talleraas 2015).

Citizenship law in most countries starts with rules for citizenship acquisition at birth, de facto placing other forms of citizenship acquisition in a hierarchy below acquisition at birth (de Groot \& Vink 2010). Citizenship acquisition through naturalization - either by application or declaration - is premised on ius domicile, the right to citizenship based on residence, while in most countries other requirements on top of residence also apply.

The past two decades have seen what is often referred to as a "civic turn" in citizenship policies in Europe. This turn is neither clearly restrictive, nor liberalizing but rather emphasizes requirements for newcomers to be eligible to naturalize (Goodman 2010, 2012, 2014). Across countries, length of residence is a key criterion for naturalization, including intricate rules for calculating periods abroad, their frequency and length, within the required period of residence prior to naturalization. Language and societal knowledge are two further criteria that apply in many countries across Europe and are often subject to standardized tests. In some countries, such as Denmark and Iceland, there are also requirements for financial self-sufficiency that must be met prior to naturalization. Naturalization policies increasingly also include more symbolic dimensions, such as citizenship ceremonies and oaths for new citizens (Byrne 2014; Damsholt 2017; Hagelund \& Reegård 2011). Ceremonies and oaths are in some countries mandatory, while they are voluntary in countries like Sweden and Norway.

Norway is the only among the Nordic countries, and one of six European countries that does not allow dual citizenship (as of February 2018, though the Norwegian Government has drafted a proposal to change legislation to allow dual citizenship). Hence, a requirement for naturalization in the Norwegian context remains to renounce any former citizenship, although many exceptions apply (e.g., countries where renunciation is legally or practically impossible or otherwise unreasonable to fulfill). 


\subsection{Rights and duties}

Citizenship gives citizens the fundamental right to freely enter and exit the territory of the state, as well as to reside there. Following the shared understanding in today's nation state system, as also reflected in human rights, every person has the right not to be stateless. In practical terms, this entails the right to citizenship. This is a right that has concrete implications for the ways in which states may legally organize citizenship acquisition and for when states are obliged to provide extraordinary measures to help individuals out of statelessness.

Citizenship grants the right to vote in national and local elections though there are also provisions for voting in local elections for non-citizens who are residents. Citizenship is also a prerequisite for standing for election to parliament in most countries. Where dual citizenship is permitted, whether or not voting and standing for election is possible for dual citizens vary, underscoring the salience of the citizenship institution as a tie between the individual and the state, where singularity of attachments is still of concern to some states. This is perhaps in particular a concern when it comes to military service (conscription especially) and to holding senior government positions, for instance in the intelligence services or in diplomacy. Similar to the issue of standing for election, different countries have developed alternative forms of regulation to manage the reality of increasing proportions of dual citizens. Again, this underscores the basic rule that citizenship is the premise for military service and holding senior positions in intelligence services or diplomacy.

Citizenship also entails duties on the part of citizens. In countries with conscription, military service is perhaps the primary example of a requirement on the part of states for citizens to contribute with their time, energy, and loyalty to the protection of the state. Meanwhile, duty and loyalty, in the sense of committed membership, are a clear expectation, also when it comes to voting in local and national elections as well as referenda, although in democracies there are no direct and individual implications if a citizen chooses not to perform such duties. Rather, the duties of the citizen are to be performed on a voluntary basis (except for conscription to military service), as the citizens' contribution to the citizen-state relationship that the citizenship institution manifests. The most clear articulation of expectations toward citizens, also in the form of duties, understood in terms of "committed membership", is perhaps to be found in naturalization requirements, conveying ideals of conduct, knowledge and practices of "good citizens" (Hoekstra 2015; Goodman 2014).

\subsection{Participation}

In liberal democracies, the legitimacy of state rule is reliant on a state-citizenship relationship that is substantively two-way. Thus, citizen participation in the statecitizen relationship becomes another important dimension of the citizenship institution. The participation dimension in liberal democracies such as in the Nordic countries complements the focus on rights and duties in the section above. While duties 
may involve participation, participation also goes beyond what are formally or informally defined as citizen duties. Beyond the vertical state-citizen relationship, participation is also essential for the sustenance of the horizontal citizen-citizen relationship in society.

In normative terms, the obligation to participate is most explicitly articulated vis-ávis immigrants who seek naturalization. In this context, participation is closely intertwined with ideals of "the good citizen" (Mouritsen 2013). Meanwhile, the political participation of citizens also lies at the heart of both vertical and horizontal dimensions of citizenship (Bauböck 2006). Yet, in liberal democracies, political participation is voluntary.

In the context of the naturalization of immigrants, participation has also become intertwined with broader agendas on integration and social cohesion (Midtbøen 2015; Morales \& Giugni 2016), which we return to in Chapter 6. Critical perspectives on such approaches to participation point out that there are certain kinds of - and arenas for civic participation that are more highly valued than others, thus not creating a level playing field in relation to citizen participation (Suárez-Orozco, Hernández \& Casanova 2015). In other words, particular kinds of participation are foregrounded as more valuable than others in the context of naturalization. Participation - in the context of naturalization requirements - is ultimately strongly connected with the aims of integration and social cohesion, where a key divide in academic and policy circles centers around whether citizenship ought to be the end-point of integration or rather a stop on the way there (Hainmueller, Hangartner \& Pietrantuono 2017).

\subsection{Membership}

As an institution, a key function of citizenship is to distinguish between insiders and outsiders, members and non-members, citizens and aliens. Hence, citizenship is at the same time both internally inclusive and externally exclusive: citizenship grants equal membership for every citizen within, while simultaneously excluding non-citizens, whether within or outside of the territorial boundaries of the state (Brubaker 1992; Joppke 2010).

Indeed, the very invention of citizenship laws in Europe in the late 18th century also invented "the foreigner" as a social category anchored in law (Brubaker 1992: 46). Till then mobility had been less controlled, a situation that changed with the introduction of the passport (Torpey 2000). The foreigner, the alien, or the immigrant within the nation state have become salient social categories, which in contemporary Europe often perform the role of defining the "us" within, as does the foreigner abroad.

The term citizenship is often used synonymously with membership in a selfgoverning political community - which today usually means membership in a nation state (Bauböck 2006: 9). Here, it is worth noting that the straight forward zero-sum game vision of "one person, one citizenship", which the nation state system would logically suggest, has always had its exceptions and complications. This continues to be the case today, at an increasing pace, especially due to the rise in the prevalence of dual 
citizenship across Europe and globally (Bloemraad 2004; Faist \& Kivisto 2007; Schlenker 2016; Sejersen 2008; Stokke \& Erdal 2017).

Dual citizenship itself poses new dilemmas for nation states, as it does for individuals, in terms of loyalties. While identities can clearly be multiple, there are questions as to whether loyalties can be both multiple and not hierarchical (Aptekar 2015). In short, in terms of loyalty to states - can you be one of "us" if you are also one of "them"? (FitzGerald et al 2018; Erdal \& Talleraas 2015). In practice, states around the world resolve the concrete challenges that dual citizenship might entail, such as in relation to military service, posts at high levels in diplomacy, or posts in the intelligence services. In any case, the prevalence of dual citizenship underscores the observable reality that for many individuals - and states - multiplicity is the norm when it comes to questions of membership in nation states (Schlenker 2016). This is furthermore reflected in the fact that extraterritorial citizens often retain voting rights in national elections for 8-10 years or longer after emigration (Collyer 2014).

In most of the world, citizenship as membership means membership in the nation state. Hence the term nationality, as a descriptor of nationals, is also used for citizens (such as on visa application forms and the like). In fact, citizenship legislation in many countries is called nationality legislation. However, the relationship between being a member of the nation state - a citizen - is not necessarily a one-to-one fit with that of being a member of a nation, as such, for instance in contemporary Europe (Bauder 2013; Bloemraad, Korteweg \& Yurdakul 2008; Brubaker 2010). The complex population compositions of present-day European nation states, characterized by migrationrelated diversity (Meissner 2015), are contexts where questions of membership and citizenship intersect with quests for recognition, especially among the children of immigrants (Bloemraad 2018; Street 2014).

Different philosophies of citizenship (Favell 1998) have different genealogies of belonging underlying them, as more connected with ancestry, race, and ethnicity - or less. Meanwhile, the relationship between the nation and the state remain, on the one hand, taken for granted, yet often opaque. On the other hand, this relationship is at the center of heated political debates on membership. Arguably, emphasis on social cohesion and the magnitude of naturalization requirements for new citizens are shaped by the prevailing philosophies of citizenship with underlying genealogies of belonging, and by the ways in which the nation is understood in relation to the state in a given national context.

The key challenge lies neither with the nation state nor with the citizenship institution but rather with contemporary conceptualizations of nationhood in a context of increasing migration-related diversity. Despite the rise in attention to nationalism in recent years there is in most European contexts a lack of a clear and decisive conceptualization of nationhood on the part of states. Such conceptualizations by states might seek to steer contemporary nation-building in European societies, whose populations are increasingly diverse and where the need for clearer and inclusive conceptualizations of nationhood are evident (Antonsich \& Matejskova 2015).

The traditional understanding of nationhood, in "ideal type" terms, as ethnic or civic (Brubaker 1992) has provided useful tools for analyzing the mechanisms at work 
in different forms of nationalism. However, it is by now well-established that ethnic and civic forms of nationalism are intertwined and often mutually constitutive (Antonsich 2016; Koch 2015; Zimmer 2003). Furthermore, nationalism studies have moved from a preoccupation with the past, with the historical origins of nations, to focus on the present (and future), and include not only the nation-building enterprises of states but also their interplay with the people (Billig 1995; Fox 2017; Skey 2010).

This is not to say that the past is ignored, but rather that attention - especially for states - may purposefully be turned to the populations that (legally) inhabit territorially and politically bounded national spaces (Bauböck 2002). When considering the populations actually inhabiting national spaces, and those that are citizens among them, there are reasons to reconsider static approaches to what a nation might be. While the boundaries of nationhood remain to an extent contested, these are the sites of negotiations among nationals (Brubaker 2004, 2006, 2009).

Arguably, naturalization policies constitute demarcation lines of nationhood in nation states. Yet, citizenship does not (necessarily) grant membership in the nation, though it formally grants membership in the nation state. This distinction of membership to the nation state and membership of the nation is noted as one of the key challenges for further strengthening a sense of membership in modern-day nation states (Brubaker 2010). The realities of contested yet dynamic forms of nationhood remain in need of translation into concrete boundaries to be crossed for the inclusion of new citizens, and upheld for the exclusion of non-citizens, in citizenship legislation.

Membership constitutes a key dimension of citizenship together with rights and duties and participation, but most importantly - with legal status. In the context of Nordic citizenship legislation and its development, these two dimensionsmembership and legal status - have arguably been more important than the others. This, in turn, is related to the fact that most recent changes in citizenship law have been concerned with the integration of immigrants and have drawn instrumentally on citizenship as a tool to serve a purpose (Midtbøen 2015). Meanwhile, the often unresolved relationship between citizenship (as membership to the nation state) and nationality (as membership in the nation, in the sense of a politics of belonging) lingers in the context of present-day citizenship policy developments. 



\section{Historical background: Citizenship in the Nordic region 1880-2017}

In the 2000s, citizenship legislation in the Nordic countries has evolved in very different directions. Admittedly, all the countries have retained ius sanguinis - the principle of descent - as the basic rule for the acquisition of citizenship by birth, but they differ in their views on dual citizenship; whether ceremonies and oaths of allegiance are to be included; and on the requirements for time of residence, financial self-sufficiency, language proficiency, and knowledge of society and culture for the acquisition of citizenship through naturalization. This variation stands in sharp contrast to the historical efforts of creating a uniform citizenship regime in the Nordic region.

In this chapter, we will look into the historical development of citizenship laws in Sweden, Norway, Denmark, Iceland and Finland. In the period from 1880 to 1950 , we focus on the three Scandinavian countries because they engaged in a close cooperation on citizenship issues in this time period. Iceland and Finland were not included in a wider Nordic cooperation until the 1940 s, the time from which we include these countries in our historical review. ${ }^{3}$

\subsection{The first Scandinavian citizenship laws 4}

During the 19th century, Norway, Sweden, and Denmark obtained independent constitutions with provisions concerning citizenship, but none of the countries actually got citizenship laws until the end of the century. However, Sweden had developed customary rules on citizenship based on the principle of ius sanguinis, which Norway and Denmark adopted when the new laws came into place (Ersbøll 2003: 148).

Several conditions at the end of the 19th century increased the need to distinguish citizens from foreigners: Immigration increased in size and changed character; economic liberalism was gradually abandoned in Europe in favor of protectionism on the rise, and national concerns gradually became more important (Myhre 2003: 219). In this context, the ius sanguinis principle was regarded as best suited as family bonds would ensure emotional attachment to the nation state. The principle was already recognized by countries such as Germany, France, Austria, and Italy, and the Scandinavian countries followed suit (Nordhaug 2000: 96).

\footnotetext{
3 Readers interested in the origins of citizenship law in Iceland and Finland are recommended to consult the respective EUDOCIT country reports (Jóhannesson et al. 2013; Fagerlund \& Brander 2013).

4 Sections 3.1, 3.2 and 3.3 build on Ch. 4 in Midtbøen (2008).
} 
In view of the need for citizenship laws and a resolution from a Nordic lawyer meeting in 1881, the Swedish government in 1888 took the initiative that Sweden and Denmark should seek as uniform citizenship legislations as possible. The reason for the initiative was the unintended consequences of Sweden's customary rules on citizenship: Due to the practice of ius sanguinis in Sweden, Danish immigrants could not become citizens in Sweden and their descendants could not acquire Swedish citizenship - nor had they Danish birthright. A Swedish woman who married a Danish man, in turn, would lose her Swedish citizenship and would not receive Danish citizenship at the time of marriage. Hence, the main motivation for the collaboration between Sweden and Denmark was initially a desire to avoid cases of statelessness, and rested on a basic idea that every person should have citizenship - but only one (Nordhaug 2000: 85).

Norway eventually entered the negotiations, and in 1889 the Scandinavian neighbors set up a commission to discuss the possibilities for civil-law cooperation in Scandinavia. In 1890, the commission issued a draft Law on Acquisition and Loss of Citizenship. Norway had, however, adopted the nationality act of 21 April 1888 - that is, before the Scandinavian cooperation in the area of civil law had begun. The law draft did not lead to new Norwegian legislation as the main features were already in place in Norwegian law. Sweden, on the other hand, was granted a law on October 1,1894, on the acquisition and loss of Swedish citizenship, while Denmark authorized a law on 19 March 1898, for the acquisition and loss of right of birth (Ersbøll 2003: 149). (This law applied with full force in Iceland, as Iceland was under Danish rule at the time). The three countries' legislation was now built on the principle of ius sanguinis, cases of dual citizenship were to be avoided, and the principle of family civil justice was introduced. Upon the acquisition of citizenship through application, three years of residence were required in all three countries.

Despite the similarities in the Scandinavian legislation, it is worth noting one important difference between Norway and the two neighboring countries: in the Scandinavian Commission's recommendation of 1890, it was proposed that children of immigrants should have automatic access to citizenship at the age of majority if the child was born and raised in the country. This can be regarded as a modification of a strict use of the ius sanguinis principle and was adopted in Swedish and Danish law. In Norway, however, such a modification was not incorporated into the law of 1888 (Nordhaug 2000: 97).

\subsection{New negotiations, new moments: The laws of $1924 / 25$}

In the first decades of the 2oth century, it became clear that the existing legislation in the three countries had several shortcomings. Hence, in 1920, the Swedish government again invited the Danish and Norwegian governments to collaborate on new amendments, with the objective to improve and co-ordinate legislation in the area of citizenship. The negotiations were concluded in 1922 with a common proposition and a draft law for each of the countries. However, the controversial question of married 
women's independence in civil law put an end to the collaboration, primarily due to criticism from the women's movement and because the Swedish law proposal was rejected by the Swedish Parliament (Nordhaug 2000: 106).

Still, the desire for a common Scandinavian citizenship solution was so strong that the negotiations were resumed and formally concluded with a new draft law in November 1923. Against this background, Sweden adopted a new law on Swedish citizenship on 23 May 1924; Norway did the same on 8 August 1924, and Denmark adopted its new legislation on Danish law of birth 18 April 1925 (Ersbøll 2003: 150). These laws differed from the existing law in the sense that women's civil status was to a certain extent strengthened, that the naturalization requirement for time of residence was raised from three to five years and, for Norway's part, that foreigners born and raised in the country automatically received Norwegian citizenship at the age of 22 if they did not deny their right to this (Nordhaug 2000: 111). These changes in Norwegian legislation were in line with the already existing Swedish and Danish rules for secondgeneration immigrants, and as Vassbotn (2006) notes, this meant that the basic principle, ius sanguinis, was supplemented by a combination of ius soli and ius domicili, as birth in the territory now automatically gave the right to citizenship after a certain number of years of residence.

The basic rationale behind the amendments to the ius sanguinis principle was the prevention of cases of statelessness. The introduction of ius sanguinis in the Norwegian law of 1888 had been effective in preventing dual citizenship, but indirectly contributed to creating statelessness (Nordhaug 2000: 111). With the modified version of ius sanguinis, supplemented by both the territorial and residential principles, the idea was to be able to avoid both. However, the Norwegian 1924 law that granted citizenship to children of immigrants automatically at the age of 22 had no condition for renouncing their former citizenship (NOU 2000:32, 81). Thus, the desire for a common Scandinavian law - in this case by incorporating foreign nationals with strong ties to the country in the Norwegian state community - weighed heavier than the desire to prevent cases of dual citizenship.

\subsection{The postwar years: A uniform citizenship in the Nordic region?}

After World War II, the Scandinavian cooperation was further strengthened, and - at least on paper - expanded to include Iceland and Finland. Iceland had passed its first separate law on citizenship in 1919 (which largely corresponded with the Danish law of 1898), and the Icelandic law continued to be modified in line with developments in the Nordic region in the 1920 (Jóhannesson et al. 2013). In Finland, the first nationality act was adopted in 1920 (Fagerlund \& Brander 2013).

At the first Nordic interparliamentary meeting after the war, in August 1945, the question of the creation of a common Nordic citizenship was raised by Sweden. The objective was that Nordic citizens should have the same rights throughout the Nordic region. The result of the meeting was a resolution to investigate any problems in this regard. The reforms resulted in a joint recommendation prepared by a committee from 
Norway, Sweden, and Denmark in 1949, and in 1950 the three countries agreed on the implementation of a number of provisions with favorable rules for Nordic citizens. This agreement also led to new citizenship laws: In Denmark, on 27 May 1950, in Sweden, on 22 June 1950, and in Norway, on 8 December 1950. All three laws came into force on 1 January 1951 (Ersbøll 2003: 151).

Of the general and non-specific Nordic issues raised in the Scandinavian proposition, married women's position in civil relations was among the most important. This time it was decided that women should not lose their citizenship by marriage, despite the fact that this amendment would increase the likelihood of multiple cases of dual citizenship. Still, the principle of unitary citizenship was continued. In addition, the 1950 laws increased the time of residence requirement to seven years in all three countries.

The 1949 joint recommendation also included a number of proposals for special arrangements for Nordic citizens. For example, it was proposed that, in certain cases, a shorter period of residence for Nordic citizens would be required in the case of the acquisition of citizenship upon application, that residence periods in a Nordic country would be considered residence in another, and that Nordic citizens could become citizens of the country of residence by declaration (NOU 2000:32, 19). Because Finland and Iceland did not participate in the discussions, it was decided that the distinctive legislation of all Nordic citizens would only be implemented by agreement between the countries, and only Norway, Sweden, and Denmark participated in this cooperation in the first few years.

In 1952, Iceland passed a citizenship law very similar to the laws in Norway, Sweden, and Denmark, including the special arrangements for Nordic citizens. However, a unique feature in the Icelandic legislation, which lasted until the mid-1990s, was that an individual who acquired Icelandic citizenship was required to adopt an Icelandic name (Jóhannesson et al. 2013).

Finland did not revise its citizenship law until 1968. Following the 1962 Nordic Treaty of Co-operation (the Helsinki Treaty) and a recommendation of the now established Nordic Council, this law introduced special rules for Nordic citizens who wanted to acquire Finnish citizenship, among them the ability to acquire Finnish nationality by declaration. Finland took formal part in the Nordic Agreement in 1969 (Fagerlund \& Brander 2013).

\subsection{From the postwar era to the end of the 2oth century}

The vision of a common Nordic citizenship was not realized in the 1950s, nor would it ever be. Despite the goal of creating a common legal entity in the Nordic region, national differences were maintained. For example, Danish and Icelandic legislation differs from the others by the fact that applications for naturalization are dealt with by the respective parliaments according to the rules governing the processing of litigation. This means that there is no right of appeal against the decision of the parliaments and, in the area of citizenship, that the terms for acquiring citizenship are not stated by law, 
but by guidelines (Ot.prp.nr.41 (2004-2005):17). Despite these formal differences, the content of the citizenship laws in the Nordic countries was very similar in the first decades following World War II.

Gradually, however, differences began to emerge between the Nordic countries. Stronger international influence on citizenship matters was one of the driving factors behind the diverging development. Some countries quickly acceded to international conventions pertaining to citizenship law, most importantly the 1961 United Nations Convention on the Reduction of Statelessness, the 1963 European Convention on Nationality and the 1997 European Convention on Nationality, while others were more hesitant. The divergence was propelled by the formal termination of the Nordic cooperation in 1979, and a number of legislative changes in each country (Brochmann \& Seland 2010).

Legislative changes were for years most notable in Sweden, which liberalized the law from the 1970s onwards. In 1974, a prohibition against the deprivation of citizenship came into force, explicitly laid down as a constitutional principle in the Instrument of Government. Sweden also abolished the requirements of self-support and language and lowered the residence requirement period from seven to five years in the 1970s, because immigrants' prerequisites for integration into Swedish society were considered to be greatly improved through a number of measures (SOU 1999:34, 59). The changes in Norway in the latter half of the 2oth century were piecemeal and similar to the changes in Sweden characterized as "modernizations" or liberalizations (Brochmann 2013: 4). For instance, Norway also abandoned the language requirement around the same time as Sweden (Brochmann 2013: 20).

Compared to Sweden and Norway, citizenship matters became a highly politicized field in Denmark from the 1970s onwards. Support for "old parties" fell, while new parties, such as the Progress Party (Fremskridtspartiet), entered the political scene. This political shift of power influenced the parliamentary debates on naturalization. Traditionally, naturalization acts had been adopted without discussion in parliament, but this practice changed during the 1970 and 1980 . Members of the Progress Party proposed to exclude persons with a criminal record and public debt from bills on naturalization (Ersbøll 2015a: 19). Although such proposals were controversial at first, they gained traction over the course of time. Accordingly, the criteria for naturalization was tightened in 1981, and in 1994 two centrist parties, the Liberals (Venstre) and the Conservatives (Det Konservative Folkeparti), proposed to make requirements for naturalization more stringent, including the introduction of language skills and no overdue debt to the public as conditions for naturalization while also prohibiting naturalization in cases of serious crimes (Ersbøll 2015a: 19-20). Language skills and no overdue debt to the state were subsequently introduced as conditions for naturalization, while the permanent exclusion of persons committing serious crimes had yet to be introduced at the turn of the millennium. The restrictive trend in Denmark stands in stark contrast to the liberalizing development in Sweden (and partly Norway), a gap that would continue to widen in the early 2000 s.

Iceland has not been a forerunner in changing its citizenship law but rather mostly followed developments in the other Nordic countries as well as abiding by international 
conventions (Jóhannesson et al. 2013: 13). From the adoption of the 1952 Act to the end of the century, Icelandic citizenship law was substantially amended two times - in 1982 and 1998 - signaling both convergence with and divergence from traditional features of Nordic citizenship law. The 1982 amendment addressed gender equality, adoption rules, and the prevention of statelessness and entrenched the privileged position of Nordic citizens. The 1998 amendment introduced ius soli rules to avoid statelessness, greatly inspired by the 1997 European Convention on Nationality and the 1989 UN Convention on the Rights of the Child. Notably, the 1998 amendment also brought about a procedural change that represented a departure from Icelandic - or more precisely, Danish - citizenship tradition: the introduction of an administrative method of awarding citizenship. Until then, naturalization only occurred through law enacted by the parliament, as in Denmark. Thus, the amendment enabled the executive branch (then the Ministry of Interior, now the Directorate of Immigration) to award citizenship by administrative decision. At the same time, naturalization criteria were laid down in the citizenship act, including, among other things, conduct and no debt to the state. The legal criteria were largely in line with the guidelines used by the General Committee in Parliament (the committee authorized to grant citizenship), albeit more stringent (Jóhannesson et al. 2013: 13).

The most significant changes in Finnish citizenship law in the second half of the 2oth century were the adoption of a new Nationality Act in 1968 and subsequent amendments in 1984 and 1985 . In the 1968 Act, several steps were made to improve gender equality and prevention against statelessness (based on the 1961 Convention on Reduction of Statelessness). Following the 1962 Nordic Treaty of Co-operation, Finland facilitated citizenship acquisition for Nordic citizens by introducing a declaration procedure in the 1968 Nationality Act. The 1984 amendment took further steps toward gender equality and the prevention of statelessness and facilitated access to citizenship for adopted children. While Sweden and Norway abolished language requirements in the 1980s, Finland on the contrary decided to introduce skills in Finnish or Swedish as a condition for naturalization in 1985 (Fagerlund \& Brander 2013: 8). And while Sweden did not introduce language skills in the new nationality act of 2001, Finland chose to tighten this condition for naturalization when the 2003 Act on Finnish Nationality was adopted. Differing views on language proficiency as a naturalization condition is merely one example of the development during the 2000 , characterized by increasing divergence.

\subsection{The 2000s: Revisions, amendments, divergence}

In the 2000s, the gradual move in different directions was formalized by law revisions or amendments in all five Nordic countries. Sweden, Norway, and Finland adopted new citizenship laws in the early 2000s, while Denmark and Iceland have made several amendments. In the following, we outline the most important legislative changes in each Nordic country during the 2000 s. 


\subsubsection{Sweden}

A new Swedish Citizenship Act was adopted in 2001, which replaced the existing act from 1950. The Swedish Citizenship Act of 2001 represented a departure from Scandinavian - and later Nordic - cooperation in the field of nationality legislation. Sweden's initiative for a legal reform and the preparatory work undertaken by the Swedish committee was conducted without any Nordic consultations. Wishes to modernize the legislation and to implement international conventions on citizenship (particularly the 1997 European Convention on Nationality) were driving forces behind the law reform (Bernitz \& Bernitz 2006; Midtbøen 2015).

Even though the new act in many ways was based on tradition and the continuance of previous regulations, it also contained distinct features that depart from previous practices, and a number of its aspects testify to a new and more inclusive attitude toward immigrants who are permanent residents in the country. Most importantly, Sweden accepted dual citizenship in full as the first Nordic country to do so. Other examples of change vis-à-vis the 1950 law, were strengthening individuals' and particularly children's right to citizenship by extending possibilities of acquisition through declaration to more groups, and continuing to ease access through naturalization (Midtbøen 2008: 56). Combined with a prohibition of denaturalization, these changes signal a generous attitude toward the individual (Bernitz 2012: 19).

Since 2001, only minor legal changes have been made. One of them was the introduction of a citizenship ceremony in 2006. The municipalities were given the responsibility to organize the ceremonies, but it was stated that participation should be voluntary. Interestingly, in 2014, a provision was introduced to the effect that it became mandatory for the municipalities to organize at least one citizenship ceremony a year, albeit still voluntary for new citizens to participate. The same amendment introduced a new Article 1 that set out to define "the meaning of citizenship" (Medborgarskapets betydelse), a provision that had been lacking in previous acts. The introduction of these two provisions may be interpreted as an assertion to upgrade the Swedish citizenship institution, although only by using symbolical measures.

\subsubsection{Norway}

Norway adopted a new citizenship act in 2006. The Norwegian Nationality Act of 2005 is highly ambiguous. On one hand, the principle of unitary citizenship was maintained, naturalization was conditioned on requirements for language proficiency, and an oath of allegiance was reintroduced as an element of what in the Norwegian context was an innovation: a ceremony for persons who have been granted citizenship. On the other hand, all those who fulfill the conditions for naturalization are currently entitled to Norwegian citizenship, a fact that represents a significant curtailment of the power of the authorities to exercise discretionary judgment. Furthermore, it was decided that the oath of allegiance should be mandatory only for those who participate in the voluntary ceremony, which leaves each free to assess its value (Brochmann 2007; Midtbøen 2015). 
As to newer developments, two restrictive changes must be noted. Since 2017, it is now required that applicants for citizenship must have completed tuition in the Norwegian language and have passed an oral Norwegian test and a social studies test. Completed tuition in the Norwegian language has been a requirement for naturalization since the 2006 act was introduced, so the novelty is the introduction of mandatory tests in Norwegian and social studies.

\subsubsection{Denmark}

Unlike Sweden, Norway, and Finland, Denmark did not adopt a new citizenship law in the 2000s. Still, a range of amendments to the law of 1950 has been made, particularly with regard to naturalization requirements. Rather than following European trends of facilitating naturalization and extending entitlement to citizenship, Denmark has raised the bar for acquiring citizenship (Ersbøll 2015a). The most prominent changes in Danish nationality legislation in the 2000 s concern the requirements for naturalization. These requirements are - also in contrast to the other Nordic countries - not spelled out in the nationality act but defined in guidelines issued by the Ministry of Immigration and Integration. Guidelines are subject to negotiation and are decided by the political parties that represent the majority in the parliament (Midtbøen 2015: 5). Because of this arrangement, naturalization requirements are much more subject to politicization than in other countries, which accounts for the frequent - predominantly restrictive changes that have occurred since the turn of the millennium.

In 2002, an agreement between the Liberals (Venstre), the Conservatives (Det Konservative Folkeparti), and the Danish People's Party (Dansk Folkeparti) was struck, making conditions for naturalization more stringent (Ersbøll 2015a). The required time of residence increased from seven to nine years, conduct requirements were tightened, and two new conditions for naturalization were introduced: an oath of allegiance and a requirement regarding Danish language proficiency and familiarity with Danish society, history, and culture was introduced, to be documented by a separate examination (Danish Ministry of Refugees, Immigrants and Integration 2002). Apart from changes in naturalization policies, rules on second-generation immigrant descendants entitlement to Danish citizenship by declaration were repealed, and provisions on the deprivation of citizenship due to fraud and serious prejudicial behavior were implemented in the nationality act in 2002 and 2004, respectively (Ersbøll 2015b: 200).

The restrictive trend continued after the re-election of the liberal-conservative government in 2005, resulting in a new Circular Document entering into force in 2006 (Danish Ministry of Refugees, Immigrants and Integration 2006). Henceforth, applicants for naturalization have to declare that they have not committed any criminal acts while also making the conduct requirement stricter (a prison sentence of 18 months or more implies permanent exclusion from naturalization). The level of required language skills was raised, and new requirements concerning financial self-sufficiency and passing a citizenship test (indfødsretsprøve) were adopted.

The election of a new center-left government, comprising the Social Democrats (then Socialdemokraterne, now Socialdemokratiet), The Socialist People's Party 
(Socialistisk Folkeparti) and the Social Liberals (Radikale Venstre), put a preliminary end to the restrictive trend in Danish citizenship policies. The 2013 Circular Document contained relaxations in the requirements of language and civic knowledge and selfsufficiency (Justitsministeriet 2013). In 2014, Denmark decided to accept dual citizenship (entering into force in 2015), a remarkable move in a traditionally singlecitizenship country. Interestingly, one of the key arguments for accepting dual citizenship was allowing for the citizenship revocation of dual citizens who engage in or support acts of terror (as it is considered illegitimate to make people stateless) (Midtbøen 2017). At the same time, the ius soli-entitlement to Danish citizenship to immigrant descendants was reinstated, which represented a considerable liberalization (Ersbøll 2015a: 30).

However, the relaxations in Danish citizenship policies were quickly annulled by the succeeding government. The government party the Liberal Party (Venstre) struck a deal with the Social Democrats (Socialdemokraterne), the Danish People's Party (Dansk Folkeparti), the Liberal Alliance (Liberal Alliance), and the Conservative People's Party (Det Konservative Folkeparti), which resulted in the 2015 Circular Document, still in force today (Udlændinge-, Integrations- og Boligministeriet 2015). Requirements of language skills, citizenship, test and self-sufficiency were raised to the same level they were prior to the liberalization in 2013. Further, the conduct requirement was tightened (overall, the waiting period for naturalization due to committed crimes increased by 50\%). Lastly, the ius soli-entitlement to citizenship acquisition for immigrant descendants was deleted in 2016, merely one and a half years after it was adopted (Institut for menneskerettigheder 2016: 28).

\subsubsection{Iceland}

No major law reform has taken place in the new millennium in Iceland, which means that the Act of 1952 is still in force today. During the 2000s, however, the act has been substantially amended two times: in 2003 and 2007. In 2003, Iceland fully accepted dual citizenship. One of the driving forces behind this unprecedented move was pressure from Icelandic citizens who had lost their citizenship. Officially, there were also two other reasons for accepting dual citizenship. First, dual citizenship was already de facto tolerated, since those who acquired citizenship through application were not explicitly required to renounce their other citizenship. Second, concerns related to conflicting military duties (historically, one of the main reasons for prohibiting dual citizenship) did not pertain to Iceland, as the country has never had a military (Jóhannesson et al. 2013: 15-16).

The 2007 amendment included some important changes concerning citizenship acquisition through application, in terms of procedure and the introduction of new requirements. Regarding procedure, the amendment emphasized that the main rule for granting citizenship shall be by adoption of statutory law, thus underscoring that the granting power still lies with the Icelandic Parliament. Administrative decisionmaking by the Minister (introduced with the 1998 amendment) should only be considered the exception to the main rule (Jóhannesson et al. 2013: 20). Henceforth, 
the Minister's authority should be limited to applications that clearly comply with the naturalization criteria. New requirements of identity documentation, financial selfsufficiency, and language tests (the latter entering into force in 2009) were also introduced with the 2007 amendment. Overall, the new requirements for naturalization and the limitation of administrative decision-making clearly signaled that Icelandic citizenship is not a right (Jóhannesson et al. 2013: 24), much like the official view in Denmark.

\subsubsection{Finland}

A new Nationality Act was adopted in Finland in 2003. Rising immigration during the $1990 s$ (and consequently higher numbers of applications for citizenship), expatriate Finns lobbying for the acceptance of dual citizenship, and a desire to implement international conventions were the background for the law revision. The law of 1968 was considered outdated, calling, among other things, for a clearer formulation of requirements for naturalization (Fagerlund \& Brander 2013).

The 2003 Act represented both continuity and change. On one hand, Nordic cooperation was maintained by facilitating access to citizenship for Nordic citizens (through application and declaration) and the principle of ius sanguinis was retained as the main principle for the birth-based acquisition of citizenship. On the other hand, the acceptance of dual citizenship represented a major change from previous practice. The reasoning behind this legislative change was multilayered; it was considered to be in the best interest of immigrants, emigrants, and the state - as granting full rights and duties was deemed to stimulate increased participation in Finnish society. Additionally, Nordic coordination was a factor of influence; Sweden had already accepted dual citizenship in 2001, and Finland was under the impression that Norway was going to as well (Fagerlund \& Brander 2013: 15).

The prevention of statelessness was behind the secondary provisions of ius soli implemented in the 2003 act (in the reformed Constitution of Finland of 2000 it was stipulated that loss of Finnish citizenship may not lead to statelessness). The acceptance of dual citizenship and introducing ius soli provisions were indisputably a liberalization of the existing law, yet restrictive elements were also noticeable. Finland followed the Danish example by adopting in the new act a provision on loss of citizenship due to fraud (Ersbøll 2015b: 200). Conditions for naturalization were also tightened. The residence requirement was raised from five to six years, and requirements of identity documentation and language skills were codified and made stricter (Fagerlund \& Brander 2013: 22). The official view at the time was that citizenship acquisition was a reward for successful integration into Finnish society.

In 2011, changes were made in a liberal direction. With a need to facilitate workrelated immigration, the goal behind the amendment was to ease - rather than to restrict - access to citizenship. Interestingly, the logic behind the liberalization was quite different from the one put forward in the 2003 act. Rather than a reward for successful integration, citizenship acquisition was now seen as a tool to promote the integration of immigrants (Fagerlund \& Brander 2013: 13). For this reason, the residence 
requirement for naturalization was reduced from six to five years (that is, the same level before the adoption of the 2003 act). Moreover, a single declaration procedure for all former citizens (regardless of country of residence) was also implemented to streamline this mode of citizenship acquisition.

Summing up, the Nordic countries have moved in different directions throughout the 2000s. Today, Sweden has one of the most liberal citizenship policies in Europe, while Denmark has one of the most restrictive. In Norway, Finland, and Iceland, both liberal and restrictive changes have occurred, positioning them between their Nordic neighbors. Interestingly, however, the naturalization policies of the Nordic countries have maintained a privileged path to citizenship for Nordic citizens, which very likely will continue into the future (Wickström 2017). The reasons why the Nordic countries have chosen such divergent paths in their overall approach to citizenship is subject for discussion in Chapter 6. In the following two chapters, we will describe in detail the current citizenship regime and provide statistics on the acquisition and loss of citizenship in each of the Nordic countries. 



\section{Current citizenship regimes in the Nordic countries}

The preceding chapter displayed the diverging trajectories of citizenship legislation within the Nordic region. Sweden, Finland, and Norway revised and adopted new citizenship laws in 2001, 2003 and 2006, respectively. Subsequent amendments have been made, but these laws remain in force today in these three countries. Denmark and Iceland, on the other hand, have not adopted new citizenship laws in the 21st century. Denmark's current citizenship regime is based on the law of 1950 and Iceland's regime on the law of 1952. A series of amendments have been implemented in both countries since the 1950s, but no major law revisions have been undertaken.

In this chapter, we will describe in detail the current citizenship regimes in each Nordic country, paying particular attention to modes of acquisition and loss of citizenship. Before we delve into the specifics of the regimes of each country, however, we will explain the special procedural arrangements of awarding citizenship in Denmark and Iceland, as this constitutes a fundamental difference between Denmark and Iceland on one hand, and Sweden, Norway, and Finland on the other.

A traditional feature of Danish and Icelandic citizenship law is that citizenship must be granted by enacting statutory law. In Denmark, the sole competence to make decisions on naturalization matters rests with the legislature - that is, the Parliament (Folketinget). Unlike most other countries, naturalization requirements are not adopted by law but negotiated and agreed upon behind closed doors by political parties representing a majority in the Parliament (Ersbøll 2015a). Icelandic citizenship law is based on the same principle. As a main rule, applications for Icelandic citizenship must be granted through law enacted by the Parliament (the Althing), with decision-making based on internal guidelines rather than legal criteria. However, as a supplement to the traditional (parliamentary) method, citizenship can also be granted through an administrative method, whereby decisions are based on legal criteria laid down in the nationality act (Jóhannesson et al. 2013). In principle, decisions on naturalization are at the discretion of the parliaments in Denmark and Iceland, and consequently applicants cannot claim a "right" to citizenship - even if they fulfill all criteria for naturalization (Ersbøll 2003: 239).

In Finland, Norway and Sweden, grant of citizenship is solely a task of the executive branches, that is, the administrative agencies (today, the Finnish Immigration Service, the Norwegian Directorate of Immigration and the Swedish Migration Agency). The leeway for making discretionary decisions is curtailed by law and administrative practice. In contrast to applicants for Danish and Icelandic citizenship, applicants for Finnish, Norwegian, and Swedish citizenship have a legal right to citizenship upon fulfillment of the naturalization criteria. Thus, the distinction between parliamentary 
and administrative procedures of granting citizenship is perhaps just as important as differing naturalization criteria because the degree of discretion may be decisive for applicants' access to citizenship.

This chapter is structured in the following way: In the next section, we will briefly describe the three main modes of citizenship acquisition: by birth, by declaration and by application for naturalization. We then outline each country's provisions concerning acquisition by birth, declaration, and application (naturalization). After describing the naturalization requirements of each country individually, we conduct a cross-country comparison. Naturalization requirements have been subject to frequent changes in each country since 2000, which makes it interesting to compare them across countries in terms of leniency and strictness. We then proceed to another area of Nordic citizenship law characterized by divergence: loss of citizenship. We outline the different modes of loss in the each country, concluding with a cross-country comparison, before we briefly discuss the existing rules concerning extraterritorial citizenship - that is, the rules applying for citizens residing abroad.

\subsection{Modes of acquisition}

There are three main modes for the acquisition of citizenship in the Nordic countries: citizenship acquisition by birth, by declaration and by application for naturalization. Acquisition at birth is the predominant means of acquiring nationality, which in the Nordic countries is mainly based on ius sanguinis (the principle of descent), and to some degree ius soli (the territorial principle). ${ }^{5}$ Acquisition by declaration is a simplified, formal procedure whereby a person is entitled to citizenship if he or she meets certain legal requirements (Bernitz 2013). ${ }^{6}$ Historically, this procedure has been reserved for Nordic citizens based on a pan-Nordic wish to facilitate settlement and integration within the Nordic region (Wickström 2017). More recently, however, new groups (particularly in Finland and Sweden) have gained a right to citizenship through this mode of acquisition. Finally, citizenship may be granted after approval of an application for naturalization (Ersbøll 2003: 235). In general, acquisition by application, in contrast to acquisition by declaration, is a procedure that entails more discretion on part of the authorities.

\footnotetext{
5 Acquisition through adoption and legitimation (acquisition through parents' marriage) are supplemental modes of citizenship acquisition, which we deal with in the section concerning acquisition by birth.

6 "Notification" is used to describe the same procedure in Sweden and Iceland, but we will consistently refer to "declaration" for the purpose of clarity in this report.
} 


\subsection{Citizenship acquisition by birth}

4.2.1 Sweden

Ius sanguinis is the main principle for awarding citizenship in Sweden. The main rule states that a child acquires citizenship if one of the parents is a Swedish citizen or if a deceased parent was Swedish at the time of death (Section 2 of the Swedish Citizenship Act). The law also provides for acquisition for foundlings and adopted children. Abandoned children discovered in Sweden are considered to be Swedish citizens until evidence prove otherwise (Section 3). A child who has reached the age of 12 and who has been adopted by a Swedish citizen becomes a Swedish citizen if he or she was adopted in Sweden, Denmark, Finland, Iceland, or Norway, or the adoption order was issued in another country accepted by Swedish authorities (Section 4).

\subsubsection{Norway}

The acquisition of Norwegian citizenship at birth is based on the ius sanguinis principle. According to the main rule (Section 4 of the Norwegian Nationality Act), a child acquires Norwegian citizenship at birth if the father or mother possesses Norwegian citizenship. If the father dies before the child is born, the child will still acquire citizenship if the father was Norwegian at the time of death. Abandoned children found in the realm are considered Norwegian citizens until the contrary has been proven.

A child adopted by a Norwegian citizen acquires citizenship if he or she is under 18 years of age at the time of the adoption and if the adoption order issued by the Norwegian authorities is pursuant to the Adoption Act (Section 5). If the basis for the acquisition of citizenship by birth or adoption is false, the child shall never have been considered as Norwegian (a so-called "nullity") unless this will make the child stateless. If the child has reached the age of 18 years, he or she is able to retain Norwegian citizenship (Section 6).

\subsubsection{Denmark}

In Denmark, the main rule for attribution of citizenship is based on ius sanguinis. Article 1 of the Danish Citizenship Act states that a child acquires citizenship if the father, mother or co-mother is Danish. A child found abandoned ("foundlings") in Denmark is considered a Danish citizen until evidence proves otherwise. This mode of acquisition is based on the presumption that one of the parents is Danish. If it is later learned that the parents are foreigners, the citizenship acquisition is considered a nullity - in other words that citizenship was never (legitimately) acquired. No time or age limit exist in the law, and such a nullity decision can be enforced even if it makes the person stateless.

Moreover, Danish citizenship can be obtained by children through adoption or legitimation. A child under the age of 12 can acquire Danish citizenship through a Danish adoption order and will become a Danish citizen if the child is adopted by a 
married or cohabiting couple and at least one of the spouses or the cohabiting partners is a Danish citizen, or by a single Danish citizen. A child of a Danish father and an alien mother who has not acquired Danish citizenship at birth will acquire Danish citizenship through the parents' subsequent marriage (conditional on the child being unmarried, and under 18 years of age when the marriage takes place).

\subsubsection{Iceland}

lus sanguinis is the main principle for granting citizenship in Iceland (Jóhannesson et al. 2013: 14). According to Article 1 of the Icelandic Nationality Act, a child acquires Icelandic citizenship automatically by birth if the mother is an Icelandic citizen and if the father is an Icelandic citizen and married to the mother of the child (Jóhannesson et al. 2013: 14). The law also provides for citizenship acquisition for foundlings and adopted children. A child found in Iceland is considered an Icelandic citizen until it is proved otherwise (Article 1, subsection 2). Adopted children under the age of 12 acquire Icelandic citizenship upon adoption (Article $2 \mathrm{~A}$ ).

Elements of ius soli are also present in the Icelandic Nationality Act (Jóhannesson et al. 2013: 15). Article 2 states that if an unmarried woman, who is a foreign citizen, gives birth to a child in Iceland, the child shall acquire Icelandic citizenship if the father is an Icelandic citizen. If an unmarried woman, as a foreign citizen, gives birth to a child abroad, and the father is an Icelandic citizen, the father may apply to the Ministry of Interior, before the child reaches the age of 18 , for the child to acquire Icelandic citizenship. If the parents marry, the child acquires Icelandic citizenship automatically, provided that the child is unmarried and has not attained the age of 18 (legitimation). Another provision based on ius soli is found in Article 10. Here, it is stated that the Minister of Interior may grant Icelandic citizenship to a child born in Iceland who has not demonstrably acquired other citizenship at birth and has not yet acquired Icelandic citizenship or the right to acquire it when the application is made. Domicile and residency in Iceland for at least three years from birth is required.

Foreign children who have grown up in Iceland may also be granted Icelandic citizenship through domicile. Article 3 states that a foreign national who has been domiciled and resided in Iceland continuously since reaching the age of 11 or (or since the age of 13 in the case of a stateless person) may acquire citizenship by notifying the ministry after reaching the age of 18 and before reaching age of 20 .

\subsubsection{Finland}

Ius sanguinis has been a traditional feature of Finnish citizenship law. According to Section 9 (1.1), a child acquires Finnish citizenship through the mother if she is a Finnish citizen. A child may also derive Finnish citizenship through the father in two circumstances. A child acquires Finnish citizenship through the father if he is a Finnish citizen and is either married to the child's mother, or if the child is born in Finland and the man's paternity of the child is established (Section $9.2 a$ and b). If the father is dead but was a Finnish citizen at the time of his death and was married to the child's mother 
or the child was born in Finland and the man's paternity of the child is established, the child may acquire Finnish citizenship (Section 9.3a and b).

More recently, elements of ius soli have been introduced in Finnish citizenship law, with the expressed purpose to prevent statelessness (Fagerlund \& Brander 2013: 17). A child who is born in Finland and does not acquire citizenship of any other state at birth, and does not have a secondary right to acquire citizenship of any other state, has a right to acquire Finnish citizenship at birth (Section 9.4). Furthermore, a child born in Finland to parents who are recognized refugees (or persons who have been granted protection on similar grounds) acquires Finnish citizenship if he or she does not acquire the citizenship of their parents without a procedure requiring the assistance of the authorities of the parents' state of citizenship (Section 9.5).

Concerning foundlings, the rule is that abandoned children found in Finland are regarded as Finnish citizens until otherwise proven. If it has been established that a child in question is a foreign citizen after the child has reached the age of five, Finnish citizenship is retained (Section 12).

The Finnish Nationality Act also provides for rules on acquisition through adoption and legitimation. A foreign child under the age of 12 who is adopted automatically becomes a Finnish citizen if at least one of the adoptive parents is a Finnish citizen (Section 10). A child born to a foreign mother and a Finnish father acquires Finnish citizenship through the marriage of his or her parents, provided that the father was a Finnish citizen at the time of the birth of the child and that paternity has been established (Section 11).

\subsection{Citizenship acquisition by declaration}

\subsubsection{Sweden}

Three different groups can acquire citizenship by declaration in Sweden: children who have grown up in Sweden and fulfill the residence requirement, persons who reacquire Swedish citizenship, and Nordic citizens. Regarding children who have grown up in Sweden, three different categories of people can acquire Swedish citizenship by declaration. First, stateless children born in Sweden can acquire citizenship by declaration if they have been stateless since birth, reside in Sweden and hold a permanent residence permit (Section 6). Second, other children with a permanent residence permit and at least three years of residence in Sweden (two years if the child is stateless) can acquire citizenship (Section 7). For stateless children, as well as other children who have grown up in the country, the child's guardian must submit the declaration before the child has attained the age of 18 . Third, persons who have reached the age of 18 but not 21 can also acquire citizenship by declaration if he or she has a permanent residence permit and has been domiciled in Sweden since the age of 13 (or 15 if the person is stateless) (Section 8). 
A former Swedish citizen who has reached 18 years of age may reacquire Swedish citizenship by declaration if the person has a permanent residence permit and a total of 10 years of residence and domicile in Sweden for the two preceding years (Section 9). ${ }^{7}$

A Nordic citizen can acquire Swedish citizenship through the procedure of declaration if he or she has turned 18 years of age, has resided in Sweden for five years, and during this time has not been sentenced to imprisonment (Section 18). A person who has lost his or her Swedish citizenship and subsequently has been a citizen of a Nordic country may recover Swedish citizenship by declaration if he or she becomes domiciled in Sweden (Section 19). If citizenship is acquired according to sections 18 and 19, children of the declarant are awarded Swedish citizenship as well (in accordance with Section 10).

The Swedish Migration Agency processes declarations for citizenship made by nonNordic citizens, while the county administrative boards (länstyrelsen) have, since 2014, handled declarations submitted by Nordic citizens. For children under 18 years of age, young persons (between 18 and 21 years of age) and former Swedish citizens (reacquiring citizenship) the fee for making a declaration is SEK 175 (EUR 18). For Nordic citizens and those regaining Swedish citizenship that was lost before 1 July 2001, the fee is SEK 475 (EUR 48). The processing time for declarations is seven months on average (Bernitz 2013: 6).

\subsubsection{Norway}

In Norway, three groups can use the facilitated procedure of declaration: Nordic citizens, former Norwegian citizens, and children of these two groups. First, any Danish, Finnish, Icelandic, and Swedish citizen has the right upon declaration to become a Norwegian citizen if the person concerned has turned 18 years of age, has been a resident in Norway for the last seven years, and during this time has not been given a custodial sentence or special sanction due to a criminal act (Section 20). The declarant must submit proof of release of former citizenship at the time of the acquisition. The person must also enclose a certificate of good character issued by the police, proving no custodial sentence or special criminal sanction has been issued during the last seven years.

Former Norwegian citizens, who have lost their Norwegian citizenship and subsequently been citizens of another Nordic state can reacquire Norwegian citizenship by declaration when resuming residency in Norway and releasing themselves from any other citizenship (Section 21).

Children of persons who acquire Norwegian citizenship by declaration (according to sections 20 or 21), automatically acquire Norwegian citizenship at the acquisition of their parents, provided that the child concerned is resident in Norway and is released from any other citizenship (Section 22).

\footnotetext{
7 When an alien becomes a Swedish citizen according to Sections 6, 7, 8, or 9, his or her child also acquires Swedish citizenship, if the child lives in Sweden, is unmarried and not 18 years of age and the parent has sole custody of the child or joint custody with the other parent and that parent is a Swedish citizen (Section 10).
} 
The Norwegian Directorate of Immigration is responsible for processing declarations for Norwegian citizenship. Making a declaration is free of charge and processing time is approximately two months.

\subsubsection{Denmark}

In Denmark, the procedure of citizenship acquisition by declaration is reserved for Nordic citizens and former Danish citizens. Citizens of the Nordic countries may acquire citizenship by declaration if they are aged between 18 and 23 , live in Denmark and have resided in Denmark for an aggregated period of 10 years (of which an aggregate period of no less than five years must be within the last six years and have no convictions or pending criminal charges) (Section 3). ${ }^{8}$ Furthermore, Nordic citizens who have attained their Nordic citizenship by a mode other than naturalization are entitled to citizenship by declaration when they have reached the age of 18 and have lived in Denmark for at least seven years and during this time have not been sentenced to imprisonment (Section 3).

Former Danish citizens may also reacquire Danish citizenship by declaration. A Danish-born citizen who has lost Danish citizenship is entitled to reacquire Danish citizenship if he or she was a resident in Denmark until the age of 18 and has been a resident in Denmark for the previous two years (residence in another Nordic country counts as residence in Denmark until the age of 12). Persons who have lost Danish citizenship and subsequently become Nordic citizens may reacquire their Danish citizenship by declaration by taking up residency in Denmark (Section 4).

A child whose parent acquires Danish citizenship by declaration automatically acquires Danish citizenship. Such transfer of citizenship from parent to child (filial extension) is conditional on the parents having custody over the child and the child being under 18 years of age, unmarried and holding residency in Denmark (Section 5).

It is the regional state authorities, such as a regional Danish State Administration Office, the High Commissioner of the Faroe Islands, and the High Commissioner of Greenland, that are responsible for processing citizenship declarations. The fee for making a declaration is DKK 1,100 (EUR 147).

\subsubsection{Iceland}

Three groups may acquire Icelandic citizenship upon declaration: persons between 18 and 20 of age with long-term residence in Iceland, Nordic citizens, and former Icelandic citizens. A foreign citizen who has been domiciled and resided in Iceland continuously since reaching the age of 11 (or since the age of 13 , in the case of a stateless person), may acquire Icelandic citizenship by notifying the Icelandic Directorate of Immigration after reaching the age of 18 and before reaching the age of 20 (Article 3 ). Nordic citizens

\footnotetext{
${ }^{8}$ For Nordic citizens making declarations between 18 and 23, residency in another Nordic country is considered equivalent to residency in Denmark, but only if residency in another Nordic country precedes the making of the declaration and the declarant's sixteenth birthday by no less than five years.
} 
may acquire Icelandic citizenship by declaration if he or she has reached the age of 18 , has been domiciled in Iceland for the previous seven years, has not been imprisoned and has not acquired citizenship by a mode of acquisition other than naturalization (Article 14 B). Persons who have lost Icelandic citizenship and since then have been a citizen of a Nordic state may reacquire Icelandic citizenship by notifying the Ministry, providing that the applicant has been granted domicile in Iceland (Article ${ }_{14} \mathrm{C}$ ).

The Icelandic Directorate of Immigration (a subordinate agency to the Minister of Interior) processes declarations for Icelandic citizenship. The fee for making a declaration is ISK 12,500 (EUR 100).

\subsubsection{Finland}

The procedure of the acquisition of Finnish citizenship by declaration is available to five groups of individuals in Finland: alien children whose fathers are Finnish, adopted children who have reached the age of 12 years, young persons with long-term residence in Finland, former Finnish citizens and Nordic citizens.

A foreigner who does not acquire Finnish citizenship by birth may acquire Finnish citizenship by declaration if his or her father was a Finnish citizen when he or she was born, the parent was born in Finland and paternity was established after he or she had reached the age of 18 years or married before that, or the parent was born outside of Finland and paternity has been established (Section 26). Adopted children who have turned 12 years of age before adoption may acquire citizenship by declaration if at least one of the adoptive parents is a Finnish citizen and the adoption order is valid in Finland (Section 27).

Young persons between the ages of 18 and 23 may acquire Finnish citizenship by declaration, provided that they have been permanently resident and domiciled in Finland for a minimum of 10 years (with a minimum of two years without interruption before submitting the declaration), and have not been sentenced to imprisonment. If the declarant was born in Finland, however, the requirement is six years of residence. If the declarant has been a permanent resident and domiciled in Iceland, Norway, Sweden, or Denmark before submitting the declaration, this residence is considered equal to residence in Finland but only for the five years before the declaration was made and only to the extent that the period of residence occurred before the age of 16 years (Section 28).

Former Finnish citizens may acquire Finnish citizenship by declaration, provided that he or she did not lose Finnish citizenship due to annulment of paternity or fraud (Section 29). ${ }^{9}$ Nordic citizens can acquire Finnish citizenship by declaration if they have reached 18 years of age, have not acquired their other Nordic citizenship through naturalization, have lived the last five years in Finland, and have not been sentenced to unconditional imprisonment or probation (Section 30 ).

\footnotetext{
9 When Finland accepted dual citizenship in 2003, a provisional five-year's declaration procedure was made available specifically to former Finnish citizens and their descendants. The 2011 amendment, however, created a single declaration procedure available to all former citizens regardless of their country of residence (Fagerlund \& Brander 2013: 29).
} 
The Finnish Immigration Service (an administrative agency subordinate to the Ministry of Interior) is responsible for processing citizenship declarations (and applications). For adults, the fee for making a citizenship declaration is EUR 250 for paper forms and EUR 200 for electronically submitted forms. For children under 18 years of age, the fee is EUR 100 for paper forms and EUR 80 for electronically submitted forms.

\subsection{Citizenship acquisition by application}

\subsubsection{Sweden}

Among the five Nordic countries, Sweden has the least complicated set of rules with regard to naturalization. All criteria for naturalization are found in Section 11 of the Swedish Nationality Act. This provision states that an alien can apply for and be granted Swedish citizenship if he or she has provided proof of identity, has reached the age of 18 , holds a permanent residence permit, has resided in Sweden for the last five years, and has led and is expected to lead a respectable life (good conduct).

Regarding the requirement to provide proof of identity, three possibilities exist. An applicant can submit a national passport from his or her country of origin in the original, submit other identity documents in the original, or have a close relative attest to the applicant's identity. As to the third possibility, the applicant's husband, wife, or close relative may attest to the applicant's identity, provided that the relative is a Swedish citizen and has proven his or her identity by means of showing a national passport or another identity document in the original. Occasionally, the Swedish Migration Agency makes an exception if the applicant has lived in Sweden for at least eight years, it is likely that the stated identity is correct (i.e., has used the same identity throughout the period of eight years), and he or she is unable to obtain acceptable documents to prove the identity (Section 12).

As to the residence requirement, several groups may apply after a shorter period of residence than the main rule of five years. Recognized refugees and stateless persons can apply after four years, spouses of Swedish citizens after three years ${ }^{10}$, and Nordic citizens after two years of residence in Sweden. According to law and practice, exemptions can also be granted for emigrants returning to Sweden, persons working on Swedish ships, persons working abroad for a Swedish company and who had previously lived in Sweden and persons who have been married to a Swedish citizen abroad for at least 10 years and who does not live in their country of origin (Bernitz 2012: 13; Bernitz 2013: 4).

The requirement of good conduct primarily concerns criminal actions. Committing a crime does not disqualify a person permanently from acquiring Swedish citizenship, but may result in a waiting period that has to be endured before citizenship can be

${ }^{10}$ If the person has been the spouse or cohabitant with the Swedish citizen at least two years. 
granted. For instance, if the custodial sentence is one year the waiting period is seven years (Bernitz 2012: 5). Marks on a person's record, for instance unpaid taxes, fines or child support, may also disqualify applicants under this condition (Bernitz 2012: 13).

In naturalization decisions, it shall be examined whether the unmarried children under 18 years shall acquire Swedish citizenship along with the parent (Section 13).

The Swedish Migration Agency is responsible for the processing of citizenship applications lodged from residents in Sweden. ${ }^{11}$ The wording in Section 11 - "an alien can apply and be granted Swedish citizenship" - allows for discretion in the examination of every requirement. However, the discretion must not be arbitrary (Bernitz 2012: 15). As mentioned, exceptions can be made to requirements of identity, age, and residence, while exceptions from the requirements of permanent residency and conduct are rarely made (Bernitz 2013: 5).

The main fee for applying for Swedish citizenship is SEK 1,500 (EUR 152). For adoptive children, the fee is SEK 175 (EUR 18). For stateless persons who either have been declared a refugee or have a Swedish travel document, there are no fees for applying for citizenship, nor is there any additional fee for co-applicant children. No official time limit for the processing of citizenship applications exists, but the Migration Agency has estimated that it normally takes one year after the application has been lodged (Bernitz 2013: 6). If the application is rejected, the applicant can appeal the decision to the Migration Agency. If the appeal does not go through there, the applicant can take it to the Migration Court. A decision made by the Migration Court can be appealed to the Migration Court of Appeal (Bernitz 2013: 7).

Every municipality in Sweden is legally bound by the Swedish Citizenship Act (Section 29) to organize a ceremony at least once a year for all new Swedish citizens. Participation in the ceremonies is voluntary and no oath of allegiance or similar is required by the participants.

\subsubsection{Norway}

The conditions of the acquisition of Norwegian citizenship are based on Chapter 3 of the Norwegian Citizenship Act. The main rule (Section 7) is that every person has upon application a right to citizenship if he or she meets the requirements of establishment of identity, age, residence, permanent residence permit, language training, tests in Norwegian and social studies, renunciation of former citizenship, and good conduct.

The requirement of identity entails, first, that the applicant must have provided documentary evidence of, or otherwise clearly has established his or her identity. The main rule is submitting a national passport, but applicants who have been granted asylum, applicants from Somalia or other countries where it is impossible for Norwegian authorities to verify the information in the passport, can instead hand in other identity documents (UDI 2018a). A precondition for the Norwegian Directorate of

${ }^{11}$ Applications lodged from persons residing abroad are examined by the Swedish embassy or consulate in the relevant country takes care of. However, the Swedish Migration Agency has the final say in accepting or rejecting the application. 
Immigration (UDI) to approve these documents, however, is that there exists no doubt that the information about the applicant's identity is correct.

Second, the applicant must have reached the age of 12, reside in Norway, and intend to remain in Norway in the future. Third, he or she must have spent a total of seven out of the previous 10 years in Norway, with residence or work permits of at least one year's duration. Certain groups are exempted from the general residence requirement. Stateless individuals can apply after three years of residence in Norway with a work or residence permit of at least one year's duration. ${ }^{12} \mathrm{~A}$ person who is married to, or is a registered partner of or cohabitant with a Norwegian citizen can apply if he or she has spent at least three out of the last 10 years in the country, if the person has held residence or work permits of at least one year's duration. Three years of residence also applies to citizens of countries in the European Economic Area (EEA) (if the initial residence permit was granted for five years). Nordic citizens can apply after two years of residence, and former Norwegian citizens can (re)acquire Norwegian citizenship after two years with residence or work permits of at least one year's duration (Brochmann 2013: 10).

Fourth, the person must hold or satisfy the conditions for a permanent residence permit. Eligibility for a permanent residence permit is conditional on continuous residency in Norway for the last three years, fulfilling requirements for a temporary residence permit, good conduct, language skills and civic knowledge, and self-support (the Norwegian Immigration Act, Section 62). However, Nordic citizens, EEA citizens and former Norwegian citizens are exempted from the requirement of holding a permanent residence permit (Sections 13, 14 and 15).

Fifth, the applicant must have documented language training and have passed tests in Norwegian and social studies. Persons between 18 and 67 years of age (lodging an application for citizenship after January 1,2017 ) must have completed 600 hours of approved tuition in the Norwegian language (including 50 hours of tuition in social science) or document sufficient knowledge of Norwegian or Sami and have passed an oral Norwegian test (on CEFR level A2) and a social studies test ("citizenship test"). Exemptions from the requirement of language skills and tests can be granted if the relevant person is seriously ill or has a chronic disease (documented by means of a medical certificate) or if there are other weighty reasons. However, UDI stresses that exemptions are only granted in exceptional circumstances.

Sixth, the applicant must have renounced his or her former citizenship. As a consequence of the single citizenship policy, applicants must renounce their former citizenship if the applicant does not automatically lose citizenship in another country when acquiring Norwegian citizenship. However, if it is not possible to be released from the other citizenship before the application is granted, the applicant must, within one year of being granted Norwegian citizenship, document that he or she has been released from the other citizenship. If the applicant cannot be released from the other citizenship before a certain age is reached, the applicant must, within one year after

12 It should also be mentioned that stateless persons are exempted from requirements of age and release from other citizenships (Section 16). 
reaching this age, document that he or she has been released from the other citizenship. Exemptions may also be granted if release from another citizenship is legally or practically impossible or otherwise unreasonable to fulfill.

Lastly, it is required that the applicant has not been sentenced to a penalty or special criminal sanction (Brochmann 2013). Persons who have been sentenced to a penalty or a special criminal sanction cannot acquire Norwegian citizenship until a waiting period (depending on the gravity of the criminal action) has been endured. Applicants who have been sentenced to imprisonment between 10 and 20 days must wait two years from the day he or she was sentenced, while sentences to imprisonment for 21 years leads to a disqualification period of 34.5 years.

The child of an applicant who acquires Norwegian citizenship has a right upon application to acquire Norwegian citizenship along with the parent if the identity of the child has been established and if the child intends to stay in the country, has not been sentenced to penalty or special criminal sanction, and is released from former citizenship(s) (Section 17).

The UDI (a subordinate agency to the Ministry of Justice and Public Security) is responsible for handling applications for citizenship. As mentioned, every person fulfilling the conditions for naturalization has a right to Norwegian citizenship. This was a considerable liberalization of the previous 1950 Act, effectively removing the administrative discretion in the decision-making (Brochmann 2013: 10). On the other hand, the applicant does not have a right to citizenship if is deemed contrary to the interests of national security or to foreign policy considerations, which in principle, can entail discretionary decision-making.

For adult applicants, the fee for applying for Norwegian citizenship is NOK 3,700 (EUR 382). Applications on behalf of children under 18 years of age are free of charge. The processing time on each application depends on the citizenship of the applicant. For some it may only take four months from when the application was handed to the police until UDI makes a decision. For other applicants, such as Somali citizens, the processing time can be 18 months because of difficulties establishing the identity of these persons (UDI 2018b). ${ }^{13}$ If the application is rejected, it is possible to appeal the decision. UDI will then reconsider the case. UDI can grant the appeal or forward it to the Immigration Appeals Board (UNE) for further consideration. In the latter case, UNE examines the case again and either grants or rejects the appeal. UNE's decision is not possible to appeal further.

A citizenship ceremony was also (re)introduced when the reformed Nationality Act took effect in 2006..$^{14}$ All newly naturalized citizens are invited to a ceremony organized by the relevant County Governor. The ceremony has no legal function, and participation is voluntary. However, those who participate must pledge an oath of allegiance to the Norwegian state (Hagelund \& Reegård 2011).

\footnotetext{
13 See UDI's webpages for more information on processing times for different groups.

${ }_{14}$ An oath of allegiance was a part of the first Norwegian Nationality Act of 1888 , but was abolished when the law was reformed in 1976 (Hagelund \& Reegård 2011: 739).
} 


\subsubsection{Denmark}

Conditions for naturalization in Denmark are laid down in Citizenship Act Section 6 and in the 2015 Circular Document (Udlændinge-, Integrations- og Boligministeriet 2015). In short, the granting of Danish citizenship by application is conditional on nine years of residence, good conduct, no public debt, financial self-support, language skills and knowledge of Danish culture and society, and an oath of allegiance.

First, the applicant must have a permanent residence permit and have resided in Denmark for nine years. However, Nordic citizens can apply after two years of uninterrupted residence, recognized refugees and stateless after eight years, and spouses of Danish citizens after six years of residence (Chapter 3, 2015 Circular Document). ${ }^{15}$

As to the requirement of good conduct, the applicant cannot have been convicted of Criminal Code parts 12 or 13 (concerning crimes against the state). ${ }^{16}$ Applicants who have been sentenced to imprisonment for 60 days or more due to violations of Criminal Code parts 12 or 13 , and persons who have been sentenced imprisonment for 18 months or more are permanently excluded from naturalization (Chapter 5, 2015 Circular Document). Other, less grave violations of the law may lead to waiting periods for the applicant. The waiting periods range from four months (for smaller fines) to 30 years (for preventive detention sentences) (Supplement 2, 2015 Circular Document).

Applicants must have no debts to the state, and fulfill a requirement of financial self-sufficiency. Applicants cannot have received any social benefits one year prior to the introduction of the naturalization bill and for no more than an aggregate of six months within the last five years (Chapter 6, 2015 Circular Document).

Further, applicants must show a certification of knowledge of the Danish language (Danskprøve 3) and pass a citizenship test (Indfødsretsprøve), which includes questions about Danish society, culture, and history (Chapter 7, 2015 Circular Document). The Danish language requirement is comparable to CEFR level B2, making it one of the highest in Europe (Ersbøll 2015a). For applicants who meet the requirement of selfsupport and during the latest nine years have not received any social benefits in an aggregate period of more than six months, a lower requirement of Danish applies (Danskprøve 2). If there are special circumstances that favor, such as a long-term physical, psychological, sensory or intellectually handicap that prevents a person from satisfying the required level of language skills and passing the citizenship test, dispensation can be given.

Lastly, as part of the naturalization procedure, applicants must sign a written declaration of allegiance and loyalty to Denmark and the Danish society and willingness to observe Danish legislation and respect fundamental Danish principles of law (Ersbøll 2013: 8).

${ }_{15}$ Provided that the spouse has been a Danish citizen and the marriage has lasted for at least three years. If the marriage has lasted for two years, seven years of residence is required, and if the marriage has lasted for one year, eight years is required. ${ }^{16}$ Incorrect testimonies to this regard may lead to a subsequent revocation of Danish citizenship, in accordance with section $8 \mathrm{~B}$ of the Nationality Act, regarding loss of citizenship due to crimes against the state (see Section 4.5). 
A child of an applicant who is granted Danish citizenship acquires Danish citizenship along with his or her parent, provided that the child is unmarried, has not reached the age of 18 , and resides in Denmark, and the applicant (parent) has custody over the child. If a child has a parent who theoretically can apply for naturalization, the child cannot independently apply for Danish citizenship. ${ }^{17}$ Thus, if parents cannot meet the naturalization criteria, their children cannot naturalize (Ersbøll 2015a: 34-35). ${ }^{18}$

The Ministry of Immigration and Integration is responsible for examining whether or not applicants fulfill the criteria for acquiring Danish citizenship. In the examination of the different criteria, the Ministry cannot exercise any discretion. Applications subject to possible dispensation must be handed over from the Ministry of Justice to the Naturalization Committee in the Parliament. The Naturalization Committee comprises 17 members of Parliament. Each political party is represented in proportion to the party's number of seats in the Parliament. The naturalization committee can then decide, without being bound by any clear-cut legal criteria, to grant or reject dispensation. If the Naturalization Committee accepts the applicants, they are included in a bill on naturalization, usually introduced twice a year to the Parliament. Bills on naturalization are given three readings in Parliament, which take two to three months (Ersbøll 2013: 4).

The possibilities of appealing a negative decision on application for citizenship are very limited. Since Danish citizenship can only be granted by law, and the Naturalization Committee - representing the Parliament - is not a part of the public administration and therefore not bound by general rules of administrative law, there is no right to an administrative review. Introducing a right to review would require an amendment to the Danish constitution, which is a complicated and lengthy process. There is, however, a right to judicial review as to whether international obligations have been violated in a naturalization case but no right to judicial review to the applicant's right to acquire Danish citizenship, as this possibility is excluded from the constitution (Ersbøll 2013: 20; Ersbøll 2015a: 45).

The cost of submitting an application for Danish citizenship is DKK 1,200 (EUR 160). The fee also includes the applicant's children who acquire Danish citizenship by extension of the acquisition of the parent. Children who apply independently have to pay the full fee (Ersbøll 2013: 23). In addition, a fee for the citizenship test of DKK 753 (EUR 100) must be paid to the test organizer.

Since 2006, a "citizenship day", an official welcoming celebration for new Danish citizens and their families, has been organized by the Parliament each year. Like the Norwegian and Swedish ceremony, it has no legal function, and participation is voluntary.

\footnotetext{
17 If the child is over 15 years of age, conduct requirements apply as well (Ersbøll 2015a: 34).

${ }^{18}$ Except for certain adoptive children, children born out of wedlock by a foreign mother and a Danish father after 1993 and children who are born stateless in Denmark (Sections 14, 16 and 17, 2015 Circular Document).
} 


\subsubsection{Iceland}

Iceland has a dual system of awarding citizenship by naturalization. Icelandic citizenship can either be granted by legislation enacted by the Parliament, or by an executive decision made by the Directorate of Immigration. The main rule is that the Parliament (the Althing) can grant citizenship by legislation to any individual after receiving comments from the applicant's local commissioner of police and from the Directorate of Immigration (Article 6). ${ }^{19}$ The Parliament is not bound by any legal criteria, except the constitution and general constitutional principles, and may exercise full discretion in citizenship decisions. Executive (administrative) decisions on citizenship applications made by the Icelandic Directorate of Immigration, however, are guided by legal criteria laid down in articles 8 and 9 in the Icelandic Nationality Act. The acquisition of Icelandic citizenship is conditional on residence, establishment of identity, good reputation, passing a test in Icelandic, lack of public debt, financial selfsupport, and conduct.

The main rule is seven years of domicile in Iceland (Article 8). However, certain groups can apply after a shorter period of time. Nordic citizens can apply after four years, spouses of Icelandic citizens after three years (if the spouse has been an Icelandic citizen for no less than five years), applicants living in a registered cohabitational union with an Icelandic citizen after five years (if the partner has been an Icelandic citizen for no less than five years), recognized refugees after five years, and former Icelandic citizens after only one year. Applicants must also meet the requirements for being issued a permanent residence permit by the Directorate of Immigration and shall hold such a permit when applying for Icelandic citizenship.

The other conditions for acquisition by application are found in Article 9. First, the applicant must demonstrate his or her identity satisfactorily. Second, he or she shall be employable and have a good reputation, which two respectable Icelandic citizens shall attest to. Third, the applicant must pass a test in Icelandic. The test involves speaking, aural understanding, writing and reading comprehension and corresponds to CEFR level $A 1$, which is the lowest on this scale (Kristinsson 2012). Exemptions may nonetheless be granted if it is considered unfair to impose such a requirement. This could be the case, for instance, if the applicant has reached the age of 65 and has been legally domiciled in Iceland for seven years prior to the submission of the application, if the applicant is attending an Icelandic junior school or has not yet reached junior school age, if the applicant cannot take the test due to physical or mental impairments (proven by a medical certificate), or if the applicant can confirm that he or she possesses skills that meets the requirement (demonstrated by a relevant certificate from an Icelandic educational institution.

Fourth, the applicant shall not, during the previous three years, have had unpaid taxes or have been declared bankrupt. Fifth, applicants are required to be able to support themselves financially. This means that during the previous three years the applicant may not have received any support grants from local authorities.

19 If the person who is granted citizenship has children, his or her children acquires Icelandic citizenship as well. 
Lastly, the applicant may not have been fined or imprisoned in Iceland or abroad or be involved in a criminal case pending in the justice system. Minor offenses may be exempted but lead to waiting periods of different lengths depending on the gravity of the offence (Jóhannesson et al. 2013: 20). For instance (as stated in Article 9.6), if an applicant has received a fine between ISK 50,000 and 100,000 (EUR 400-800), he or she must wait one year after the commission of the offense to be naturalized. If an applicant has been sentenced to imprisonment for more than one year, he or she has to wait 14 years from the sentence has been served (Article 9.6).

The administrative procedure is considered only an additional method to the traditional (parliamentary) method. The Directorate of Immigration (formally the Minister of Interior) is only to deal with cases that clearly comply with the legal criteria above, while less clear-cut cases should be transferred to the Althing, which ultimately decides whether or not to grant citizenship. The amendment to the Citizenship Act in 2007 made it clear that decisions made by the Minister of Interior do not have to comply with general administrative principles since they are positively excluded by the Citizenship Act (Article 7, subsection 3). The 2007 amendment made it clear that a right to Icelandic citizenship does not exist, even if an applicant fully complies with the naturalization conditions (Jóhannesson et al. 2013: 20, 24). This is because the granting power lies, in principle, with the Parliament (legislature), and not with the executive branch of government. In the case of a denial by the Minister of Interior, the only available alternative is to apply for citizenship to the Althing. If the application is submitted to the Parliament, the General Committee, one of 12 standing committees in the Althing, prepares the statutory act of granting citizenship, normally passed twice a year (Jóhannesson et al. 2013: 20).

As previously mentioned, the Directorate of Immigration handles applications for Icelandic citizenship. The cost of applying for citizenship - both applications submitted to the Directorate of Immigration and the Althing - is ISK 25,000 (EUR 200). No official time limit is set on processing citizenship applications. A decision made by the Ministry of Interior (in practice, the Directorate of Immigration) on naturalization is not possible to appeal as this office is the highest level of authority within the Icelandic state administration. Nevertheless, it is possible to appeal an administrative decision before a court. This is, however, not a straightforward procedure because the applicant has no legal claim to citizenship, despite satisfying all conditions laid down in the Citizenship Act. Appealing a negative decision made by the Althing before a court is also very difficult, since the Icelandic court system is prevented from annulling legislation enacted by the Althing. Therefore, possibilities for an administrative or judicial review are very limited (Bjornsson \& Petursson 2013: 5-6).

\subsubsection{Finland}

A foreigner who applies for Finnish citizenship must fulfill a general identity requirement - a condition for all modes of citizenship acquisition - and specific naturalization requirements pertaining to age, residence period, language skills, integrity, debt, and account of livelihood. 
The requirement of established identity is laid down in Section 6 of the Finnish Nationality Act. According to this provision, the applicant's identity must be established by means of documents or by providing other reliable information on the person's name, date of birth, family relations, citizenship, and other relevant information. If applicants cannot put forward reliable identity documentation, which may be the case for some asylum seekers, citizenship may nevertheless be granted if the person has used the same identity entered in the population system since taking up residence in Finland. If a foreigner has used more than one identity, he or she can still fulfill the identity requirement if he or she has used the same identity for at least 10 years, as registered in the population system (Section 6, subsection 3). The identity requirement must be fulfilled in order for other conditions for naturalization to be examined at all (Fagerlund \& Brander 2013: 18).

Specific requirements for naturalization are found in Chapter 6 in the Nationality Act. First, the applicant must have reached the age of 18 years (or been married before that). It is also required that the applicant had lived permanently in Finland for the previous five years without interruption (continuous period of residence) or a total of seven years since he or she turned 15 , with two of those years without interruption (accumulated period of residence).

There are, however, several exceptions to the residence requirement laid down in the Nationality Act. Citizenship may be granted after four years of continuous residence or six years of accumulated residence to a person who meet the language skills requirements (provided that he or she fulfills the other requirements and have strong ties to Finland). Other exceptions can be based on the situation of an individual or on membership in a certain group or legal category. Individuals who have strong ties to Finland and have been permanently domiciled in Finland for the previous two years (without interruption), providing special and weighty reasons for exception, such as being engaged in permanent in full-time work wherein acquisition of Finnish citizenship is crucial, can be exempted from the general residence requirement. Stateless individuals and recognized refugees (or individuals whose residence permit is based on humanitarian grounds) may apply for citizenship after four years of continuous residence or six years of accumulated residence since the age of 15 , the two last years interrupted (Fagerlund \& Brander 2013: 20). Spouses of Finnish citizens can apply after four years of uninterrupted residence or a total of six years since the age of 15 , with the two last years uninterrupted (conditional on the spouses having lived together for at least two years). For Nordic citizens, the requirement is to have been a permanent resident and domiciled in Finland for the previous two years with no interruption (Fagerlund \& Brander 2013: 21). ${ }^{20}$

The integrity requirement states that an applicant may not have committed any punishable act or been placed under a restraining order. Nevertheless, a person may be

${ }^{20}$ Additionally, exemptions from the residence period are granted to co-applicant children and children who apply independently. Children who have reached the age of 15 can apply after the last four years or six years in total since the age of 7, with the last two years uninterrupted. Children under the age of 15 can apply immediately after taking residence in Finland (Fagerlund \& Brander 2013: 21). 
naturalized if there are well-founded reasons for making an exception to the integrity requirement, taking into consideration the time passed since the commission of the crime, the nature of the criminal act, the severity of the punishment, and the overall criminal record of the applicant. If no such well-founded reasons exist, the applicant has to undergo a waiting period before naturalization can take place. The length of the waiting period varies according to the severity of the criminal act, but the maximum time is seven years (Fagerlund \& Brander 2013: 24-25).

The language requirement entails demonstrating satisfactory skills in Finnish or Swedish or similar skills in Finnish sign language. Prior to the 2003 Act, the requirement of language skills was stipulated only by decree and with no clear rules on how applicants should prove their language competency. Section 13 of the 2003 Act, however, states that an applicant must have satisfactory oral and written language skills, corresponding to level $\mathrm{B}_{1}$ in the Common European Framework Reference of Languages (CEFR) (Fagerlund \& Brander 2013: 22). Passing a general language examination (National Certificate of Language Proficiency test) is the most common way of demonstrating language skills, but a range of other options are accepted as well. Even though the level of language skills required was made more difficult with the 2003 Nationality Act, exemptions are made in various circumstances (Fagerlund \& Brander 2013: 22). Persons who are dependent on having Finnish citizenship in their line of duty are exempted if it is deemed to be unreasonably difficult for them to work full-time in Finland without Finnish citizenship. The same goes for persons over 65 years of age who have refugee status (or similar), persons who have health issues preventing them from fulfilling the requirement, and persons who otherwise can provide weighty reasons for exception (Section 18).

Lastly, the applicant must not have materially failed to provide maintenance or to meet his or her obligations under public law, and he or she must be able to provide a reliable account of his or her livelihood. Unlike the requirements of residence, integrity, and language, no deviation from these two requirements is allowed. The requirement of providing a reliable account of livelihood is intended to ensure that the source of income is legal. The level of income does not matter, thus it is not conditional on financial self-support, meaning that even persons living on income support can acquire citizenship (Fagerlund \& Brander 2013: 26).

A co-applicant child (under the age of 15) can be granted Finnish citizenship if he or she is a permanent resident and domiciled in Finland. A co-applicant who has reached the age of 15 may be granted Finnish citizenship if the applicant has been a permanent resident and domiciled in Finland for the previous four years without interruption or a total of six years since reaching the age of seven years, with the last two years uninterrupted (Section 23). A child may naturalized independently on an application made by his or her parent or guardian if the person who makes the application is a Finnish citizen and the child lives with this person or if there otherwise are weighty reasons for naturalizing the child (Section 24$).^{21}$

${ }^{21}$ For children under the age of 15 , the requirement is that the child is permanently resident and domiciled in Finland. If the child is older than 15 , the requirement is that the child has been permanently resident and domiciled in Finland for four years 
According the Finnish Constitution (Section 5), decisions on naturalization must entirely rest on legal provisions (Fagerlund \& Brander 2013: 26). Thus, every person who fulfills the legal requirements laid down in the Finnish Nationality Act has a right to Finnish citizenship. However, the Act leaves some room for the discretion of the authorities. Despite fulfilling all requirements for naturalization, a person may not be naturalized if there are "well-founded reasons for suspecting that the naturalization will jeopardize the security of the State or public order", or if the intention to naturalize is to take advantage of citizenship benefits without aiming to settle in Finland, or "if naturalisation conflicts with the best interests of the State" (Section 13). Thus, there is a "kind of right" to citizenship by naturalization, yet some discretion remains in the hands of the Administrative Courts when they determine what the "best interests of the State" are (Fagerlund \& Brander 2013: 26).

The Finnish Immigration Service, subordinate to the Ministry of Interior, is responsible for processing citizenship applications. The fee for submitting an application is EUR 440 for applications submitted on paper and EUR 350 for electronic applications. For applicants under 18 years of age, the fee is EUR 100 for paper applications and EUR 80 for electronic applications. Fees may be reduced for social reasons, such as health, education or legal aid (Gozdecka 2013: 8). The law does not stipulate any maximum processing time for citizenship applications, but the expected processing time is between eight and 16 months, depending on the case. Processing may take longer if the applicant does not meet all requirements or if the applicant does not provide a valid national passport. A decision by the Finnish Immigration Service is subject to judicial appeal in an Administrative Court. Decisions made by an Administrative Court can lastly be appealed to the Supreme Administrative Court (Gozdecka 2013: 14).

\subsection{Citizenship acquisition by application: A cross-country comparison}

Naturalization requirements have increasingly become a politicized policy area in Western societies, with significant cross-country variations, including the Nordic region. Table 1 summarizes and compares the naturalization requirements in the Nordic countries. The identity requirement is a common feature of the nationality acts in all Nordic countries except Denmark. Proof of identity is not an explicit requirement in Danish citizenship law but rather is an integral part of the procedure for issuing immigrants residence permits. Nevertheless, it is required that identity documents (national passports, as a rule) must be submitted with the application for citizenship (Ersbøll 2013: 10, 16-17). Based on the citizenship laws, Norway and Iceland follow the most restrictive practice of enforcing the identity requirement, as Finnish and Swedish law provides for lenient exceptions to the main rule.

without interruption, or a total of six years since reaching the age of seven, with the two last years uninterrupted. If the child is a former Finnish citizen or a Nordic citizen, only two years of residence is required for granting the application. 
Table 1: Naturalization requirements in the Nordic countries

\begin{tabular}{|c|c|c|c|c|c|}
\hline Requirement & Sweden & Norway & Denmark & Iceland & Finland \\
\hline Identity documentation & Yes & Yes & No & Yes & Yes \\
\hline Residence & 5 years & 7 years & 9 years & 7 years & 5 or 7 years \\
\hline Release from other citizenship & No & Yes & No & No & No \\
\hline Language skills & $\begin{array}{l}\text { No } \\
\text { requirement }\end{array}$ & $\begin{array}{l}\text { Test (CEFR level } \\
\mathrm{A} 2 \text { ) }\end{array}$ & $\begin{array}{l}\text { Test (CEFR } \\
\text { level B2) }\end{array}$ & $\begin{array}{l}\text { Test (CEFR } \\
\text { level } A 1)\end{array}$ & $\begin{array}{l}\text { Yes (CEFR } \\
\text { level B1) }\end{array}$ \\
\hline Citizenship test & No & Yes & Yes & No & No \\
\hline Self-support & No & No & Yes & Yes & No \\
\hline No debt to the state & Yes & No & Yes & Yes & Yes \\
\hline $\begin{array}{l}\text { Conduct (max. waiting time for a } \\
\text { criminal act) }\end{array}$ & 7 years & 34.5 years & $\begin{array}{l}\text { Permanent } \\
\text { exclusion }\end{array}$ & 14 years & 7 years \\
\hline Citizenship ceremony & Voluntary & Voluntary & Voluntary & No & No \\
\hline Oath of allegiance & No & $\begin{array}{l}\text { Yes (if attending } \\
\text { ceremony) }\end{array}$ & Mandatory & No & No \\
\hline
\end{tabular}

Sweden and Finland have the lowest residence requirement of five years, in Iceland and Norway seven years is required, while Denmark requires nine years. In all five countries, however, shorter residence periods apply for spouses of citizens, Nordic citizens, former citizens, and stateless persons. Finland is the only Nordic country requiring a shorter residence period from applicants who meets the language skills requirement (four years uninterrupted or six years in total).

Norway is the only Nordic country that requires prospective citizens to renounce their original citizenship upon naturalization. As previously noted, the requirement is not absolute as several circumstances allow for retention of former citizenships. Thus, dual citizenship is to some degree permitted, and it is likely that it will be fully accepted by the current government in power (comprising the Conservative Party [Høyre], the Progress Party [Fremskrittspartiet], and the Liberal Party [Venstre]).

Sweden is the only country where language skills are not a naturalization requirement. In Norway, Denmark and Iceland, as a main rule, applicants have to pass an official language test to acquire citizenship, while in Finland a broad range of options exist as to fulfilling the requirement. The level of language skills required and the possibilities of being granted exemptions from the requirement are also important factors. The Danish language requirement (comparable to the CEFR level B2) is at the highest level in Europe (Ersbøll 2015a: 38). At the same time, the possibilities of being granted dispensation from the language requirement are slim. The Finnish language requirement was made more stringent when the new Act of 2003 was adopted and corresponds to CEFR level B1, a level below the Danish requirement (Fagerlund \& Brander 2013: 23). More important than the main rule, perhaps, is the wide range of exceptions to the language skills requirement laid down in the law. In Norway, 
documented language training and passing tests in Norwegian and social science is required. The required level in the Norwegian test is CEFR level A2, thus lower than in Denmark and Finland. However, similar to Denmark, possibilities for dispensation are limited. Iceland has the lowest required level of language skills in the citizenship test (CEFR level $\mathrm{A} 1$ ) and also grants exemptions on various grounds, making it a quite lenient requirement compared to the requirements in Denmark, Finland, and Norway.

As to requirements of self-support and lack of debt to the state, Denmark and Iceland follow the most restrictive practices. In both countries there is a requirement of financial self-sufficiency, but the level of sufficiency differs. In Denmark, financial selfsupport is required within four and a half of the previous five years, while in Iceland selfsupport is required within the previous three years. Failure to meet financial obligations under public law disqualifies applicants - without exceptions - from obtaining Finnish citizenship, and in Sweden unpaid taxes or fines (as part of the conduct requirement) may cause an application to be rejected (Bernitz 2012: 13; Fagerlund \& Brander 2013: 26). No such requirements exist in the Norwegian Nationality Act, making Norway the most liberal in this regard. Indirectly, however, self-support is a requirement to acquire Norwegian citizenship, as self-support recently has been made a condition to grant a permanent residence permit (which again is a naturalization requirement).

The strictness of the conduct requirement also varies between the countries. Denmark is the only Nordic country where certain criminal sanctions may exclude foreigners from acquiring citizenship on a permanent basis. Additionally, the maximum waiting time is quite high compared to the other countries (30 years), only surpassed by Norway (34.5 years). In Iceland, the maximum waiting time for a criminal sanction is 14 years, twice as high as the numbers in Finland and Sweden.

It is interesting that Finland and Iceland do not organize citizenship ceremonies nor require any form of oath of allegiance upon naturalization. The Scandinavian countries, on the other hand, adopted such symbolic requirements after the turn of the millennium, albeit in different ways and constellations. Participation in the Danish citizenship ceremony is voluntary, but signing an oath of allegiance is a mandatory part of the naturalization process. In Norway, participation in the ceremony is voluntary, and an oath of allegiance is a mandatory part of the ceremony. Sweden is the least demanding in this regard, wherein participation in the ceremony is voluntary and no oath of allegiance is required.

Overall, Denmark has the highest barriers to naturalization among the Nordic countries. The Danish requirements of residence, language skills, citizenship tests, selfsupport and conduct are considerably higher than those of its Nordic counterparts. On the other end of the scale, we find Sweden, where access to citizenship is quite lenient. Norway, Finland, and Iceland find themselves in the middle of the restrictive-liberal axis. However, a strict enforcement of the identity documentation requirement and the persisting ban on dual citizenship in Norway may be significant hurdles for applicants for Norwegian citizenship. In the next section, we look at the lenience and strictness in another area of the legislation: loss of citizenship. 


\subsection{Loss of citizenship}

Historically, the provisions of loss of citizenship in the Nordic countries have been very similar. Since the beginning of the new millennium, however, marked legal differences have emerged (Ersbøll 2015b: 185). The most significant change - by far - is the acceptance of dual citizenship. Sweden led the way by accepting dual citizenship in 2001. Two years later, Finland and Iceland followed suit, while Denmark accepted dual citizenship in 2015. As a consequence, the acquisition of citizenship in another country no longer results in loss of Swedish, Finnish, Icelandic, or Danish citizenship. Norway is now the only Nordic country that provides for loss of citizenship due to the acquisition of a foreign citizenship and the only country that revokes Norwegian citizenship if the foreign citizenship has not been renounced upon granting Norwegian citizenship.

While older loss provisions have been deleted, new modes have also been introduced. Rules on the revocation of citizenship due to fraudulent conduct was adopted in Denmark (2002), Finland (2003) and Norway (2006), while Iceland and Sweden do not provide for loss under such circumstances. In 2004, Denmark also introduced a provision providing for loss of Danish citizenship in cases of serious prejudicial behavior. ${ }^{22}$ As of today, only two provisions are common Nordic property: voluntary renunciation of citizenship (release) and automatic loss at age 22 due to birth and continuous residence abroad (Ersbøll 2015b). In the following, we will describe both old and new provisions pertaining to loss of citizenship in the Nordic countries and conclude with a cross-country comparison.

\subsubsection{Sweden}

After Sweden fully accepted dual citizenship in 2001, only two modes of loss remain in the Citizenship Act: voluntary renunciation of citizenship (Article 15) and automatic loss due to birth and residence abroad (Section 14). If a person for any reason wants to release him or herself from Swedish citizenship, release is conditional on the acquisition of citizenship in another country within a certain time period unless he or she has already acquired another citizenship (Section 15).

A person may lose his or her citizenship when he or she reaches 22years of age if the person is born abroad, never has resided in Sweden, and has not been in Sweden under any circumstances that indicate ties with the country (Section 14). However, a person may apply for permission to retain Swedish citizenship before he or she reaches the age of 22. The Swedish Migration Agency deals with these applications, and may turn them down if the link between the person and Sweden is deemed insufficient (Bernitz 2012: 15-16). Loss of citizenship according to this provision may also include the child of the relevant person, if the child acquired citizenship through this parent. In cases where the other parent is also a Swedish citizen and the children derived

\footnotetext{
${ }^{22}$ Norway is currently considering to adopt a similar provision in its Nationality Act, and recently, the Moderate Party in Sweden argued that Sweden ought to do the same.
} 
citizenship from this parent, the child does not lose citizenship. This provision does not apply if it makes the person stateless.

Automatic loss of citizenship due to birth and residence abroad is the only way Swedish citizenship can be lost involuntarily (Bernitz 2012). In fact, according to the Instrument of Government (Chapter 2, Article 7[2]) - one of four fundamental laws making up the constitution in Sweden - no citizen, whether currently or previously domiciled in the realm may be deprived of his or her citizenship (Bernitz 2012: 6-7).

\subsubsection{Norway}

The Norwegian Nationality Act contains five provisions for loss of citizenship: loss due to a change in the basis for citizenship acquisition by birth or adoption (Section 6), loss due to the acquisition of another citizenship (Section 23), loss due to long-term absence from the realm (Section 24), voluntary renunciation of citizenship (Section 25), and revocation of citizenship (Section 26). ${ }^{23}$

As mentioned previously (see section 4.2 on acquisition by birth in Norway), in the event of a decision or admission that the circumstances that formed the basis for acquisition of citizenship pursuant to Sections 4 and 5 (acquisition by birth and adoption) do not subsist, the child shall be regarded as never having been Norwegian (so-called "quasi-loss"). This shall not apply, however, if the child thereby becomes stateless or if the person concerned has reached the age of 18 (Section 6).

A logical consequence of the single citizenship policy, a person who acquires another citizenship by application or explicit consent loses his or her Norwegian citizenship (Section 23). This provision also applies to children under the age of 18 who automatically acquires another citizenship when one of their parents who shares parental responsibility acquires another citizenship.

Moreover, a person who acquired Norwegian citizenship at birth but who has not been a resident in Norway for more than two years or seven years in total in Norway and other Nordic countries in total loses his or her Norwegian citizenship at age 22 (Section 24). However, a person may be entitled to retain his or her Norwegian citizenship if he or she lodges an application before reaching the age of 22 and where he or she demonstrates the existence of a sufficient connection to Norway. If a person loses Norwegian citizenship under this provision, the children of the person concerned also lose Norwegian citizenship, unless the other parent is a Norwegian citizen or if the child meets the requirements for retaining citizenship. Loss under this provision may, however, not be applied if it leads to statelessness. Applications for retention lodged after the deadline (the person reaching the age of 22) may be processed if the person is not to blame for the delay.

Loss of Norwegian citizenship may also occur in cases where a Norwegian citizen who is resident outside Norway, applies for release from Norwegian citizenship on the

\footnotetext{
23 The current Norwegian government has proposed to introduce legal provisions providing for loss of citizenship concerning persons who have been convicted of serious criminal acts and criminal acts that defy fundamental national interests (see Prop. $146 \mathrm{~L}$ (2016-2017)). The proposal is to be processed by the Norwegian Parliament (Stortinget) 15 March 2018.
} 
condition that the person has been granted another citizenship (Section 25). The applicant may be released from Norwegian citizenship if he or she is a resident outside Norway and this is necessary for acquiring another citizenship. In these cases, a time limit of one year for when another citizenship must be acquired is set. If the time limit expires, and the applicant has not been granted another citizenship, he or she is still regarded as a Norwegian citizen (Brochmann 2013: 11-12). If a person is a resident in Norway and has another citizenship, applications for release shall only be granted in cases where it is deemed unreasonable to deny release. Irrespective of place of residence, a person cannot be released from Norwegian citizenship if the person becomes stateless as a consequence of release.

Rules pertaining to revocation of citizenship were made more restrictive when the Norwegian Nationality Act was reformed in 2005. A wish to consolidate the single citizenship policy made Norway introduce a provision regarding revocation due to nonrenunciation of another citizenship (Brochmann 2013: 12). Thus, Section 26 (subsection 1) states that Norwegian citizenship shall be revoked if the requirement of release from another citizenship upon the acquisition of Norwegian citizenship has not been fulfilled. However, as described above, there are exceptions to this rule (see Section 4.3 about naturalization requirements in Norway). The second subsection regards revocation of Norwegian citizenship due to fraudulent acquisition. This provision states that revocation based on incorrect or incomplete information may only be executed if the applicant has furnished incorrect information against his or her better judgment or has suppressed information that was relevant for the decision. ${ }^{24}$ Similar to the Danish loss provision on fraud, and dissimilar to the Finnish provision, there is no limitation period as to when Norwegian citizenship can be revoked.

If the target person has children that acquired citizenship along with him or her, their citizenships may also be revoked together with him or her, but such revocation must be based on an individual assessment (Ersbøll 2015b: 201).

\subsubsection{Denmark}

Loss of Danish citizenship can occur in four different circumstances: voluntary renunciation of Danish citizenship (Section 9), automatic loss at age 22 due to birth and residence abroad (Section 8 ), revocation of citizenship due to fraudulent acquisition (Section 8A) and revocation due to serious prejudicial behavior (Section 8B)

A person can be released from Danish citizenship when he or she wants to become a foreign citizen. Release is conditional on the acquisition of another citizenship within a certain period of time. If that person is a foreign resident, he or she cannot be denied release (Section 9).

Any person abroad who has never lived or stayed in Denmark under circumstances indicating any association with Denmark will automatically lose his or her Danish

\footnotetext{
24 Actually, revocation on this ground has been possible for a longer time been possible in Norway, although not based on the Norwegian Nationality Act but on section 35 of the Public Administration Act and general principles of Administrative Law (Brochmann 2013: 12).
} 
citizenship at age of 22 unless this will make the person stateless (Section 8). A child who derived Danish citizenship from a parent who loses citizenship according to this provision also loses his or her Danish citizenship unless the child will become stateless. A sufficient association is, for instance, indicated by stays in Denmark for a longer duration (e.g., for educational purposes), serving in the Danish military, or longer recurrent vacations in Denmark (Ersbøll 2015a: 35). In cases where such associations are non-existent, it is possible to lodge an application for retention before turning 22 of age. The application must be filed to the Ministry of Justice, and its approval is conditional on language skills, attachment to Denmark through holidays, and contact with Danish relatives or Danish societies abroad. Applications lodged too late are not considered, and Danish authorities are not obliged to notify persons of loss of citizenship on this ground (Ersbøll 2015a: 35).

Denmark was the first Nordic country, in 2002, to introduce a provision of loss of citizenship due to fraud (Ersbøll 2015b). According to Section 8A of the Danish Nationality Act, loss of Danish citizenship may occur if a person has acquired Danish citizenship by fraudulent conduct, that is, by intentionally providing incorrect or misleading information or withholding information - even if the decision makes the person stateless.

Denmark was also the first Nordic country, in 2004, to adopt a provision regarding deprivation due to seriously prejudicial behavior against the interest of the state (Ersbøll 2015b). A person who is convicted of a violation of part 12 or 13 of the Criminal Code may be deprived of his or her Danish citizenship - unless the person becomes stateless as a result (Section 8B). Deprivation of Danish citizenship, both in cases of fraud and serious prejudicial behavior, is resolved by court order, and proceedings must follow the rules of administrative justice (Ersbøll 2015a: 36).

In addition, a person may lose Danish citizenship due to loss of a family relationship or as a consequence of administrative error (so-called "quasi-loss"). Breached paternity assumptions, invalid adoption orders, or the discovery of a foundling being born to nonDanish parents are instances of loss of family relationship. An instance of an administrative error may be wrongfully registering a person in the Civil Registry as a Danish citizen (Ersbøll 2015a: 36).

\subsubsection{Iceland}

In Iceland, there are only two grounds for loss of citizenship: voluntary renunciation (release) and automatic loss due to birth and residence abroad. The Icelandic Nationality Act states that an Icelandic citizen who was born abroad and has never been domiciled in Iceland, or resided in Iceland for any purpose that may be interpreted as indicating that he or she wishes to be an Icelandic citizen, shall lose Icelandic citizenship upon reaching the age of 22 years (Article 12). The Minister of Interior may permit the citizen to retain his Icelandic citizenship if he or she applies before that time. If a person loses Icelandic citizenship under this provision, the children of this person also lose Icelandic citizenship (if they acquired citizenship on the basis of this parent). 
A precondition for this mode of loss is that it does not result in statelessness (pertaining to both the target person and the children).

As to renunciation of Icelandic citizenship, a person who resides abroad may be released from Icelandic citizenship if he or she wishes to become or has become a foreign citizen (Article 13). If the person has not already become a foreign citizen, he or she must demonstrate that he or she will become so within a certain period of time. A person who resides in Iceland may not be released unless the Ministry deems there are special reasons for this.

\subsubsection{Finland}

The Finnish Nationality Act provides for three modes of loss of citizenship: loss due to fraudulent acquisition (Section 33), automatic loss at age 22 due to insufficient connection to Finland (Section 34), and voluntary renunciation of citizenship (Section 35).

A person who has provided false or misleading information upon declaration or application for citizenship, which was decisive for granting it, shall lose Finnish citizenship (Section 33). There is a limitation period of five years after the acquisition of citizenship, which means that thereafter deprivation may not occur. If a child has acquired Finnish citizenship together with the person who has acquired citizenship by fraud, or if the citizenship of the person has been a requirement for the child to acquire Finnish citizenship, a decision on loss of citizenship may also be made with regard to the child. A child cannot, however, lose Finnish citizenship if the child's other parent is a Finnish citizen. A decision regarding loss of Finnish citizenship on the basis of false information is based on an overall consideration of the person's situation and that of the child.

A Finnish citizen who also holds a foreign citizenship loses his or her Finnish citizenship automatically if he or she does not have a sufficient connection with Finland (Section 34). However, a sufficient connection is deemed to exist in several cases, thus the possibilities for retaining citizenship are quite lenient (Ersbøll 2015b). Birth in Finland and having one's municipality of residence in Finland at the age of 22 are considered sufficient. A person whose municipality of residence has been in Finland or who has been a permanent resident and domiciled in Iceland, Norway, Sweden, or Denmark for at least seven years may also retain his or her Finnish citizenship. A sufficient connection to Finland is also deemed to exist if the person has, between the ages of 18 and 22, given written notice to a Finnish diplomatic mission or consulate expressing his or her wish to retain citizenship, or if the person has been issued a Finnish passport or completed military or civil service in Finland.

Voluntary renunciation of Finnish citizenship is possible upon application if the relevant person is a foreign citizen or is in the process of acquiring a foreign citizenship (Section 35). The reason why the person wants to be released from Finnish citizenship shall be stated in the application. Applications for release will not be granted if the person is domiciled in Finland or the purpose of release is to avoid military service. A decision of release may not be made if it leads to statelessness, but if the acquisition of 
another citizenship is conditional on the renunciation of Finnish citizenship, he or she may be released - even if this makes the person involved stateless for a short period of time (Fagerlund \& Brander 2013: 31).

The Act also provides for instances of a "quasi-loss" of citizenship. A person may lose Finnish citizenship if citizenship was granted on the basis of the father's citizenship and paternity is annulled (Section 32). Loss due to breached paternity assumptions may not occur after the child has reached the age of five years. This mode of loss is, however, not automatic, but based on an overall consideration of the child's situation, with particular weight on the child's age and ties to Finland.

\subsection{Loss of citizenship: A cross-country comparison}

As the previous sections have illustrated, the Nordic countries have different provisions on loss of citizenship, which are compared in Table 2. Two provisions are common property among the Nordic states: renunciation and loss of citizenship due to birth and continuous residence abroad. In all five countries, citizens who live abroad and wish to acquire a foreign citizenship have a right to be released from their citizenship. Release will be granted as long as the person has or will acquire a foreign citizenship within a certain period of time. For citizens residing on state territory, however, grant of release is dependent upon the discretion of the authorities. In Denmark, Finland, Iceland and Norway release may be granted if a legitimate interest is established. In Sweden, release is offered on easier terms (Ersbøll 2015b: 209).

Table 2: Provisions on loss of citizenship in the Nordic countries

\begin{tabular}{llllll} 
Provision & Sweden & Norway & Denmark & Finland & Iceland \\
Voluntary renunciation & Yes & Yes & Yes & Yes & Yes \\
Loss due to birth and residence abroad & Yes & Yes & Yes & Yes & Yes \\
Loss due to single citizenship policy & No & Yes & No & No & No \\
Fraud & No & Yes & Yes & Yes & No \\
Serious prejudicial behavior & No & No & Yes & No & No \\
\hline
\end{tabular}

As to the provision of loss at age 22 due to birth and residence abroad, there are both common features and differences between the countries. Common features are the target persons in question (Nordic citizens born abroad and who have never resided in the state of their citizenship under circumstances that indicate ties to that country); that loss occurs automatically at age 22; that loss may extend to the target person's children as well; and that loss under this provision, however, cannot lead to statelessness. Another common feature is that persons subject to this provision can submit an application for retention before reaching the age of 22, if they can document having sufficient ties to the country (Ersbøll 2015b: 209-10).

Notable differences relate to formulation, circumstances that prevent loss, actions that can prevent loss, information obligations, procedures of dealing with applications 
for retention submitted too late and reacquisition possibilities (Ersbøll 2015b: 210). Denmark, following the most restrictive practice, sets relatively high criteria as to what qualifies as sufficient ties, and relatedly, high criteria for granting applications for retention of citizenship. Danish authorities are not obliged to inform persons that may lose citizenship according to this provision, they do not process applications handed in too late, and no entitlement to reacquisition exists.

In Finland, the provision is labeled "Retaining citizenship at the age of 22" (emphasis added) and applies to a wider category of persons than those born and raised abroad (Ersbøll 2015b: 2010). Association to Finland, thus possibilities to retain citizenship, can be proved in a number of ways (stipulated by Section 34), and Finnish authorities are obliged to inform persons who may lose their citizenship on how they can retain it. Persons who have lost Finnish citizenship under this provision (and other provisions) are allowed to reacquire it by making a declaration to Finnish authorities. In Norway, a stay of six months in the country can prevent automatic loss, and holding a valid passport at age 22 may qualify as having a sufficient tie to the country. Further, Norwegian authorities, in some cases, process applications for retention lodged too late. In Sweden, stays in Sweden and knowledge of the Swedish language are circumstances that indicate associations to the country, thus preventing loss. Use of a Swedish passport or being registered with the tax authorities are also grounds for circumventing loss. Applications from first-generation individuals born abroad are usually granted and in some cases also applications from subsequent generations. ${ }^{25}$

As Denmark, Finland, Iceland and Sweden have fully accepted dual citizenship, and consequently abolished previous provisions of loss due to acquisition a foreign citizenship, Norway is now the only country providing for loss in these situations. The persisting ban on dual citizenship also has consequences for persons who wish to acquire Norwegian citizenship; regarding persons who have not released themselves from their former citizenship (within a certain time limit), Norwegian authorities may revoke the person's Norwegian citizenship.

Another significant difference between the countries is whether or not deprivation (revocation) is possible. Denmark, Finland, and Norway have adopted a provision in their respective Nationality Acts providing for loss due to fraudulent acquisition in the 21st century. Nevertheless, two important differences must be noted concerning this provision. First, in Finland, a limitation period of five years applies to revocation decisions due to fraud; in Norway and Denmark, no such limitation period exist - a revocation decision can take effect regardless of how many years have passed since citizenship acquisition. Second, a Finnish child may also lose his or her citizenship due to loss of citizenship by the parent. This possibility also exists in Norway, but is precluded in Denmark (Ersbøll 2015b: 200-201). As to loss due to serious prejudicial behavior, Denmark is thus far the only Nordic country who has implemented such a provision, but the Norwegian government has proposed to introduce a similar provision (see Prop. 146 L (2016-2017)).

25 Iceland has not amended its provision, and no available information exists as to the interpretation and practice of this mode of loss. 
Summing up, two provisions are still common to all Nordic countries: voluntary renunciation of a foreign citizenship and automatic loss due to birth and residence abroad. The practice of the latter rule, however, varies. Denmark follows the most restrictive practice, Sweden and Finland the most liberal, while Norway and Iceland are positioned between these two poles. A more striking and fundamental difference between the countries, however, is whether deprivation is possible (Denmark, Finland and Norway) or not (Sweden and Iceland). Denmark, Finland and Norway all allow for loss due to fraud. Here, Norway employs the strictest practice, with no limitation period while also allowing for children to lose their Norwegian citizenship based on the revocation of the parent's citizenship.

\subsection{Extraterritorial citizenship}

The development of citizenship law in the Nordic countries also has implications for citizens who are living abroad, for both shorter and longer periods of time. Citizenship is closely associated with residency; therefore, "non-resident citizens" is a common way of labeling citizens abroad, underscoring that the normal condition for citizens is to be residents of the nation state of their citizenship (Caramani \& Grotz 2015; Erdal 2016; Raj 2015). Meanwhile, extraterritorial citizenship also requires regulation and often alternative bureaucratic procedures.

The circumstances of non-resident citizens, as regards their citizenship, are interesting and important in the context of a review of developments in Nordic citizenship law for three reasons. The first is because the number of emigrants from the Nordic countries is not insignificant, and the bureaucracies of the Nordic countries are increasingly dealing with citizens living abroad, as part of their regular work (Gustafson 2008; Haug, Dann \& Mehmetoglu 2007). Because much of the existing legislation assumes residence as a starting point, new procedures and solutions are necessary when citizens are not residents. Second, a proportion of citizens live for periods, or even most of their lives in another country, a trend likely to increase with dual citizenship, which is relatively recent across the Nordic region (except in Norway, which does not permit dual citizenship as of February 2018) (Talleraas 2018). Third, the ways in which extraterritorial citizenship is regulated, in law as well as through the practical implementation of administrative procedures, provide an interesting window into questions that are of principled importance, not least: who has the right to citizenship, and on what basis? (Gamlen 2008; Smith 2003). Such questions are more frequently raised in connection with immigration and naturalization but arguably have important parallels in the context of emigration.

Statistics on the numbers of extraterritorial citizens in the Nordic countries are not easily available. Estimates are often calculated based on the numbers indicated by embassies and consulates abroad. Data on annual emigration rates are largely available, such as for Finland, yet aggregate numbers of the stock of non-resident citizens are not. In Norway, government sources confirm that they do not have exact records of the numbers of non-resident Norwegian citizens. This is partly due to the fact 
that Norwegian citizens do not de-register from the population register when moving abroad. The population registers in different Nordic countries have different types of bureaucratic procedures in connection with extraterritorial citizens, which for instance become important in relation to voting in national elections.

This section provides a country-by-country review for the five Nordic countries of existing regulations regarding citizenship acquisition in the context of citizens abroad: extraterritorial citizenship. We conclude with some reflections on the implications of the case of extraterritorial citizenship for a broader discussion on the development of citizenship law in the Nordic countries.

\subsubsection{Sweden}

For extraterritorial citizens, the question of passing citizenship on to children born abroad is often pressing. Citizens of Sweden can pass on their citizenship to any children born whilst living abroad, based on the ius sanguinis principle, which Swedish citizenship law has traditionally built on. In practical terms, children's names need to be formally registered and a "coordination" number obtained from Swedish tax authorities, which adds the child to the Swedish population register, before a citizenship application can be filed. All of this can be organized through an embassy (or consulate).

Swedes born abroad, who have not lived in Sweden, must apply to retain their Swedish citizenship, at some point between the ages of 18-22. Here, the connection with Sweden is scrutinized. Sweden has allowed dual citizenship since 2001. Special rules apply (since 2015) for those who renounced their citizenship or those who lost it, getting another citizenship before Sweden allowed dual citizenship in 2001, which enable them to apply to regain their Swedish citizenship.

\subsubsection{Norway}

A child born to a Norwegian citizen abroad becomes a Norwegian citizen automatically. But in order to apply for a Norwegian passport, a Norwegian personal identification number has to be obtained. The application for a Norwegian personal identification number can be submitted jointly with the application for a Norwegian passport.

Children born abroad, who have not lived in Norway for at least two years (or in another Nordic country for seven years) before they are 22 years old have to apply to retain their Norwegian citizenship before they are 22 years old. Documentation of having stayed in Norway for more than six months (during the life-course) is required. 


\subsubsection{Denmark}

Danish citizens living abroad may pass on citizenship to children who are born abroad, and this happens automatically as long as one of the parents is a Danish citizen. Until 2014, the father could only pass on Danish citizenship if the child was born to a married couple. Children born abroad do not need a Danish personal identification number in order to obtain a Danish passport.

Danish nationals born abroad may lose their Danish citizenship at the age of 22, if they do not apply to retain it between the ages of 21-22 years. In order to be eligible to retain Danish citizenship, applicants must either be a resident in Denmark when applying and document a stay of a minimum of three months (seven years of aggregate residence in Norway, Sweden, Finland or Iceland is equated with residence in Denmark), or have spent at least one year in Denmark before the age of 22 (or a total of seven years in another Nordic country) under circumstances indicating some association with the country and be able to document a working knowledge of Danish, or that losing Danish citizenship would make the applicant stateless.

Danes who previously renounced or lost their Danish citizenship as a result of gaining another citizenship may, due to the change in legislation now permitting dual citizenship for Danes, apply to regain their Danish citizenship in the period 1 September 2015 to 31 August 2020.

\subsubsection{Iceland}

Icelandic citizens residing abroad can have their children registered in the National Registry of Iceland at birth. If there is doubt as to whether a parent is an Icelandic citizen, documents to confirm the citizenship of the parent are requested. If a married man who is an Icelandic citizen has a child abroad with a foreign national, an application for the child's registration is directed to the National Registry of Iceland. If an unmarried man who is an Icelandic citizen has a child abroad with a foreign national, an application for the child's registration has to be directed to the Directorate of Immigration.

\subsubsection{Finland}

A child born abroad acquires Finnish citizenship automatically if the mother is a Finnish citizen. Also, if the child's father is a Finnish citizen and the parents are married the child acquires citizenship. If the parents are not married, the father must provide a declaration. When the child is born abroad the birth must be registered in The Finnish Population Register Center.

Finns born and living abroad may have to forfeit their citizenship at the age of 22 if certain criteria are not met whilst they are between the ages of 18-21:

1. if they were born in Finland and are domiciled in Finland when turning 22;

2. if they have lived in Finland, or another Nordic country (Iceland, Norway, Sweden or Denmark) for a total of seven years before reaching the age of 22; 
3. if they were issued a Finnish passport between the ages of 18-21;

4. if they between the ages of 18-21 have stated in writing to a Finnish diplomatic mission abroad or to a Finnish local registry office that they wish to retain Finnish citizenship; or

5. if they have done military or non-military service between the ages of 18-21.

Former Finnish citizens can re-apply for citizenship by declaration (as of the 2011 legislation, though dual citizenship was introduced in 2003). The citizenship will be granted regardless of whether the former Finnish citizen's domicile is in Finland or abroad. A person with dual citizenship, who is a resident outside Finland, may apply for an exemption from Finnish military service either if having lived abroad for more than seven years, having completed another country's military service or proving no ties to Finland.

\subsubsection{Citizenship law for non-resident citizens?}

One often thinks of citizens as someone who resides within the territorial bounds of the nation state, but states have and do relate to non-resident citizens, too. Non-resident citizens have, clearly, both rights and duties but there are also some specificities that are a result of living abroad, which necessitate alternative administrative procedures on the part of the state. The rights of non-resident citizens, as citizens, relate mainly to the citizenship itself, being able to pass it on, being able to renew their passports, and being able to vote (though temporal restrictions might apply). However, there are also duties associated with being a citizen, and what becomes evident in the context of nonresident citizens is especially the duty to report where you live, and to relate to the regulations applying as regards health and social security and the payment of taxes. The different Nordic countries are well-known for their sophisticated population registers, and the states also strongly encourage citizens living abroad to keep the formal records in their countries of citizenship up to date.

The Nordic countries have a relatively similar approach to non-resident citizens, where differences are mostly at the level of administrative procedures, such as for the registration of children born abroad in relation to application for citizenship. Other differences pertain to Denmark having the strictest rules for being able to retain citizenship if born abroad, and not living in Denmark; whereas Norway (still) does not permit dual citizenship, which diverges from the other Nordic countries and has particular implications for extraterritorial citizens.

The consular services provided to Nordic non-resident citizens are largely comparable. It seems the trend in rising demands for consular services, not just for visitors but also of citizens living long-term abroad, cuts across the experiences of the five Nordic countries. 


\section{Statistics: Acquisition and loss of citizenship}

Despite certain similarities, each Nordic country developed a quite distinct citizenship regime during the 2000s, as Chapters 3 and 4 illustrated. In this chapter, we turn our attention from legal to statistical developments in the Nordic countries and provide descriptive statistics on the acquisition of citizenship by declaration and application and on loss of citizenship in the Nordic countries.

As the chapter will demonstrate, the absolute numbers of citizenship acquisitions vary significantly between the five countries, with Sweden and Iceland representing two opposite poles (Sweden in the higher end of citizenship acquisitions, Iceland in the lower). ${ }^{26}$ The large differences in the number of citizenship acquisitions are mainly attributable to the fact that the size of the immigrant population is much larger in Sweden than in the other countries and much smaller in Iceland (cf. Ch. 1, Figure 1). High or low acquisition numbers can thus not be interpreted as direct effects of liberal or restrictive citizenship legislation. Concluding the chapter, we will therefore compare the countries by using a so-called naturalization rate. A naturalization rate is a commonly used indicator of the effect of national policies on citizenship acquisition. Since it is a relative number, taking into account the size of the foreign population, it enables cross-country comparison in a better way than by use of absolute numbers.

Statistics were provided by the responsible authorities for citizenship matters in each country: the Swedish Migration Agency, the Norwegian Directorate of Immigration, the Icelandic Ministry of Justice (and the Icelandic Directorate of Immigration), and the Finnish Immigration Service. For Denmark, we present statistics compiled by the Danish Institute for Human Rights (Institut for menneskerettigheder 2016). ${ }^{27}$ Citizenship statistics from the different countries vary in terms of the accuracy and scope of the data. For Sweden, we provide statistics from 2000 to 2017, for Norway from 2005 to 2017, for Denmark from 2001 to 2015 , for Iceland from 2000 to 2017 , and for Finland from 2009 to $2017 .{ }^{28}$ The Icelandic authorities have not consistently distinguished between different modes of acquisition of citizenship in their registration systems (e.g., between declaration and application), and for this reason, we present the Icelandic statistics on acquisition by declaration and application in the same section.

\footnotetext{
${ }^{26}$ At first glance, some of the figures on citizenship acquisition may look similar across countries. However, please be aware that we employ different scales for each country because the numbers vary to such a large extent.

27 Unfortunately, the Danish Ministry of Immigration and Integration was unable to provide statistics on acquisition and loss of Danish citizenship before the deadline of the report. Therefore, the statistics on acquisition and loss of Danish citizenship is limited. Data compiled by the Danish Institute for Human Rights (2016) includes the number of granted declarations (not rejected), number of granted and rejected applications, but contains no information on common grounds of rejection, applicant groups, and nor did we get access to statistics on revocation of Danish citizenship.

${ }^{28}$ It is worth noting that grounds of rejection were unregistered for some years in all countries, therefore these years are omitted.
} 


\subsection{Acquisition of citizenship by declaration}

\subsubsection{Sweden}

As described in Chapter 4, three categories of individuals can acquire Swedish citizenship through the procedure of declaration: children who have grown up in Sweden and fulfill the residence requirement, Nordic citizens, and former Swedish citizens. The county administrative boards (länstyrelsen) process declarations from Nordic citizens, while the Swedish Migration Agency handles declarations from nonNordic citizens. Between 2000 and 2017 (until September 3oth), the Swedish Migration Agency processed 77,603 declarations. A total of 61,314 (79\%) of these declarations for Swedish citizenship were granted, 11,942 (15\%) rejected and 4,347 declarations (6\%) dismissed or appealed. Annually, the granting percentage has varied between $66 \%$ (in 2000) and $87 \%$ (in 2002), averaging $80 \%$ a year in the period. Thus, in almost eight out of 10 cases each year, the decision was favorable for the declarant(s).

Figure 2: Decisions on declarations for Swedish citizenship, 2000-2017

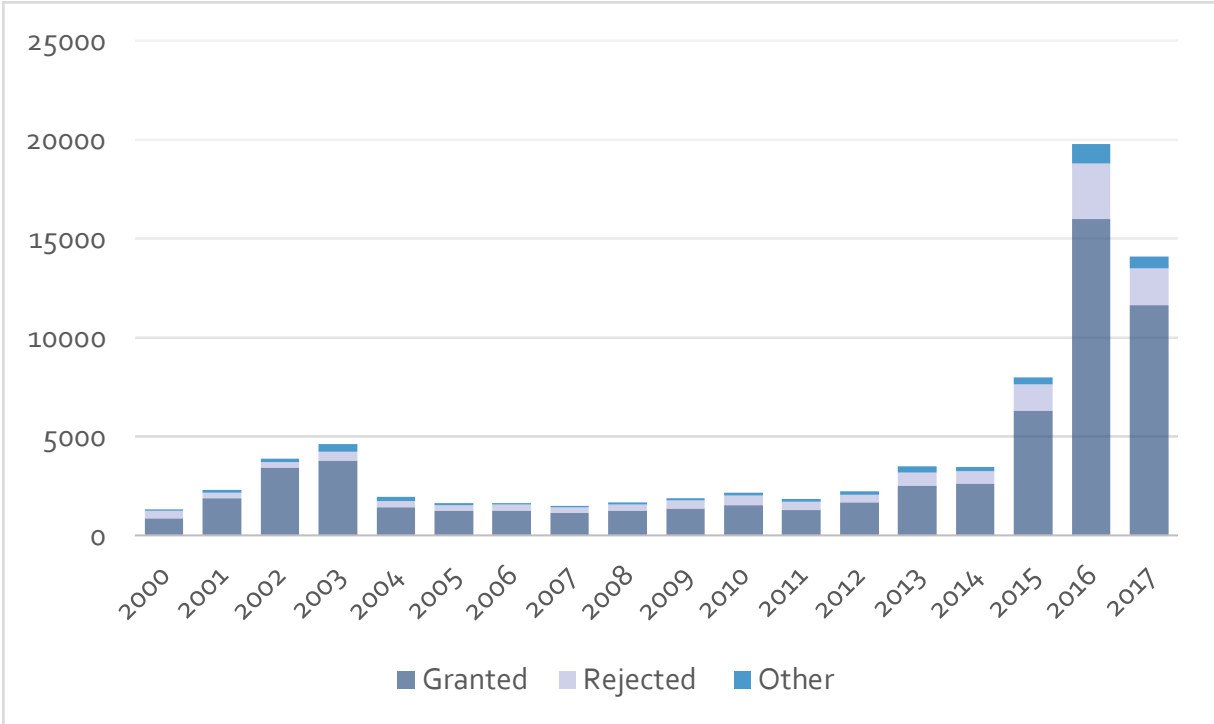

Source: The Swedish Migration Agency.

Figure 2 shows the annual number of decision on declarations for Swedish citizenship. The number of declarations granted increased from 2000 to 2003 (from 900 to 4,600 ). In the years 2004-2012, the annual number of granted declarations varied between 1,500 and 2,300. In 2013 and onward the numbers increased: it was 3,500 in 2014 and reached a high of almost 20,000 granted declarations in 2016. The number of rejected declarations has varied in accordance with the number of granted declarations, yet at a significantly lower level, ranging from only 300 to 2,800 rejected declarations per year.

Over $65 \%$ of all declarations in this period were made by citizens of Somalia (19\%), stateless persons (15\%), Syria (13\%), Afghanistan (6\%), USA (5\%), Iraq (3\%), Poland $(2 \%)$, and Thailand (2\%). The granting percentage was $80 \%$ or more for these groups, 
although with one notable exception - Iraqi citizens - with a granting percentage of $54 \%$ in the period.

The most common legal ground for rejections of all citizenship declarations (irrespective of former citizenship) has been non-fulfillment of the residence requirement, nearly comprising $70 \%$ of the total number of rejections in the period. The second most common ground for rejection registered is non-fulfillment of the permanent residence permit requirement (accounting for $3 \%$ of the total number of rejections). The remaining large proportion of rejected declarations (26\%) was either unregistered, dismissed, or expired.

\subsubsection{Norway}

The main groups eligible for the acquisition of Norwegian citizenship by declaration are Nordic citizens and former Norwegian citizens. The Norwegian Directorate of Immigration (UDI) is responsible for processing citizenship declarations, and has reliable data on these cases from 2005 to 2017 (as of November 10th). ${ }^{29}$ In this period, UDI processed a total of 4,880 declarations for Norwegian citizenship. Of these, 4,283 declarations ( $88 \%$ of all declarations) were granted, while 597 declarations (12\%) were rejected.

Figure 3 shows the annual numbers of granted and rejected declarations for Norwegian citizenship between 2005 and 2017. The annual number of granted declarations has varied between approximately 150 in 2005 and 440 in 2008. Throughout the entire period, the annual number of rejected declarations has not exceeded 100. In relative numbers, UDI granted at least $80 \%$ of the declarations made each year in the period, and in several years, the granting percentage was over $90 \%$.

Figure 3: Decisions on declarations for Norwegian citizenship, 2005-2017

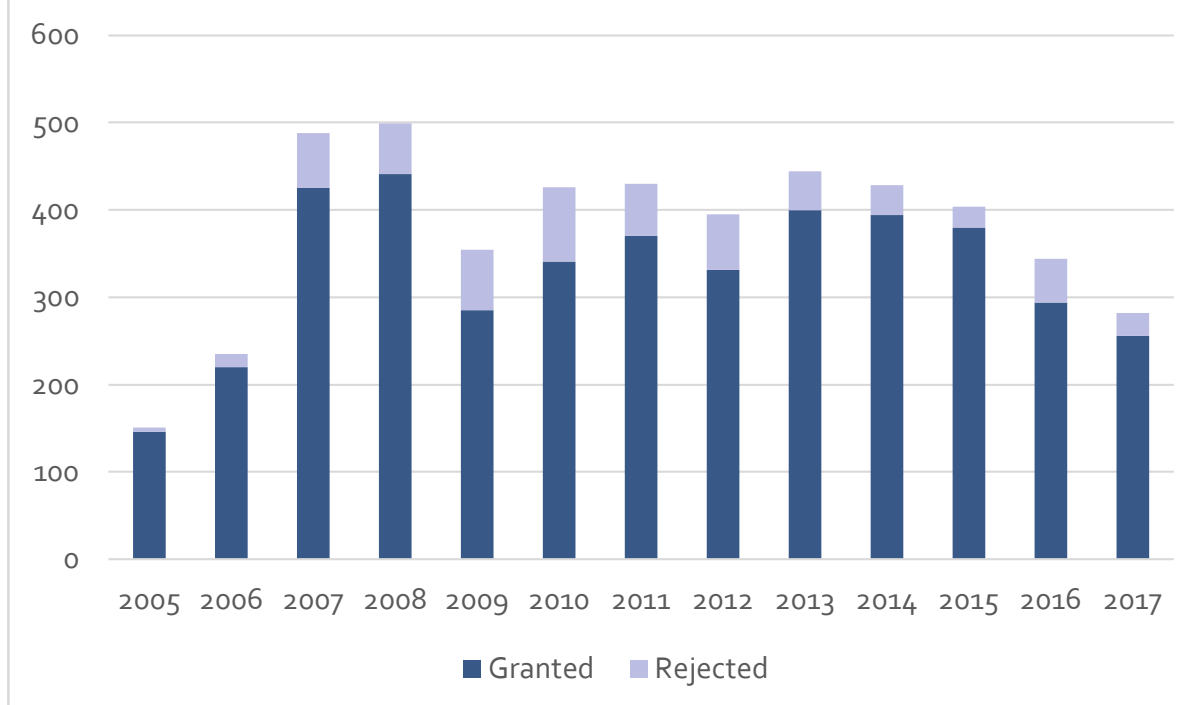

Source: The Norwegian Directorate of Immigration.

29 The Norwegian Directorate of Immigration did not prior to 2005 distinguish between applications and declarations. 
The most common ground for rejection of citizenship declarations, accounting for nearly 50\% of all rejections between 2007 and 2017, was non-compliance with the requirement of release from another citizenship. Failure to fulfill the residence requirement (seven years) was the second most common ground for rejection, comprising nearly one-third of all rejections. $10 \%$ of the rejections were based on noncompliance with the age requirement (18 years).

As mentioned, the procedure of acquiring citizenship by declaration is mainly reserved for Nordic citizens. Swedish citizens submitted most declarations in the period (37\% of all declarations), followed by Danish (22\%), Finnish (7\%) and Icelandic (5\%) citizens.

\subsubsection{Denmark}

The acquisition of Danish citizenship by declaration is a procedure available to Nordic citizens and former Danish citizens. Figure 4 shows the annual number of granted declarations for Danish citizenship in the years 2001-2015.

From 2001 to 2015, 62,595 Danish citizenships were granted via this procedure. The number of granted citizenships was particularly high in 2001. Since then, the annual number of granted citizenships has fluctuated between a low point of 1,800 (in 2013) and a high point of 6,300 (in 2015). The tripling from 2013 to 2015 is plausibly a result of Denmark accepting dual citizenship in 2015, procedure Danish emigrants have taken advantage of.

Figure 4: Granted declarations for Danish citizenship, 2001-2015

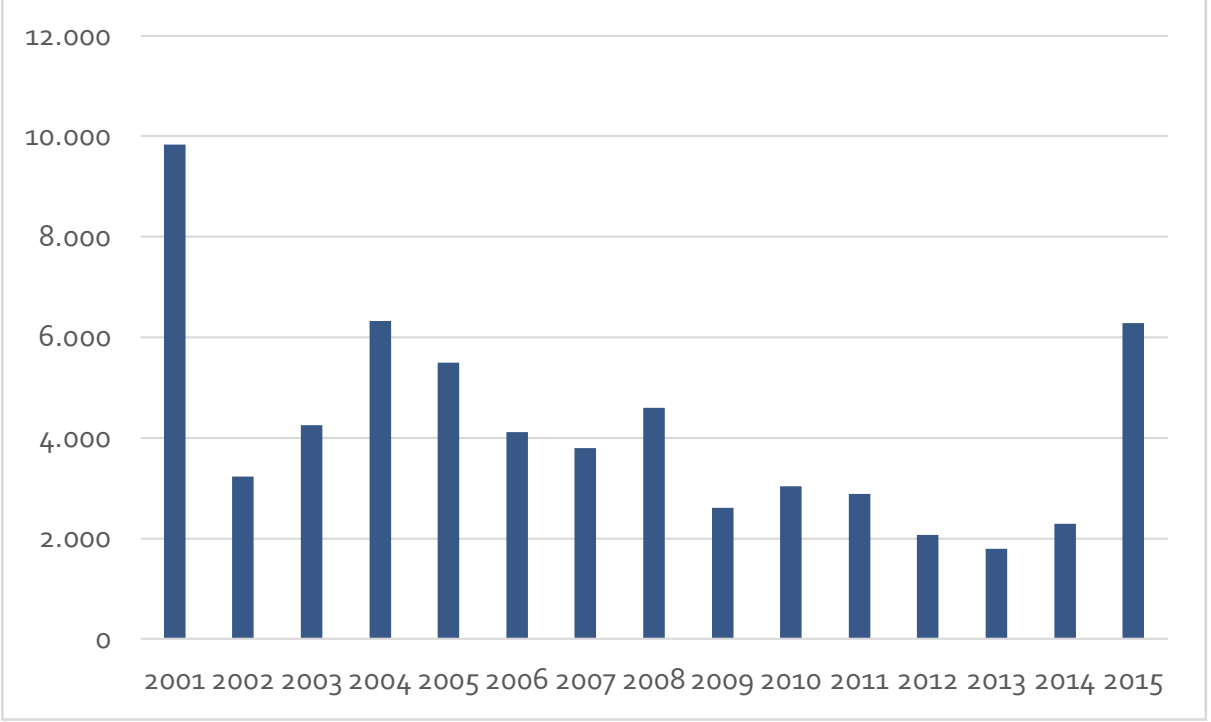

Note: Annual numbers of rejected declarations unavailable.

Source: Institut for menneskerettigheder (2016: 8, table 1.1). 


\subsubsection{Finland}

In Finland, acquiring citizenship by declaration is a procedure available to five groups: foreign citizens with a father who is a Finnish citizen, adopted children (between 12 and 17 years), young persons with long-term residence in Finland, former Finnish citizens and Nordic citizens. From 2009 to 2017, the Finnish Immigration Service made 15,689 decisions on declaration for Finnish citizenship. A total of 14,830 of these declarations were granted (95\%), and $2 \%$ of the declarations were rejected, while the remaining $3 \%$ of cases were either expired or withdrawn.

Figure 5 shows the annual number of decisions on declarations for Finnish citizenship. The most striking feature of the figure is the high number of granted declarations in 2009. As a result of former Finnish citizens (and their descendants) taking advantage of the provisional five-year declaration procedure to reacquire Finnish citizenship, available between 2003 and 2008, the numbers of submitted declarations increased considerably. The trend reached its top point between January and May 2008, when 9,000 declarations were submitted to the Finnish Immigration Service. This caused a congestion in the processing system, which accounts for the high number of granted citizenships in 2009. From 2011, the numbers decreased significantly. Between 2011 and 2017, the annual number of processed declarations has varied between 700 and 1,000.

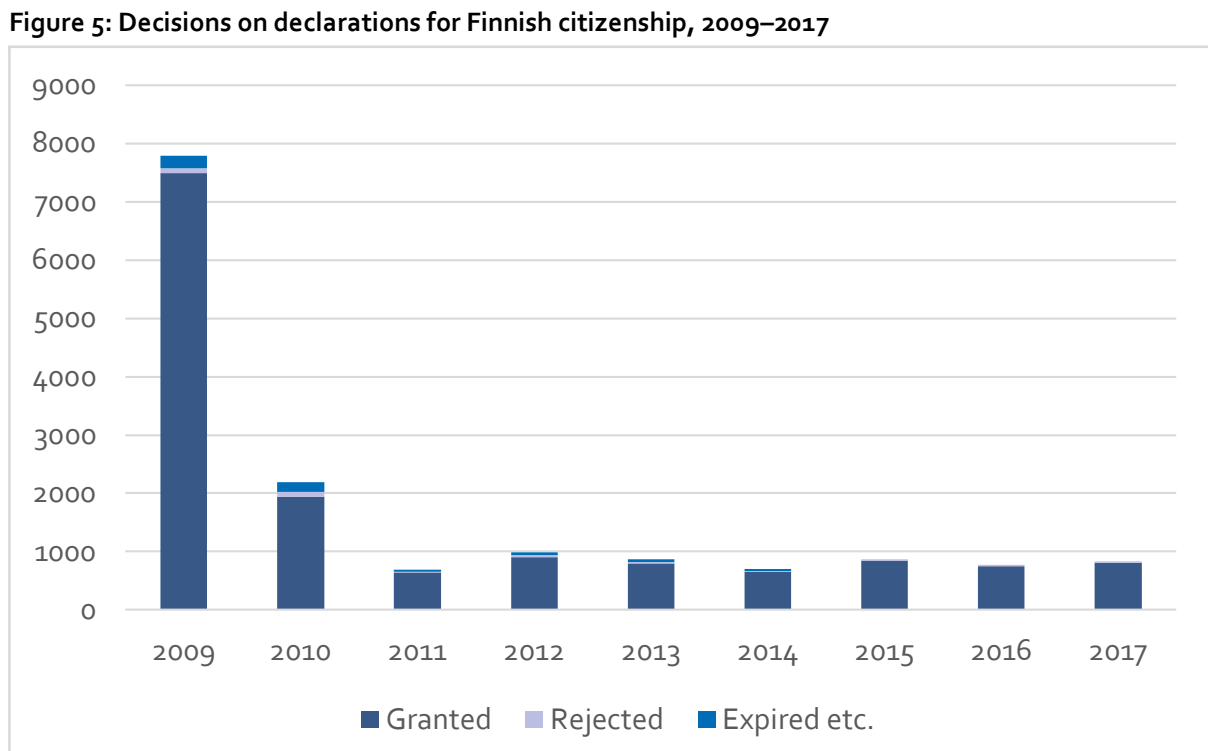

Source: The Finnish Immigration Service.

Former Finnish citizens and young persons with long-term residence in Finland are the largest groups taking advantage of the declaration procedure (in the years 2011-2014). Sorted by former citizenship, the largest applicant group between 2011 and 2017 - by far - were Swedish citizens ( $37 \%$ of all declarations). Then citizens of Russia (7\%), USA (5\%), Estonia (4\%) and Australia (4\%) follow. 


\subsection{Acquisition of citizenship by application}

\subsubsection{Sweden}

Foreigners who do not acquire citizenship automatically and are unable to acquire it through declaration can submit an application for citizenship to the Swedish Migration Agency. In the years 2000-2017, a total of 506,419 applications were processed by the Swedish Migration Agency. Of these, 433,936 applications (86\% of all applications) were granted, while 63,621 applications (13\%) were rejected. The remaining 8,862 applications ( $3 \%$ of all applications) were registered as "other" and dismissed cases (i.e., cases not resulting in a judgment).

Figure 6 shows the annual number of decisions on applications for Swedish citizenship. The number of granted applications has ranged from a low of 15,000 in 2004 to a high of 31,000 in 2006 . The proportion of granted applications has remained stable, ranging from 80 to $90 \%$, in the entire period. The number of rejected applications for citizenship has varied between 1,900 ( $9 \%$ of all applications) and 4,900 (18\%).

Figure 6: Decisions on applications for Swedish citizenship, 2000-2017

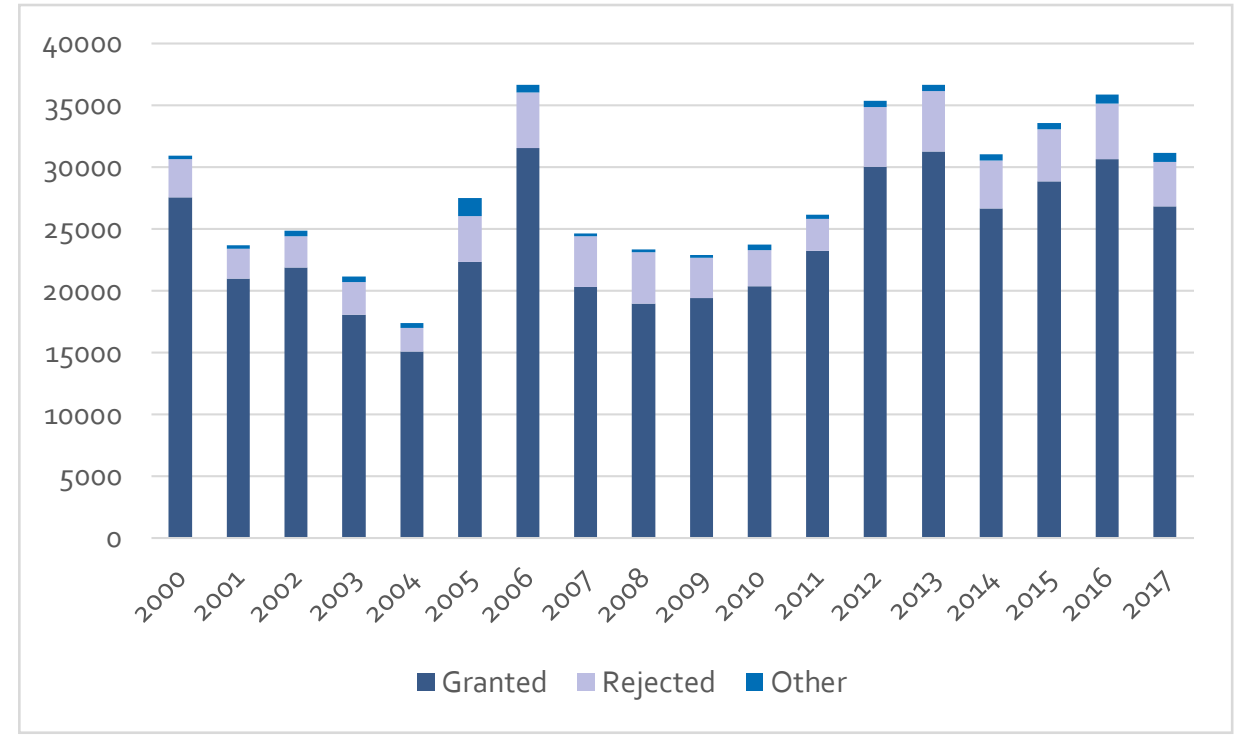

Source: The Swedish Migration Agency.

Nearly $60 \%$ of all applications for Swedish citizenship were submitted by citizens of the following countries: Iraq (18\%), Bosnia \& Hercegovina (6\%), Iran (5\%), Turkey (4\%), Poland (4\%), Somalia (4\%), Thailand (4\%), Serbia \& Montenegro (4\%), stateless persons (3\%), Syria (2\%), Russia (2\%) and Afghanistan (2\%). The granting percentage was $80 \%$ or more for applicants from these groups. However, stateless persons and Afghan citizens stand out, with granting percentages of 69 and $65 \%$, respectively.

As displayed by . 7 , the three most prevalent grounds for the rejection of citizenship applications have been non-fulfillment of requirements of identity, conduct, and dispensation from the residence requirement (i.e., cases where a person seeks 
dispensation from the residence requirement, but is refused). Combined, these three rejections grounds comprise almost $90 \%$ of the rejections in this period. The "other" category shown in the figure includes rejections based on non-fulfillment of the main residence requirement (five years), non-fulfillment of the residence and identity requirements, and not having a permanent residence permit.

Figure 7: Grounds for rejection of applications for Swedish citizenship, 2005-2017

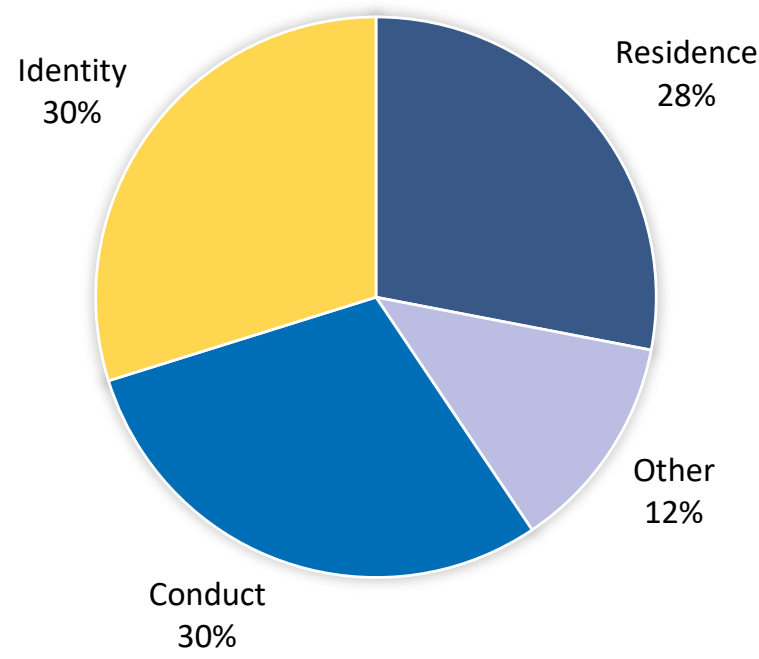

Note: Numbers from 2000 to 2005 are excluded because a large proportion of the rejections were unregistered.

Source: The Swedish Migration Agency.

\subsubsection{Norway}

Applications for Norwegian citizenship are examined by the Norwegian Directorate of Immigration (UDI). Between 2005 and 2017, UDI processed 184,673 applications. A total of 160,880 of these applications ( $87 \%$ ) were granted, while 23,793 applications (13\%) were rejected. As Figure 8 shows, during this period of 12 years, the number of granted applications has fluctuated between 9,000 (in 2008) and 16,000 (in 2017). The number of rejected applications has fluctuated between 1,000 and 2,800. In relative numbers, UDI granted $80 \%$ or more applications for citizenship each year. 
Figure 8: Decisions on applications for Norwegian citizenship, 2005-2017

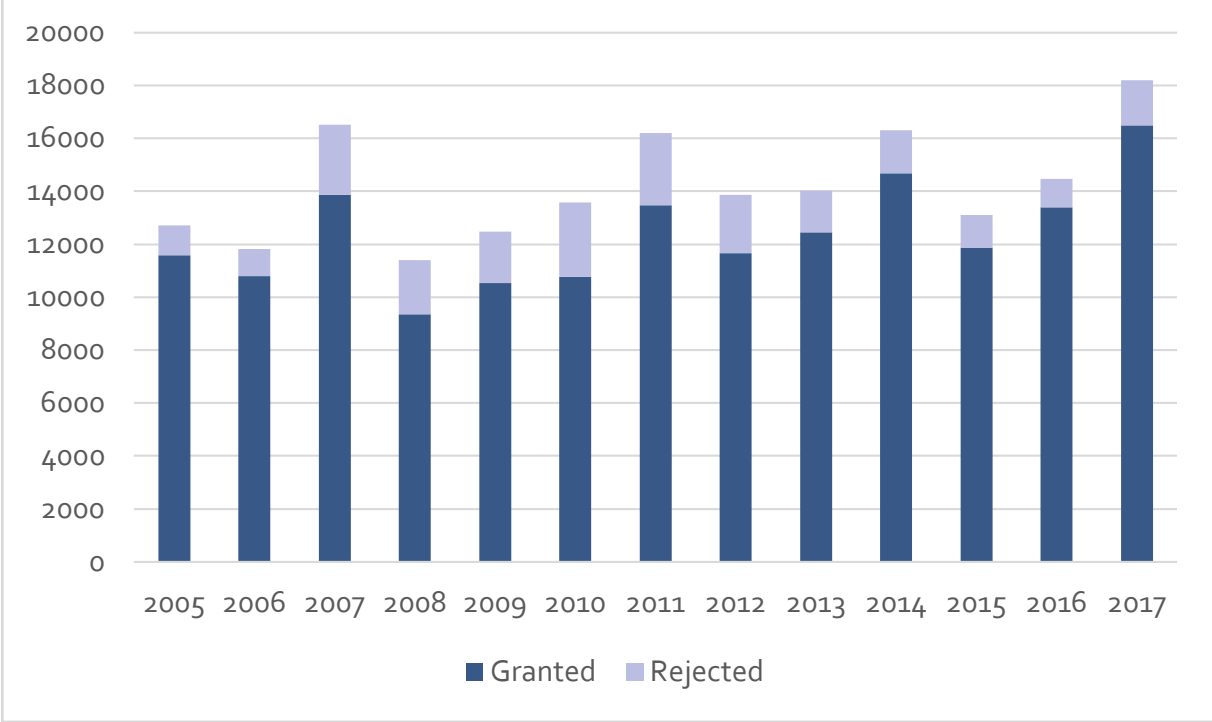

Source: The Norwegian Directorate of Immigration.

Figure 9 displays the most common grounds for rejection of applications for Norwegian citizenship between 2007 and 2017 (on applications under the main rule, Section 7). The majority of rejections were based on non-fulfilment of requirements of identity, residence, and conduct ( $57 \%$ of all rejected applications)..$^{30}$ Other common grounds for rejections were non-fulfilment of requirements of renunciation ( $10 \%$ of all rejections) and age (8\%). "Other" contains several rejection grounds, with non-fulfilment of language skills (6\%) and permanent residence permit (5\%) accounting for the largest proportions of rejections.

$3^{30}$ For applications for citizenship including children as co-applicants (Section 17), the main reason for rejection is nonfulfilment of the residence requirement (two years). For children who came to Norway before reaching 18 years of age who are exempted by the main residence requirement (section 11), failure to comply with requirements of residence (five years), age (12 years) and identity are the most prevalent reasons for rejection. 
Figure 9: Grounds for rejection of applications for Norwegian citizenship, 2007-2017

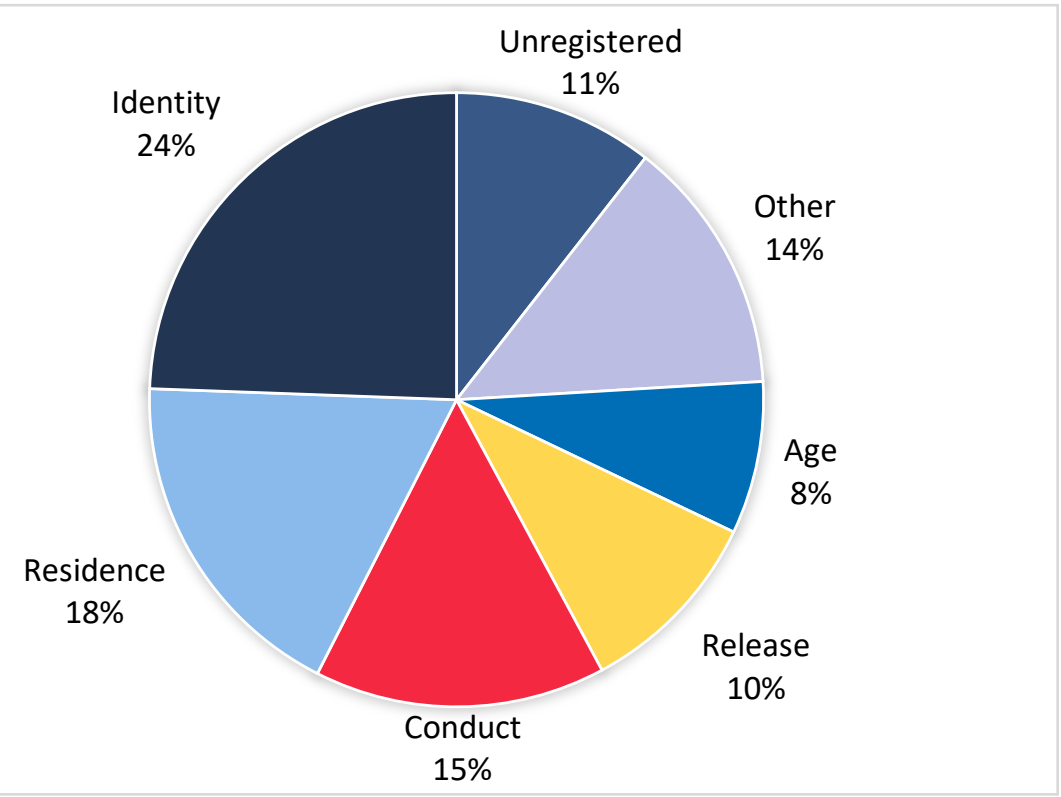

Source: The Norwegian Directorate of Immigration.

Nearly half of all applications processed by UDI between 2005 and 2017 were applications submitted by citizens of Iraq (13\%), Somalia (11\%), Afghanistan (7\%), Eritrea (4\%), Russia (4\%), Pakistan (4\%) and Iran (4\%). Three-quarters or more of the applications from each of these groups were granted by UDI.

\subsubsection{Denmark}

Applications for Danish citizenship are examined by the Ministry of Immigration and Integration. If the applicant fulfils all criteria, the application is sent to the Naturalization Committee of the Danish Parliament (Indfødsretsutvalget), which then decides to include (or not) the applicant on a bill of naturalization (Ersbøll 2015a). Figure 10, based on statistics compiled by the Danish Institute for Human Rights (2016), shows the annual number of decisions on applications for Danish citizenship in total and, further, the number of granted and rejected applications each year. 
Figure 10: Decisions on applications for Danish citizenship, 2001-2015

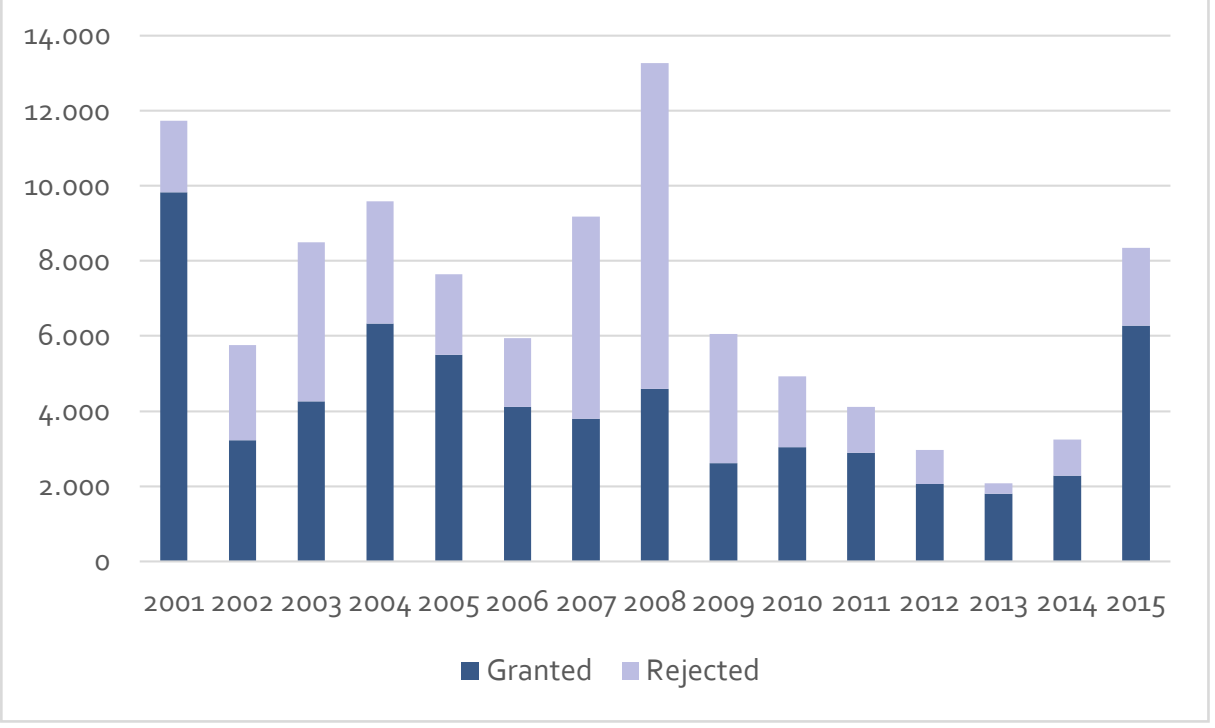

Source: Institut for menneskerettigheder (2016: 8, table 1.1).

The annual number of decisions varied significantly during the period; in 2001, nearly 12,000 decisions on applications for Danish citizenship were made and in 2008 the equivalent number exceeded 13,000. By contrast, only 2,000 applications for Danish citizenship were processed in 2013. Apart from a substantial variation in annual decisions made, the most remarkable feature in the figure is the large variation in the proportion of granted citizenships. In $2001,84 \%$ of all applications were granted. The following years, however, the granting percentage lay somewhere between 50 and $69 \%$. The granting percentage was particularly low in 2007, 2008 and 2009, when only 41,35 , and $43 \%$ of all applications were granted, respectively. A probable cause of the decrease in granted applications is the introduction of various restrictions on naturalization throughout the 2000 s (see Chapter 3.5). Since 2010, the granting percentage has, however, increased. In the last year surveyed, $2015,75 \%$ of all applications for naturalization were approved.

\subsubsection{Iceland}

Icelandic citizenship can be acquired by law or executive decision (as explained in Chapter 4). Between 2000 and 2014, the two responsible units that granted citizenship (by all modes of acquisition) were the Parliament, granting by law, and the Ministry of Justice, granting by executive decision (in 2014, the Directorate of Immigration took over as the administrative decision-making unit).

Figure 11 shows the number of granted citizenships in the years 2000-2015, both granted by law and by executive decision, sorted by mode of acquisition (application or declaration, and with children as co-applicants). A total of 10,229 persons were granted Icelandic citizenship in this period, of which 6,529 persons ( $64 \%$ of all acquisitions) were 
granted on application, 1,182 persons (11\%) on declaration and 2,219 citizenships ( $25 \%$ ) were granted to children as co-declarants.

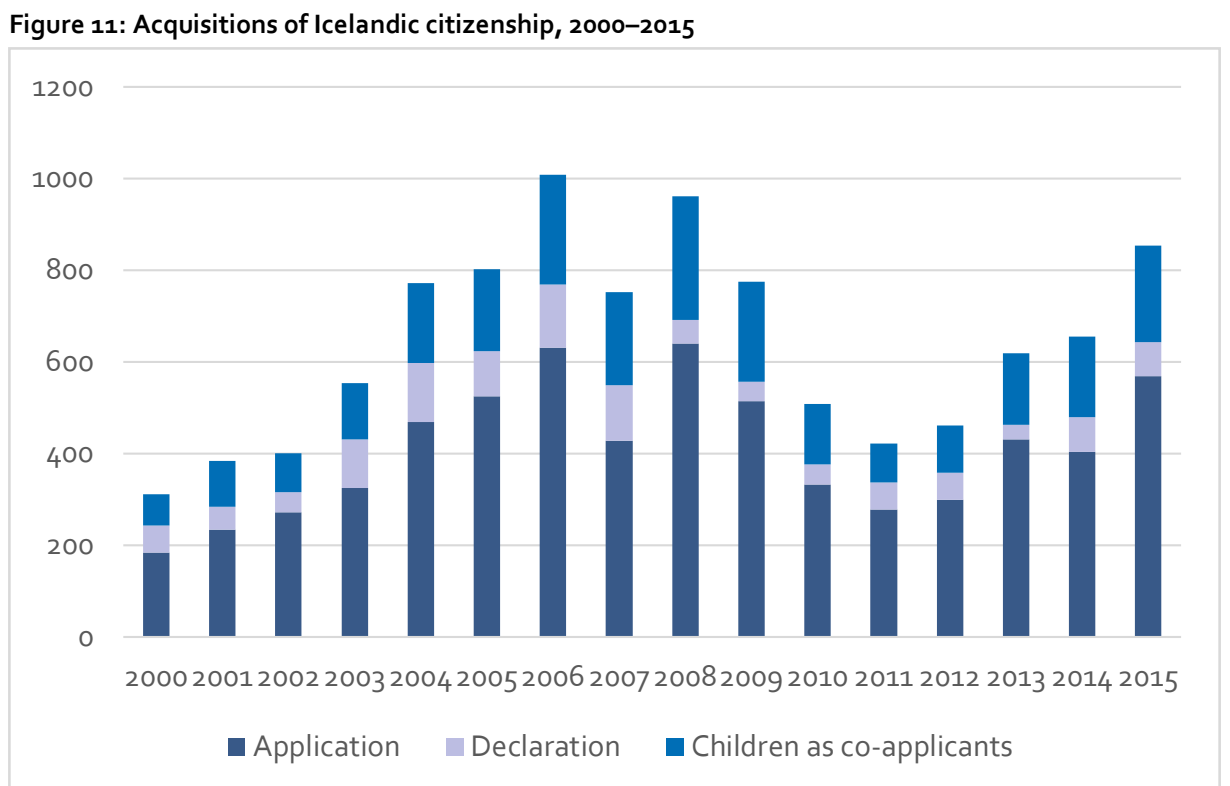

Source: The Icelandic Ministry of Interior.

The number of citizenship acquisitions increased at a steady rate from 300 in 2000 to a high point of 1,000 in 2006. In the following nine years, the annual number of citizenship acquisitions fluctuated between 400 and 900 . The Ministry of Justice does not have any statistics on the number of negative decisions on applications and declarations, nor accurate data on rejection grounds. The granting percentage on citizenship acquisition via the administrative method is therefore not possible to calculate exactly. However, the Ministry of Justice estimates that approximately $20 \%$ of all decisions on applications and declarations are negative, non-fulfilment of the conduct requirement being the most common ground for rejection (in most cases violations of the traffic law)..$^{31}$ According to the citizenship team of the Directorate of Immigration (in charge of citizenship issues from 2014), the main reason for refusals are non-fulfilment of the conduct requirement, and secondly, the residence requirement (seven years).

As to the traditional (parliamentary) method of awarding citizenship, Figure 12 displays the annual number of applications submitted to the Parliament in the period 2000-2017 (until 1 July), and the shares of granted and rejected applications. ${ }^{32}$ In total, 1,259 applications were submitted to the parliament. The Parliament granted half of these applications and rejected the other. Notably, in six years (2000, 2001, 2002, 2005, 2009, and 2013), the share of rejections was higher than the share of granted applications. Bear in mind that, as mentioned in Chapter 4, the Parliament deals with

\footnotetext{
${ }^{31}$ E-mail correspondence with Fanney Óskarsdóttir, Senior Legal Expert at the Ministry of Justice.

32 The numbers of applications submitted and rejected are missing from 2010 and 2011, which is why there are no bars for these years in the figure.
} 
less clear-cut cases than the Directorate of Immigration (previously the Ministry of Justice) and is not bound by any legal criteria. Consequently, this leaves much discretionary power in the hands of the Parliament, with the flexibility of employing both liberal and restrictive practices.

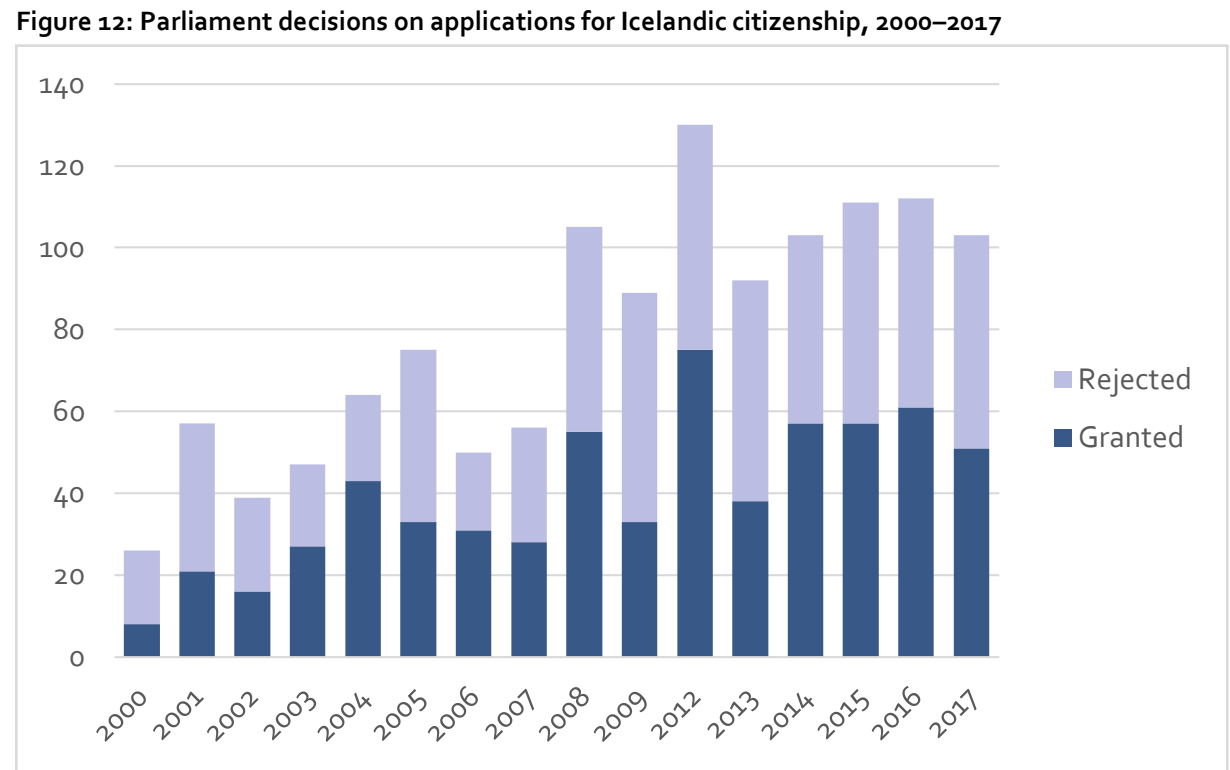

Note: Complete data for the years 2010 and 2011 are missing.

Source: The Icelandic Ministry of Interior.

The largest group that received Icelandic citizenship between 2000 and 2016 were Polish citizens, comprising $21 \%$ of all citizenship acquisitions in the period (Statistics Iceland 2017). Other large groups were citizens of the Philippines (11\%), Thailand (7\%), Vietnam (4\%), USA (4\%), Serbia (4\%), Russia (3\%) and Denmark (2\%).

\subsubsection{Finland}

The Finnish Immigration Service processes applications for Finnish citizenship. From 2009 to 2017, the Finnish Immigration Service processed citizenship applications concerning 73,652 persons (note: number of persons is not the same as the number of applications, as one application can comprise multiple persons). A total of 63,012 (86\%) of these persons were granted Finnish citizenship, while 10,092 persons (14\%) received a negative response.

Figure 13 shows the annual number of decisions on applications for Finnish citizenship between 2009 and 2017. Throughout the period, the number of processed applications nearly quadrupled - from 3,400 in 2009 to 13,000 in 2017 (referring to number of persons). Accordingly, the number of granted applications has varied between 2,800 (2009) and 11,000 (2017), meaning that during this period the granting percentage has been no less than $79 \%$ (in 2016) and as high as $94 \%$ (in 2011). The number of rejections has thus been low but has increased in tandem with the increase in the number of applications processed each year. 
Figure 13: Decisions on applications for Finnish citizenship, 2009-2017

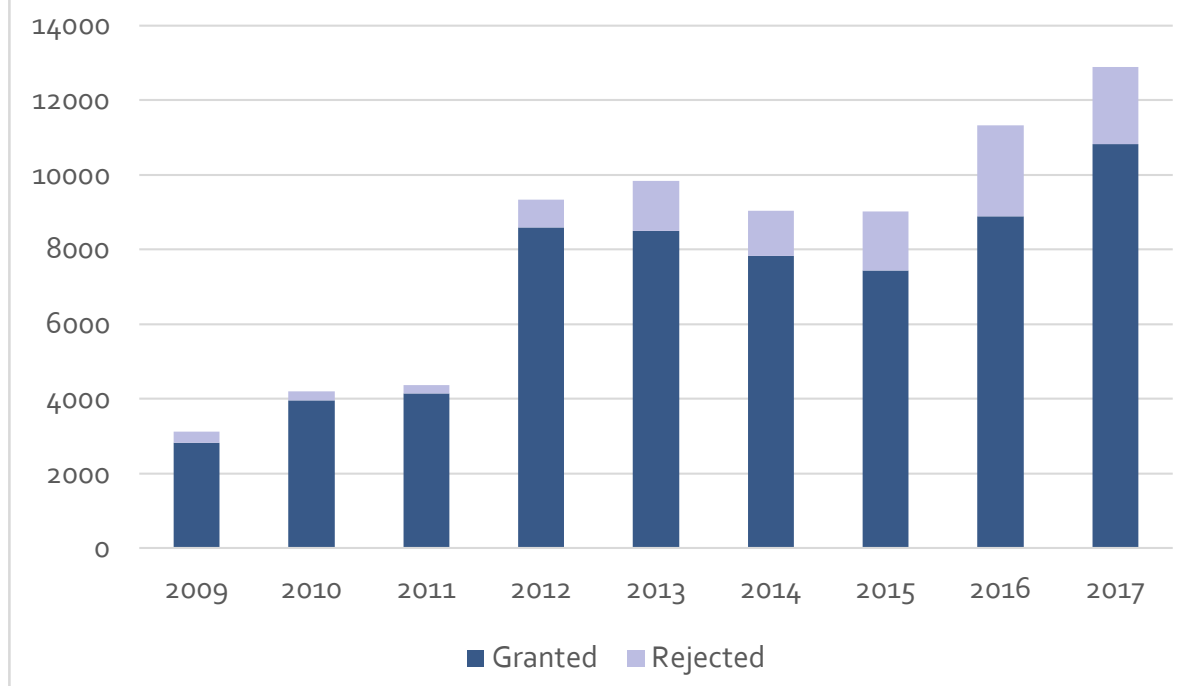

Source: The Finnish Immigration Service.

The most common ground for rejection between 2011 and 2017 (as of 10 October) was rejection of an application of a co-applicant based on a negative outcome for the principal applicant. As Figure 14 shows, this ground for rejection accounted for $37 \%$ of all negative decisions. Second, $30 \%$ of the rejections were based on non-fulfilment of the language skills requirement. Failure to comply with requirements of identity establishment ( $8 \%$ of all application refusals), integrity $(7 \%)$ and residence $(5 \%)$ were also common grounds for rejection. It should be mentioned, however, that half of all granting decisions were based on exceptions to the general requirements of language skills, residence, and integrity. 
Figure 14: Grounds for rejection of applications for Finnish citizenship, 2011-2017

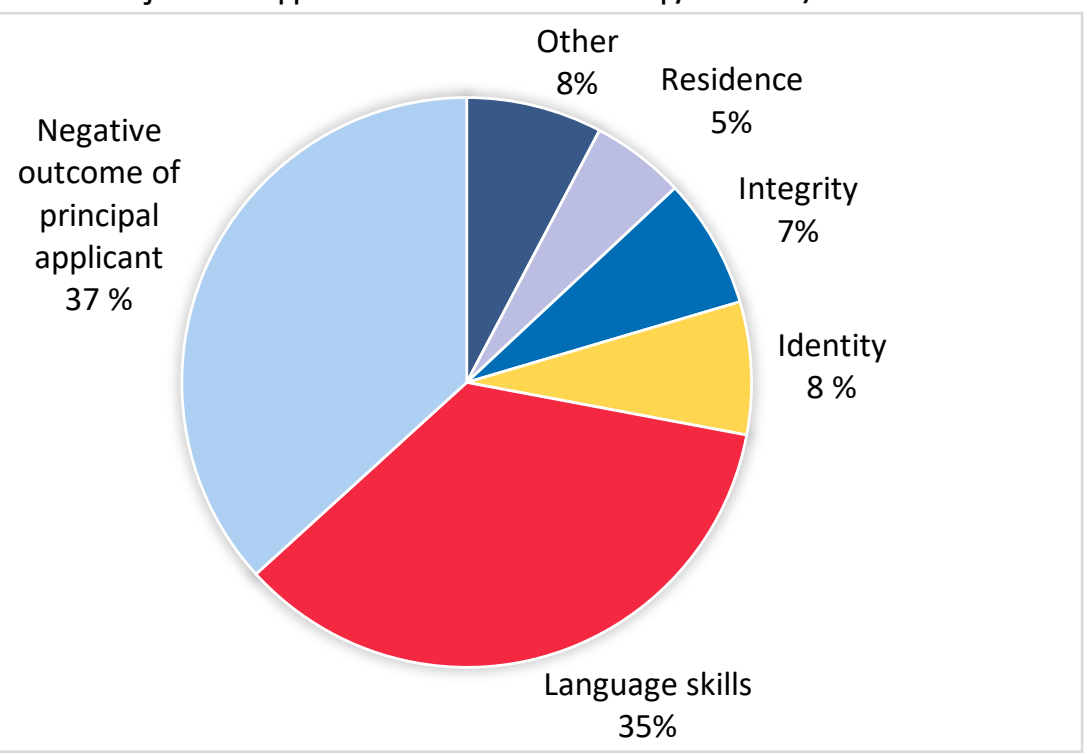

Source: The Finnish Immigration Service.

Russian citizens were the largest applicant group between 2011 and 2017 by far, representing $23 \%$ of all applicants. Citizens of Somalia (11\%), Iraq (7\%), Afghanistan (5\%), Estonia (5\%), Iran (3\%) and Turkey (3\%) were other large applicant groups. Notably, the granting percentage varies considerably between groups. For instance, Russian and Estonian applicants were granted Finnish citizenship in $97 \%$ of all cases, while Iraqi and Somali applicants were granted citizenship in only 64 and $69 \%$ of all cases, respectively.

\subsection{Revocation of citizenship 33}

\subsubsection{Norway}

The Norwegian Nationality Act of 2005 contains two provisions on the revocation of citizenship (both laid down in Section 26). First, Norwegian citizenship can be revoked if an applicant who has been granted Norwegian citizenship has not renounced his or her original citizenship within a set time limit. Second, if a person has acquired Norwegian citizenship by fraudulent conduct it may subsequently be revoked.

From 2007 to 2017, the Norwegian Directorate of Immigration (UDI) made 739 decisions to revoke citizenship. At total of 539 of these decisions ( $73 \%$ of all revocation

\footnotetext{
33 This section reports statistics on citizenship revocation in Norway and Finland. As mentioned previously, Sweden and Iceland do not allow for citizenship revocation. Revocation of citizenship is allowed in Denmark, but unfortunately we did not get access to Danish statistics.
} 
decisions) were based on non-renunciation of foreign citizenship, and $200(27 \%)$ decisions were based on fraudulent conduct.

Figure 15 shows the annual decisions to revoke citizenship from 2007 to 2017. The initial years after the introduction of this provision (Section 26), the number of decisions increased from seven in 2007 to 126 in 2010. In the following year, the number halved and it remained low in 2013 and 2014 (with less than 40 decisions being made these years). From 2014 to 2015 , the number of revocation decisions doubled (from 40 to 80 ) and increased to over 120 decisions in 2016. In 2017 (as of 10 November), 126 citizenships had been revoked. The largest portion of the revocations, in every year, is based on non-renunciation of citizenship. In 2017, all decisions except two were based on non-fulfilment of the renunciation requirement. Decisions pertaining to fraudulent conduct, however, are expected to rise as UDI currently sits with 700 cases subject to this provision. ${ }^{34}$

Figure 15: Decisions on revocation of Norwegian citizenship, 2007-2017

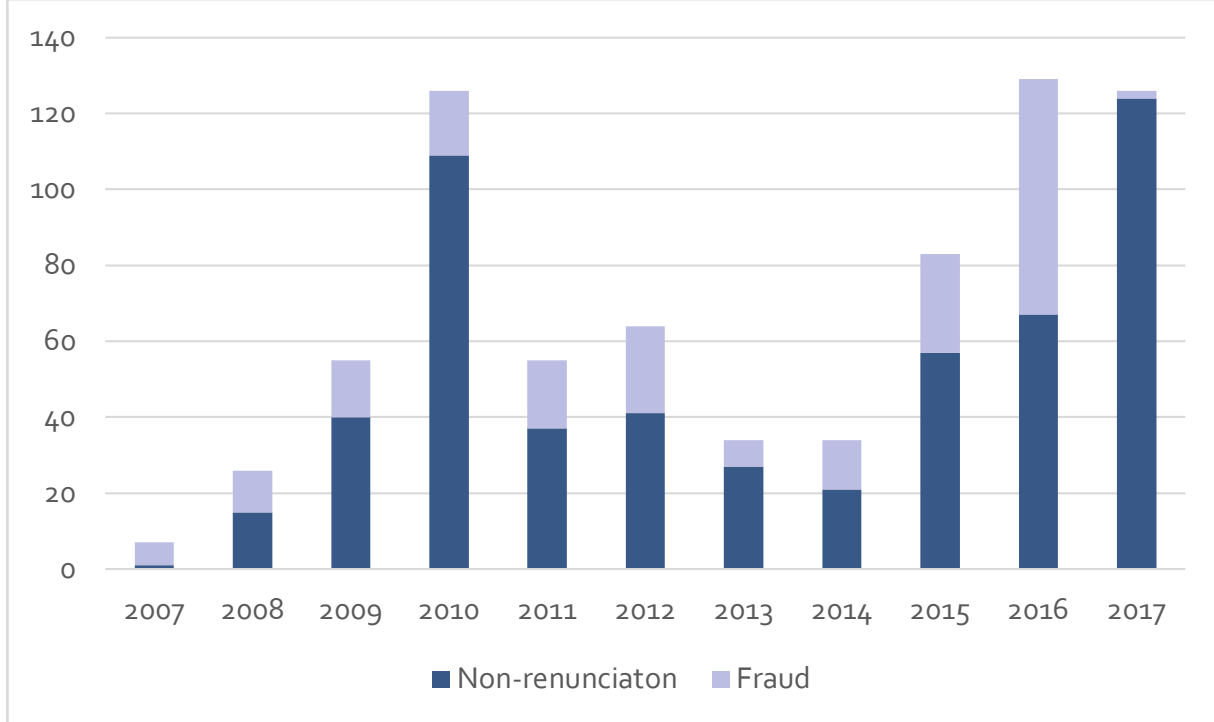

Source: The Norwegian Directorate of Immigration.

\subsubsection{Finland}

In Finland, a decision to revoke citizenship can be made based on two grounds: fraud and breached paternity assumptions (so-called "quasi-loss"). In the period 2011-2017, 16 Finnish citizenships were revoked because the persons provided false information upon naturalization. Loss of Finnish citizenship due to breached paternity assumptions also occurred in the same period, albeit rarely: the annual number of persons losing citizenship based on this legal provision ranged between 1 and 7 .

34 These cases are currently held in abeyance, as the Parliament decided in May 2017 that the power to revoke citizenship should be transferred from the Directorate of Immigration to the court system. 


\subsection{Naturalization in the Nordic countries: A cross-country comparison}

The acquisition of citizenship varies significantly between the Nordic countries. To illustrate with an example, in 2015, nearly 29,000 citizenships were granted on application in Sweden, while only 568 were granted in Iceland - including both applications and declarations. Clearly, this difference is mainly attributable to the size of the immigrant population in each country. Differing waves of immigration and the demographic composition of the respective immigrant populations may also account for the variation in citizenship acquisitions between countries (Pettersen 2012: 35). Absolute numbers on citizenship acquisition may therefore be misleading.

By contrast, the naturalization rate is a relative measure, which is widely used to compare citizenship acquisition across countries. Technically, a naturalization rate indicates the share of foreign residents who actually acquired citizenship in a given year (Eurostat 2017). In other words, naturalization rates may indicate at least two things: the popularity of citizenship acquisition in the foreign population and the strictness of national citizenship policies. Before we present and compare naturalization rates between the Nordic countries, however, we will make note of some necessary precautions when interpreting the rates.

The term "naturalization rate", as it is often used, is misleading because the numerator includes all modes of acquisition, not just naturalization proper (i.e., acquisition by application), and also since the denominator includes all foreigners - including persons who are ineligible for naturalization (i.e., foreigners who do not yet fulfill the residence requirement). Further, as the rate includes all foreigners - across very different country backgrounds and reasons for immigration - the demographic composition of the immigrant population influences the rate significantly. Immigrants coming from medium- and under-developed countries of origin are on average much more likely to apply for citizenship than those originating from highly developed countries (Vink, Breuer \& Dronkers 2012). ${ }^{35}$ Thus, if a country's immigrant population predominantly consists of immigrants coming from highly developed countries, the naturalization rate is more likely to be low - and vice versa. A low naturalization rate does not necessarily imply strict naturalization policies, because it includes both foreigners who are ineligible and foreigners who may be uninterested in naturalizing. With these reservations in mind, the rate provides a useful common ground for comparison and suggests how different national laws and policies affect citizenship acquisition.

Figure 16 displays the naturalization rate of each Nordic country between 2000 and 2015 based on numbers collected by Eurostat (2017). The naturalization rate varies significantly over time and between countries. Sweden had the highest naturalization rate throughout the entire period (only surpassed by Finland in 2004). That year, $7 \%$ of

\footnotetext{
35 At large, this is reflected in the naturalization statistics in the Nordic countries. The top three applicant groups in Sweden are immigrants from Iraq, Bosnia and Iran; in Norway, immigrants from Iraq, Somalia and Afghanistan; in Iceland, immigrants from Poland, the Philippines and Thailand; and in Finland, immigrants from Russia, Somalia and Iraq.
} 
all resident foreigners in Sweden acquired Swedish citizenship. The liberalization of the Swedish Citizenship Act in 2001 did not result in any immediate increase in the initial years (Pettersen 2012: 36), but rather decreased by three percentage points between 2000 and 2004 (from 9 to 6\%). Then the rate saw a steep increase and reached its highest point in 2006, a year in which nearly $11 \%$ of all foreign residents acquired Swedish citizenship. From 2007 to 2015 , the rate fluctuated between 5 and $7 \%$. Actually, Sweden had the highest rate in Europe in 2015. By comparison, the average naturalization rate in the EU region as a whole was $2.4 \%$ (Eurostat 2017).

Figure 16: Naturalization rates in the Nordic countries, 2000-2015

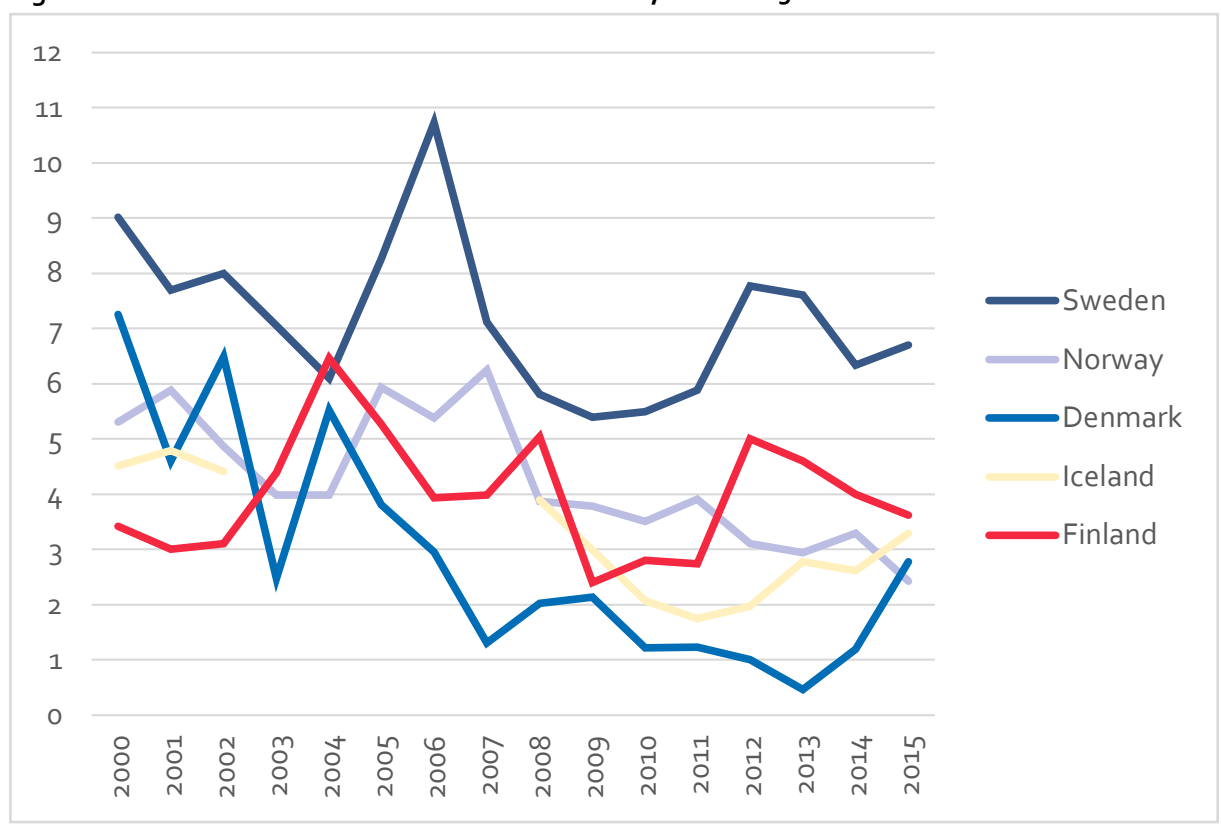

Note: Complete data from Iceland $2003-2007$ is missing.

Source: Eurostat 2017.

Denmark had the second highest naturalization rate in 2000, a year when $7 \%$ of all foreign residents acquired Danish citizenship. Between 2002 and 2003, the rate dropped significantly by four percentage points (from $6.5 \%$ to $2.5 \%$ ). This drop suggests that the restrictions introduced in 2002 (including stricter requirements of residence, conduct, language proficiency etc.) had a detrimental effect on citizenship acquisitions. However, the year after, it increased by three percentage points, a year when $5.5 \%$ of foreign residents acquired Danish citizenship. Since 2004 , the rate has dropped at a steady rate, reaching a low point of $0.5 \%$ in 2013 . As described in Chapter 3 , this period was marked by a considerable tightening of naturalization requirements, with the introduction of a requirement of self-sufficiency and a further tightening of the conditions of conduct and language skills. The rate increased from 2013 to 2015 , indicating that some of the relaxations on the naturalization policies (e.g., on language skills and self-sufficiency) had a certain effect. 
In Norway, the development is overall characterized by a steady decline in the share of foreign residents acquiring citizenship. From 2000 to 2006 (when the new Citizenship Act took effect), the naturalization rate in Norway fluctuated between 6 and $4 \%$. After reaching its high point in 2007 , the rate has almost decreased each year, dropping to its all-time low of $2.5 \%$ in 2015 - the lowest among the Nordic countries.

By the turn of the century, Finland had the lowest naturalization rate of $3.4 \%$. From 2000 to 2003 , however, the rate doubled. In the following years the rate decreased steadily, reaching a low point in 2009 , a year when approximately $2 \%$ of all foreign residents acquired Finnish citizenship. This decrease may partially be explained by the introduction of the new Citizenship Act, which included stricter residence and language skills requirements. The rate was stable from 2009 to 2011 , and then it almost doubled from 2011 to 2012. The law amendment of 2011 entailed a shortening of the residence period, which may partially account for the increase. The three last years of the period is marked by a steady decline.

It is difficult to analyze the trend over time in Iceland since data on several years (2003-2007) are missing, but overall, the naturalization rate has decreased throughout the period. In observable years, the naturalization rate in Iceland has not, however, varied as much as the rates in the other Nordic countries. The rate dropped from $4 \%$ in 2008 to under $2 \%$ in 2011. From 2010 and 2014, it was the second lowest rate among the Nordic countries, meaning that a low share of the foreign population acquired Icelandic citizenship in this period. The decline may partially have been caused by the introduction of requirements of self-sufficiency and language skills in 2007 (the latter entering into force in 2009). The development in recent years has been a positive one, increasing over one percentage point from 2012 to 2015.

The relationship between naturalization policies and naturalization rates is not one-to-one. As mentioned above, the measurement is somewhat inaccurate because it includes all foreigners, even those ineligible for naturalization and immigrant groups who are not interested in the acquisition of another citizenship.

However, Figure 16 does suggest a certain correlation between naturalization policies and naturalization rates over time, at least if one looks at Sweden and Denmark, the two countries that have made the biggest steps toward easing and restricting access to citizenship, respectively. Sweden, adopting a very liberal citizenship law in 2001, displayed the highest naturalization rate throughout the entire period and, as mentioned, exhibited the highest rate in Europe in 2015. In Denmark, where access to citizenship has been tightened significantly, the naturalization rate has gone from being the second highest among the Nordic countries in 2000 to being the lowest in most of the following 15 years. Differences in naturalization rates between the two poles, Sweden and Denmark, may reflect opposite views on naturalization and citizenship policies - that is, what each state wants to achieve with its legislation. While the official Swedish view is that citizenship acquisition should ease and promote integration, citizenship acquisition is seen as a reward for a successful integration process in Denmark (Midtbøen 2015). Differing views of immigration, integration and nationhood are one of the explanations as to why the Nordic countries have chosen such divergent paths in citizenship law, a point we will elaborate on in the next chapter. 


\section{Development of Nordic citizenship law in the 21st century - a comparative analysis}

From the late 19th century onward, Sweden, Denmark, and Norway collaborated to establish homogeneity in the citizenship legislation prevailing in the Scandinavian region (Brochmann \& Seland 2010; Ersbøll 2003; Midtbøen 2015). The main driver of these efforts was the "pan-Scandinavianism" of the time, a cultural movement which, according to Wickström, "conceptualized the nations of Sweden, Denmark (including Iceland) and Norway (at the time in personal union with Sweden) as a family of brothers that shared the same cultural and linguistic heritage; a heritage that needed to be rediscovered and reconstructed in the modern age" (2017: 676-677).

In the postwar years, Finland was included in a renewed conceptualization of a common Nordic heritage. Reflecting this "Nordism", from the 1950 onward special arrangements for Nordic citizens were included in the citizenship laws in Sweden, Denmark, Norway, and Iceland (and from 1968 in Finland). These arrangements differentiated between Nordic and non-Nordic citizens and included - among other things - that residence periods in a Nordic country would be considered residence in another and that Nordic citizens could become citizens of the country of residence by declaration, and are still part of the citizenship laws in all countries (Wickström 2017).

However, the Nordic agreement was formally abolished in 1979, and since then the Nordic countries have gradually moved in different directions. In the 2000s, starting with the Swedish law revision in 2001 and followed by law revisions in Iceland, Finland, and Norway and the restrictive changes in Danish naturalization policies, the Nordic countries represent the entire continuum in European citizenship policies - from liberal Sweden to restrictive Denmark with the other Nordic neighbors somewhere in between. In this chapter, we dig deeper into the reasons why the Nordic countries have chosen such divergent paths in their citizenship policies.

\subsection{Diverging citizenship policies in the 20005}

As noted in Chapter 1, a major tradition in the citizenship literature has perceived citizenship policies as a more or less direct reflection of nationhood. This analytical position has particularly been influenced by the seminal work of Rogers Brubaker (1992), in which the different nationality legislations in France and Germany are analysed in historical perspective. Brubaker shows how these legal traditions should be interpreted in light of historical processes of nation-building, and that rules for 
acquiring membership - which differ widely between countries - reflect particularities of national self-conceptions.

The historical cooperation between the Nordic countries on matters related to citizenship stands in a certain contrast to this view, but the perspective may nonetheless shed light on the divergent development of citizenship policies in the region, which started in the mid-1970s and culminated in the 2000s. Indeed, a closer look at the processes leading to the revisions of citizenship policies in Sweden, Denmark, Norway, Finland and Iceland suggests that different understandings of, on one hand, nationhood, and on the other, of social cohesion and integration needs prevail in the Nordic region (Jensen et al. 2017; Midtbøen 2015).

Take Sweden, for example. Even though the Swedish Citizenship Act of 2001 in many ways was based on tradition, it also contained features that depart from previous practices, and a number of its aspects testify to a new and more inclusive attitude toward immigrants - most prominently the acceptance of dual citizenship (Gustafson 2002). Of course, this does not imply that national identity lost its meaning in the Swedish context. Rather, the changes in Swedish citizenship law may demonstrate a national identity that both encompasses increasing migration-related diversity and concerns with globalization. The new nationality act was initiated by a desire to modernize legislation in the wake of immigration and internationalization, and the act can be regarded as a reflection of more recent perceptions of Sweden as a multicultural society (Midtbøen 2015).

Denmark has chosen a quite different path, which signals a more traditional conceptualization of national identity that is less inclusive of immigrants (Mouritsen 2013). Since 2002, the country has introduced a number of restrictive naturalization requirements: the required time of residence has been increased to nine years, and requirements are imposed with regard to financial self-sufficiency, and knowledge of Danish culture, society and history, as well as documented language skills at a very high level. Although Denmark accepted dual citizenship in 2015, the gradual tightening of Danish nationality legislation since the early 2000 s can be perceived as a reinforcement of the idea of citizenship as a reward for a complete and successful integration into Danish society-Danish citizenship is not open to everyone.

In light of the Swedish Citizenship Act of 2001 and the amendments to Danish naturalization policy since the early 2000s, citizenship policies in Finland, Iceland and Norway are more ambiguous. Finland and Iceland followed Sweden and accepted dual citizenship in 2003, indicating that liberalization was on its way in both countries. However, the required time of residence was not reduced and naturalization in both countries is conditioned on requirements of language proficiency. In Iceland, as in Denmark, applicants must be financially self-supporting in order to acquire citizenship. In Norway, the principle of unitary citizenship has been maintained, naturalization is conditioned on requirements of language proficiency, and an oath of allegiance has been reintroduced as part of a citizenship ceremony. On the other hand, all those who fulfill the conditions for naturalization are entitled to Norwegian citizenship. Furthermore, the oath of allegiance is mandatory only for those who participate in the voluntary ceremony. In contrast to Sweden and Denmark, changes in citizenship policies in Finland, Iceland and Norway are characterized by both liberal and restrictive elements simultaneously. 


\subsection{Immigration, membership and the re-emergence of citizenship as a policy tool}

What we have witnessed in the 2000 s is that citizenship in the Nordic region has reemerged as an important policy tool after decades in hibernation. In this process, the otherwise similar Nordic countries have chosen different paths, suggesting that distinct notions of membership in the various nation states have also emerged: the wish to define new terms for membership has trumped historical efforts of cooperation.

The key reason why citizenship has re-entered the political arena is its close coupling with the nation state's broader approach to immigration and integration - perhaps the most contested political field in the era of globalization (Goodman 2014). In the first decades following World War II, the citizenship institution was devalued and seemed to lose meaning (Brochmann 2007; Hansen \& Weil 2001; Schuck 1998). In the 2000s, by contrast, citizenship has been revalued and must today be seen as part of broader efforts of integrating immigrants and their descendants in Europe. As Sara Goodman notes: "New state articulations of belonging through language, country knowledge, and value requirements have not only defined a script of membership for newcomers to follow, they also signify a 'waking up' of the European nation state to twenty-first century realities of immigrants-related ethnic and cultural heterogeneity" (2014: 226).

The inclination to include integration requirements as conditions for naturalization, as is today present in all the Nordic countries except Sweden, is often referred to as the "civic turn" in the citizenship literature (e.g., Jensen et al. 2017; Mouritsen \& Olsen 2013). Although this concept points to a crucial aspect of citizenship reform in many countries, it has a tendency to conflate quite substantial differences between countries regarding the scope and purpose of civic integration requirements (Goodman 2014: 5). Indeed, a striking feature of the amendments to citizenship law in the Nordic countries is the tendency to regard citizenship in the context of broader integration processes (Midtbøen 2015). Interestingly, however, concerns over "lacking integration" have given rise to quite large differences in their citizenship policies. How may we explain the emergence of these differences between countries that historically have cooperated closely in this area of law?

The fact that the old tradition of wide-ranging collaboration in the area of citizenship law in the Nordic countries was abandoned in 1979 may reflect that national interests were seen as more important than Nordic cooperation in the wake of post-war migration. Comparing the divergent development of citizenship in Sweden, Denmark, and Norway, Midtbøen (2015) argues that post-war migration might have "activated latent differences in the conceptions of nationhood in the Scandinavian countries, which in turn may have weakened the incentives for collaboration in the field on citizenship law and prepared the ground for the various courses that these countries gradually have followed in their immigration policies in general since the 1970s" (see Brochmann \& Seland [2010] for a similar argument). Following this line of reasoning, the current citizenship policies in the Nordic countries are better indicators of the different ideas of nationhood prevailing in the region than the historical collaboration on citizenship issues in the first half of the 2oth century. Yet, nationhood itself is also prone to change over time and according to the 
political and socio-economic as well as demographic realities at hand (Brubaker 2006, 2010). Meanwhile, current citizenship policies are arguably as reflective of the different approaches in the Nordic countries to how integration and social cohesion can be fostered or enforced as of nationhood itself (Jensen et al. 2017).

\subsection{Immigrant integration and social cohesion}

How to achieve a sense of community, a common identity and sufficient social cohesion to keep the nation state intact in the age of migration is among the most pressing questions in European politics today (Kymlicka 2015). Against this background, it is not surprising that countries choose different paths in their approaches to immigration in general, and to citizenship policies in particular. As Goodman (2014: 231), has pointed out: "As conflicts of perceived national interest - from diffuse threats of immigration to immediate conflicts over the Eurozone debt crisis - pull states further and further apart, complicating and potentially undermining achievements in European integration over time, states are turning inward." Indeed, the Nordic countries are strikingly more inward-looking today than they were in the mid-2oth century.

Importantly, the large differences in the content of citizenship policies also reveal the fact that we do not know much about the actual relationship between social integration and citizenship acquisition (Hainmueller et al. 2017; Midtbøen 2015). In the scholarly literature, there are two contrasting perspectives on this issue. In one perspective, liberal integration policies and easy access to citizenship are viewed as the best ways to increase social and political integration because these signal a wish to accommodate a diverse population (Banting \& Kymlicka 2006; Bloemraad 2006). In another perspective, successful immigrant integration is seen as conditioned on a restrictive and more "demanding" approach to citizenship and welfare rights (Koopmans 2010). However, both perspectives lack empirical studies to support these claims, though a recent article suggests that more liberal naturalization requirements do seem to improve the social integration of immigrants in Switzerland (Hainmueller et al. 2017). The lack of a broader demonstration of the "integration effects" of citizenship policies in various national contexts may help explain the polarized character of today's citizenship laws (Midtbøen 2015).

Across Europe, countries are searching for ways to achieve solidarity and feelings of belonging in nation states that are now characterized by migration-related diversity, but through what measures such social cohesion can best be achieved is still a contested issue. Variations on the civic turn, demanding integration by raising the bar for citizenship acquisition, have been the answer in many national contexts. This probably reflects a wish to create "good citizens" that are enabled to integrate into the majority society, and indeed it may work - at least if integration is the main purpose of changing policies. However, there is a fine line between supporting to integrate and forcing to assimilate (Goodman 2014: 240). Stricter access to the national community may also give rise to more prominent lines of division between insiders and outsiders - between those with and without access to the privileges of citizenship. 


\section{The future of citizenship in the Nordic countries}

The development of citizenship law in the Nordic countries has moved away from longterm endeavors to establish homogeneity, towards the striking differences that characterize the countries' regulations today. Currently, Sweden and Denmark occupy opposite ends of the scale ranging from liberal to restrictive citizenship laws, with Norway, Finland, and Iceland in intermediate positions. In this concluding chapter, we discuss some possible consequences of the fact that the Nordic countries have developed such different citizenship regimes over that past decades, and we reflect on the prospects for strengthened cooperation between the Nordic countries in the area of citizenship legislation.

\subsection{Consequences of different citizenship regimes in the Nordic region}

The strikingly different approaches to citizenship between the Nordic countries open for a discussion of possible consequences. When one country changes its citizenship law, does this lead to changes in the others? Is the intra-Nordic mobility of Nordic citizens affected by differences in citizenship law? And finally, what consequences do different citizenship regimes have for the integration of immigrants in the Nordic countries and for the prospects of a unified Nordic region? In this section, we will discuss these questions in turn.

\subsubsection{Spill-over effects}

Given the Nordic cooperation within the area of citizenship law historically and the high level of mobility between the Nordic countries changes in one country's legislation may have direct consequences for the others. When Sweden adopted its new Citizenship Act in 2001 and chose to accept dual citizenship, for example, this provoked an immediate change in Danish legislation (Midtbøen 2015). In 2002, all Nordic citizens were required to document that their previous citizenship had been dissolved before they could naturalize in Denmark, exactly like all other foreign nationals (Ersbøll 2013). Requirements for documentation of actual dissolution of citizenship had previously been unnecessary since this happened automatically upon acquisition of citizenship in another Nordic country. When Sweden accepted dual citizenship in 2001, their rule of automatic dissolution was deleted but the new Danish requirements for documentation 
neutralized the consequences of the Swedish turnaround with regard to Denmark (Ersbøll 2006: 128).

This is an example of how revisions of citizenship law in one Nordic country can directly lead to changes in another. However, the consequences are probably more often indirect: Revisions of law in one country can inspire the other countries to introduce similar changes. It is likely no coincidence, for example, that Iceland and Finland, in 2003, chose to accept dual citizenship only two years after Sweden - as the first Nordic country - did the same. In fact, Finland's decision to accept dual citizenship was made with direct reference to the change in Swedish citizenship law. The assumption was that the law revision process underway in Norway at the time would end with the same result (Fagerlund \& Brander 2013: 12), although this proved erroneously.

Similarly, the stricter naturalization requirements that have been enacted in Norway in recent years are probably inspired by developments in Denmark. A concrete example is a recent proposed change to citizenship law in Norway (Prop. 146 L [20162017]): A legal provision to revoke Norwegian citizenship from citizens who have been convicted of criminal acts that defy fundamental national interests, but in practice only those who are dual citizens, given international conventions prohibiting statelessness. A similar amendment to the Danish citizenship law was made in 2004 , but did not receive much attention in the other Nordic countries until Denmark chose to accept dual citizenship in 2015, precisely because allowing dual citizenship made citizenship revocation potentially more accessible for actual use. In fact, part of the rationale for political support for allowing dual citizenship in Denmark was that this would make it easier to revoke citizenship from dual citizens that had engaged in or supported acts of terror (Midtbøen 2017).

\subsubsection{Mobility patterns}

May the different approaches to citizenship in the Nordic region affect mobility patterns between the Nordic countries? This issue is briefly touched upon in a recent report, written by legal scholar Inge Lorange Backer, which was commissioned by The Nordic Council of Ministers (Backer 2018)..$^{36}$ In general, the mobility between the Nordic countries is high and the different citizenship regimes do not have consequences for the possibilities of moving from one country to another, nor for working there. However, citizenship law in the Nordic countries could - at least hypothetically influence the mobility choices made by citizens of other Nordic countries. For example, the fact that Norway still does not allow dual citizenship may prevent Nordic citizens from long-term residing in Norway, and at least it may prevent them from taking full part in democratic processes because acquiring a Norwegian citizenship would require them to renounce their former citizenship. If this does not affect mobility patterns, it certainly does affect long term implications of mobility as regards to democratic

${ }^{36}$ The Backer report provides an overview of the historical development of Nordic law cooperation in general and does not discuss in detail the development or consequences of different citizenship laws in the Nordic countries. 
participation. Relatedly, Danish citizens who are long-term residents abroad, including in other Nordic countries, are (with some exceptions) denied voting right in parliamentary elections in Denmark, due to regulations pertaining to the population register in Denmark. In effect, these regulations deprive Danes abroad of a fundamental citizenship right, and in case they reside in Norway they are effectively not granted the right to vote in parliamentary elections in either country of citizenship, nor of residence, resulting in a democratic deficit. ${ }^{37}$

On another note, the European migrant crisis in 2015 is an example of international events which can lead to policy responses with implications for short-term mobility within the Nordic region. Citizens of the Nordic countries are entitled to travel without passports across the region, as in the EU/EEA area in general. However, when Sweden temporarily reintroduced ID controls in 2015 as part of border controls in response to refugee arrivals from Southern Europe this resulted in travel delays and long waiting periods for all individuals crossing the borders into Sweden. For Nordic citizens used to traveling easily from country to country this situation created some turbulence and was by some interpreted as testament to a new dawn - one with less freedom and less unity within the region than citizens in the Nordic countries had been used to since the mid2oth century. Border controls on the Swedish-Danish border was relaxed in May 2017 but there are still regular checks and Nordic citizens are obliged to carry valid Identity documents, either an identity card or a passport, when travelling to Sweden. As such, the border-less Nordic region remains changed, as a consequence of the international events in $2015-2016$.

\subsubsection{Immigration control and integration}

What consequences do different citizenship regimes have for the integration of immigrants? As showed in Chapter 5, there seems to be a correlation between naturalization policies and naturalization rates: Liberal naturalization requirements, as in Sweden, lead to higher naturalization propensities, while stricter rules, as in Denmark and increasingly in Norway, lower the naturalization rates. In that sense, different citizenship regimes seem to have different consequences for the formal integration of immigrants into the nation state.

Whether citizenship policies have a direct effect on broader patterns of immigrant integration is an open question, however. Although a common feature of the debates associated with amendments to citizenship legislation in the Nordic countries is that formal citizenship is seen in the context of more wide-ranging integration processes, no empirical research has documented a straight-forward relationship between citizenship and integration (but see Hainmueller et al. 2017 for the Swiss context). Still, the Nordic countries, along with the rest of Europe, continue to strive to find the right approach to citizenship and immigration. The recent changes in Swedish citizenship policies, upgrading the status of citizenship ceremonies and underscoring the

37 See Palmgren and Wetterberg (2017: 6) for other examples. 
significance of citizenship as a unifying institution in Swedish society, are testament to these continuous efforts. The increasing focus on citizenship revocation, either on the grounds of fraud, as in Norway, or on the grounds of participation in or support for terrorist acts, as in Denmark, reveals how citizenship is used instrumentally to signal what is expected of members of the nation state, albeit differently so in the Nordic countries (Midtbøen 2017).

The question remains whether the focus on immigrant integration over time could lead to a harmonization of citizenship laws in the Nordic region. One could imagine a restrictive convergence appearing, based on a common perception in the Nordic countries that a more demanding approach to citizenship acquisition is the best way forward. In that case, naturalization criteria would be heightened across the board as a relevant policy response to the integration challenges facing each country. However, no such convergence appears to be emerging. Despite a gradual rethinking of what citizenship means in the Swedish context, the small steps in the direction of making it more difficult to acquire a Swedish citizenship will not - at least not yet - bring Sweden significantly closer to the situation in Norway or Denmark. In Norway, for example, the Government has proposed measures to increase the required residence period for naturalization to 10 years, which would make it among the longest in Europe, and in Denmark, more restrictive requirements are continuously proposed. Still, citizenship in Sweden is now becoming a moving target. Several new requirements for naturalization are currently discussed, and so is the possibility to introduce citizenship revocation in the Swedish citizenship law. The upcoming parliamentary election in the fall of 2018 will probably be decisive in shaping the country's approach to citizenship in the years to come.

\subsection{A Nordic citizenship in the making? Reflections and recommendations}

On September 27, 2016, the Prime Ministers in the Nordic countries jointly stated that the Nordic region "should be the most integrated region in the world" (Backer 2018: 7).$^{38}$ One year earlier, The Center Group in the Nordic Council - one out of five party groups in the Council, comprised by 29 Centre, Liberal, Christian Democrat and Green parties - had proposed that the Nordic region should be established as a citizenship unit (Palmgren and Wetterberg 2017), echoing the vision from the first Nordic interparliamentary meeting after World war II. What are the prospects of reaching a new era of cooperation within the area of citizenship today? Is the mid-2oth century vision of the Nordic region as a common citizenship unit even conceivable in the current context? And if there is political will to strengthen the cooperation efforts, what needs to be in place, practically and politically, to make it happen?

$3^{8} \mathrm{http}: / /$ www.norden.org/da/aktuelt/nyheder/statsministre-norden-mest-integrerede-region-i-verden 
A range of features suggest that it would be possible to make the Nordic region a common citizenship unit: The Nordic countries are highly developed welfare states, they are "small states" with a pronounced sense of social equality, and they have historically shared a perception of each other as "Nordic brothers" (Hedetoft 2006; Wickström 2017). Not least, the Nordic countries have for more than a hundred years cooperated on a series of law areas (Backer 2018). All of this suggests that a strengthened cooperation on citizenship issues - perhaps even the realization of establishing the region as a citizenship unit - is within reach.

For this to happen, a first, basic requirement is to engage the Nordic Council and the political leadership in the different countries. As Backer (2018: 48) points out, any cooperation beyond mere sharing of information and experiences requires that initiatives and proposals are grounded in the political system. Strengthened cooperation probably also requires that the Nordic countries are willing and able to harmonize the ways in which citizenship is defined and legalized, and perhaps - in the cases of Denmark and Iceland - that the level of discretion in naturalization application processes is reduced by providing administrative agencies with the sole competence to make decisions. This is the case in Sweden, Norway and Finland today where citizenship is granted by the Swedish Migration Agency, the Norwegian Directorate of Immigration and the Finnish Immigration Service, respectively.

Finally, strengthened cooperation requires that data on acquisition and loss of citizenship in the Nordic countries are gathered, systematized, and analyzed, with the explicit goal of understanding the impact of the various citizenship regimes on both citizenship acquisition patterns and the social, economic, and political integration of new citizens. This report is a first step in that direction but the differences in quality and quantity of the data provided by the responsible agencies illustrate the need for more systematic data collection on the part of the responsible ministries, directorates or immigration services - at best with the possibility for researchers or the national statistic bureaus to easily merge statistics on citizenship acquisition with individuallevel registry data on other social and economic outcomes. If these data were systematically available, we would have come a long way in answering the basic question that remains largely empirically un-scrutinized: What effects do different citizenship regimes have on migrant integration and social cohesion?

Although closer cooperation between the Nordic countries within the area of citizenship law does seem feasible, the vision of a Nordic citizenship unit will probably be hard to realize in practice, however. This somewhat pessimistic conclusion is based on characteristics of the citizenship institution itself, on the close coupling of citizenship with nationhood, and on the politicization of citizenship that has occurred over the past few decades, as citizenship policies increasingly have become an important part of countries' broader approach to immigration and integration. Although migration across borders is international by nature, how countries regulate immigration, how they conceive of the integration process, and how they define the terms of membership are fundamentally national questions. This is because they reflect the nation states' sovereign right to define the terms of inclusion within the territory of the state, among the population inhabiting the national space. Since the early 2000s, the Nordic 
countries have turned inwards and been far more interested in finding their own solutions than submitting to the will of others. Even in a context of a hypothetical restrictive convergence in citizenship laws in the Nordic region, we find it difficult to imagine that such a convergence would be the result of, or lead to, a strengthened cooperation in this area of law.

What is at stake in the current situation is how to define membership in nation states characterized by increasing migration-related diversity (Meissner 2015). Indeed, approaches to membership in nation states of today need to be attentive to varying implications of international migration and diverse population compositions within states (Brubaker 2010). Brubaker (2010: 64) argues that "the politics of citizenship in the nation state can be distinguished analytically from the politics of belonging to the nation state, though the two are often closely linked in practice." Belonging to the nation state can formally be granted. Belonging in the nation, on the other hand, is a reciprocal exercise where the individual self-identifies as a national and is recognized as such by co-nationals (Antonsich, Mavroudi \& Mihelj 2017; Bloemraad 2018).

The distinction between formal membership in the nation state and informal membership in the nation is an important one when it comes to the citizenship institution, because this tension strikes at the very core of the citizenship institution. While formal membership to the nation state is regulated through naturalization policies, informal membership in the nation is much less clear-cut. There are of course challenges related to individuals and groups who do not have access to formal citizenship (Birkvad 2017). But arguably, there are in the Nordic countries even more substantial challenges related to individuals who are formal citizens, but who are denied informal membership in the nation (Erdal 2013). These citizens represent a paradox for the state - members of the nation state, yet not recognized fully, or a lack of themselves feeling, as members belonging in the nation.

The paradox of incomplete membership reflects limitations in conceptualizations of nationhood in the current context of increasing migration-related diversity within the populations of the Nordic countries (Erdal et al 2017). As the emergence of dual citizenship across the Nordic region (except Norway) illustrates, the empirical reality is that identity is not a zero-sum game - not even when it comes to national identities. Both emigration and immigration produces complex national identities across the Nordic region and among Nordic citizens. The ongoing changes in population compositions increasingly center on a diversification that immigrants' children, born in the Nordic countries, are contributing to. These individuals, who regularly acquire citizenship at birth due to their parents' previous naturalization, are often not granted the informal right to fully and without question belong in the nation.

Importantly, the perception of what nationhood is, what it was, and what it ought to be is slower to change than the demographic make-up of citizens within the Nordic nation states (Erdal \& Strømsø 2016). Nationhood is imagined, but it is also experienced and real in people's everyday lives (Antonsich et al. 2017; Kaufmann 2017). Ideas about who nationals are and what they look like are likely to adapt to the empirical realities on the ground over time. But perceptions and ideas are often anchored in the past and somehow intertwined not only with history but also with 
ancestry. Across the Nordic countries, issues of nationhood in more diverse societies are as much related to concerns about national cultures as they are to automatic reactions people have as to who does or does not "look like" a national (Antonsich 2018). However, nationhood - a feeling of unity and solidarity - can also be created, even in the context of diversity, through nation-building efforts (Antonsich \& Matejskova 2015). Here, the citizenship institution is clearly an important tool, if and when - its relationship with nationhood becomes more resolved in the Nordic countries. Citizenship is a powerful instrument of social closure that may still prove important in defining the lines of inclusion and cohesion in nation states characterized by increasing ethnic, religious and cultural diversity. 



\section{Sammendrag}

De nordiske landene har hatt en århundrelang tradisjon for samarbeid på statsborgerrettens område. Så sent som i 1945 forelå det et eksplisitt ønske om å etablere den nordiske regionen som en statsborgerrettslig enhet. Siden midten av 1970-tallet har de nordiske landene imidlertid beveget seg i ulik retning, en prosess som skjøt fart med lovendringer i alle land på 2000-tallet. I dag representerer de nordiske landene hele spekteret av europeisk statsborgerlovgivning - fra liberale Sverige til restriktive Danmark, med de nordiske nabolandene i mellomposisjoner.

Denne rapporten diskuterer ulike forståelser av hva et statsborgerskap innebærer, redegjør for historisk utvikling og nåværende statsborgerskapslovgivning i de fem nordiske landene, presenterer statistikk om ervervelse og tap av statsborgerskap i hvert land for de siste 10-15 årene, og analyserer årsakene til den divergerende utviklingen som har funnet sted siden tidlig 2000-tall. Avslutningsvis drøfter vi mulige konsekvenser av at de nordiske landene har utviklet en så ulik tilnærming til statsborgerskap, og vi reflekterer over muligheten for et styrket nordisk samarbeid om statsborgerrettslige spørsmål i årene som kommer.

Et styrket nordisk samarbeid på statsborgerrettens område - og ikke minst realiseringen av det historiske ønsket om å etablere regionen som en statsborgerrettslig enhet - forutsetter et sterkt engasjement fra Nordisk råd og det politiske lederskapet i ulike landene. Styrket samarbeid krever antakeligvis også at de nordiske landene er villige til å harmonisere både definisjoner og lovgivning på feltet, og det vil kreve at statistikk om ervervelse og tap av statsborgerskap samles, systematiseres og analyseres, med en målsetting om å forstå hvilke konsekvenser ulike tilnærminger har for innvandreres tilbøyelighet til å naturalisere, og for den sosiale, $ø$ øonomiske og politiske integrasjonen av nye borgere.

Selv om de nordiske landene institusjonelt sett har alle forutsetninger for et styrket samarbeid på statsborgerrettens område, konkluderer rapporten med at visjonen om et fellesnordisk statsborgerskap ikke er realistisk $\mathrm{i}$ overskuelig fremtid. Denne konklusjonen bygger på den tette koblingen mellom statsborgerskap og nasjonal selvforståelse, og det faktum at lovgivningen over tid har blitt en sentral del i landenes bredere tilnærming til innvandring og integrasjon. De nordiske landene har siden tidlig 2000-tall vært langt mer orientert mot å etablere sine egne tilnærminger enn mot å finne løsninger i samarbeid med andre. Selv $i$ en hypotetisk situasjon der landene nærmer seg hverandre i en mer restriktiv utvikling, vil en slik konvergens neppe være utslag av eller bidra til å styrke et samarbeid på statsborgerrettens område. 



\section{References}

Anderson, B. (1983). Imagined communities. Reflections on the origin and spread of nationalism. New York: Verso.

Antonsich, M., \& Matejskova, T. (2015). Conclusion: Nation and Diversity-A False Conundrum. In Governing Through Diversity, (pp. 201-209). Palgrave Macmillan, London.

Antonsich, M. (2016). International migration and the rise of the "civil" nation. Journal of Ethnic and Migration Studies, 42(11), 1790-807.

Antonsich, M., Mavroudi, E., \& Mihelj, S. (2017). Building inclusive nations in the age of migration. Identities, 24(2), 156-176.

Aptekar, S. (2015). The road to citizenship: what naturalization means for immigrants and the United States. Rutgers University Press.

Austin, C., \& Bauder, H. (2010). Jus Domicile: A Pathway to Citizenship for Temporary Foreign Workers? CERIS - The Ontario Metropolis Centre.

Backer, I. L. (2018). Styrket nordisk lovsamarbeid. Muligheter og utfordringer [Strengthened Nordic Law Cooperation. Possibilities and Challenges]. København: Nordisk ministerråd.

Banting, K., \& Kymlicka, W. (2006). Multiculturalism and the Welfare State. Recognition and Redistribution in Contemporary Democracies. Oxford: Oxford University Press.

Bauböck, R. (2002). Farewell to multiculturalism? Sharing values and identities in societies of immigration. Journal of International Migration and Integration, 3, 1-16.

Bauböck, R. 2006. Migration and citizenship: legal status, rights and political participation. Amsterdam: Amsterdam University Press.

Bauder, H. (2013). Nation, "migration" and critical practice. Area, 45(1), 56-62.

Bernitz, H. L., \& Bernitz, H. (2006). Sweden. In R. Bauböck, E. Ersbøll, K. Groenendijk, \& H. Waldrauch (Eds.), Acquisition and Loss of Nationality: Policies and Trends in 15 European Countries. Volume 2: Country Analysis. Amsterdam: Amsterdam University Press.

Bernitz, H. (2012). Country Report: Sweden. EUDO Citizenship Observatory. Badia Fiesolana: European University Institute.

Bernitz, H. (2013). Naturalisation Procedures for Immigrants. Sweden. EUDO Citizenship Observatory. Badia Fiesolana: European University Institute.

Billig, M. (1995). Banal nationalism. London: Sage.

Birkvad, S. R. (2017). The Meanings of Citizenship: Mobility, Legal Attachment and Recognition. MA Thesis. Department of Sociology and Human Geography, University of Oslo.

Björnsson, T. \& Pétursson, G.T. (2013). Naturalisation Procedures for Immigrants. Iceland. EUDO Citizenship Observatory. Badia Fiesolana: European University Institute.

Bloemraad, I. (2006). Becoming a Citizen: Incorporating Immigrants and Refugees in the United States and Canada. Berkeley and Los Angeles: University of California Press.

Bloemraad, I. (2004). Who Claims Dual Citizenship? The Limits of Postnationalism, the Possibilities of Transnationalism, and the Persistence of Traditional Citizenship. International Migration Review, 38(2), 389-426.

Bloemraad, I., Korteweg, A., Yurdakul, G. (2008). Citizenship and Immigration: Multiculturalism, Assimilation, and Challenges to the Nation-State. Annual Review of Sociology, 34, 153-179.

Bloemraad, I., \& Sheares, A. (2017). Understanding Membership in a World of Global Migration: (How) Does Citizenship Matter? International Migration Review, 51(4), 823-867.

Bloemraad, I. (2018). Theorising the power of citizenship as claims-making. Journal of Ethnic and Migration Studies, 44(1), 4-26. 
Brochmann, G. (2002). Statsborgerskap, medborgerskap og tilhørighet [Citizenship and Belonging]. In G. Brochmann, T. Borchgrevink, \& J. Rogstad (Eds.), Sand i maskineriet. Makt og demokrati i det flerkulturelle Norge (pp. 56-84). Oslo: Gyldendal Akademisk.

Brochmann, G. (2007). Til Dovre faller: ^̊ bli norsk - å være norsk - troskapsløfte og statsborgerskap i den foranderlige nasjonen [Until Dovre Falls - to Become Norwegian - to be Norwegian - Pledge of Allegiance and Citizenship in the Changing Nation] . In G. Alsmark, T. Kallehave, \& B. Moldenhawer (Eds.), Migration och tillhörighet: Inklusions- och exklusionsprocesser i Skandinavien (pp. 99-126). Lund: Makadam Förlag.

Brochmann, G. (2013). Country Report: Norway. EUDO Citizenship Observatory. Badia Fiesolana: European University Institute.

Brubaker, R. (Ed.) (1989). Immigration and the Politics of Citizenship in Europe and North America. New York: University Press of America.

Brubaker, R. (1992). Citizenship and Nationhood in France and Germany. Cambridge: Harvard University Press.

Brubaker, R. (1999). The Manichean myth: Rethinking the distinction between "civic"and "ethnic" nationalism In H. Kriesl, K. Armingeon, H. Siegrist, \& A. Wimmer (Eds.), Nation and National Identity: The European Experience in Perspective (pp. 55-71). Zürich: Verlag Rüegger.

Brubaker, R. (2004). Ethnicity without groups. Cambridge: Harvard University Press.

Brubaker, R. (2009). Ethnicity, Race, and Nationalism. Annual Review of Sociology, 35, 21-42.

Brubaker, R. (2010). Migration, Membership, and the Modern Nation-State: Internal and External Dimensions of the Politics of Belonging. The Journal of Interdisciplinary History, 41(1), 61-78.

Byrne, B. (2014). Making citizens: Public rituals and personal journeys to citizenship. Basingstoke: Palgrave Macmillan.

Caramani, D., \& Grotz, F. (2015). Beyond citizenship and residence? Exploring the extension of voting rights in the age of globalization. Democratization, 22(5), 799-819.

Castles, S., \& Miller, M. (2009). The Age of Migration: International Population Movements in the Modern World (4th ed.). London: Palgrave MacMillan.

Collyer, M. (2014). A geography of extra-territorial citizenship: Explanations of external voting. Migration Studies, 2(1), 55-72.

Damsholt, T. (2017). "I didn't think I would be emotional until I started saying the oath" emotionalising and ritualising citizenship. Journal of Ethnic and Migration Studies, 1-16.

Danish Ministry of Refugees, Immigrants and Integration. (2002). Cirkulæreskrivelse nr. 55 af 12.06.2002 om dansk indfødsret ved naturalisation [Circular Document No. 55 of 12.06.2002 on Danish Citizenship by Naturalisation]. Retrieved from http://globalcit.eu/wpcontent/plugins/rscas-national-citizenship-lawgcit/docs/DEN\%20CIR\%20No\%2055\%202002\%20(original).pdf

Danish Ministry of Refugees, Immigrants and Integration. (2006). Cirkulæreskrivelse nr. 9 af 12.01.2006 om naturalisation [Circular Document No. 9 of 12.01.2006 on Naturalisation]. Retrieved from https://www.nyidanmark.dk/NR/rdonlyres/0271E58F-oCA9-4492-B87F5C905FF7FDEB/o/cirkulaereskrivelse_nr_9_12_januar_2006_engelsk.pdf

de Groot, G.R. \& Vink, M. P. (2010). Loss of Citizenship. Trends and Regulations in Europe. Badia Fiesolana: European University Institute.

Erdal, M. B. (2013). Migrant transnationalism and multi-layered integration: Norwegian-Pakistani migrants' own reflections. Journal of Ethnic and Migration Studies, 39(6), 983-999.

Erdal, M. B. (2016). Juxtaposing Pakistani diaspora policy with migrants' transnational citizenship practices. Geoforum, 76, 1-10.

Erdal, M. B. \& Talleraas, C. (2015) Becoming One of Us?, PRIO Policy Brief, 11. Oslo: PRIO.

Erdal, Marta Bivand \& Mette Strømsø (2016) Norskhet i flertall [Plural Norwegianness], PRIO Policy Brief, 14. Oslo: PRIO.

Erdal, M. B., \& Sagmo, T. H. (2017). Descent, birthplace and residence: Aligning principles of citizenship with realities of migrant transnationalism. Norsk Geografisk Tidsskrift-Norwegian Journal of Geography, 71(4), 208-219. 
Erdal, M.B, Collyer, M, Ezzati, R.T., Fangen, K., Kolås, Å., Lacroix, T. \& Strømsø, M. (2017) Negotiating the Nation: Implications of Ethnic and Religious Diversity for National Identity, PRIO Project Summary. Oslo: PRIO.

Ersbøll, E. (2003). Statsborgerskap - medborgerskap - europæisk konvergens - nordisk divergens [Citizenship - European Convergence - Nordic Divergence]. Nordisk tidsskrift for menneskerettigheter, 2, 147-163.

Ersbøll, E. (2006). Denmark. In R. Bauböck, E. Ersbøll, K. Groenendijk, \& H. Waldrauch (Eds.), Acquisition and Loss of Nationality: Policies and Trends in 15 European Countries. Volume 2: Country Analysis. Amsterdam: Amsterdam University Press.

Ersbøll, E. (2013). Naturalization Procedures for Immigrants Denmark. EUDO Citizenship Observatory. Badia Fiesolana: European University Institute.

Ersbøll, E. (2015a). Report on Citizenship Law: Denmark. Country Report. Badia Fiesolana: European University Institute.

Ersbøll. E. (2015b). Loss of Nationality in the Nordic Countries. In S.C. Nuñez \& G.R. de Groot (Eds.), European Citizenship at the Crossroads: The Role of the European Union on Loss and Acquisition of Nationality (pp. 185-216). Oisterwijk: Wolf Legal Publishers.

Eurostat (2017). Acquisition of citizenship statistics. Retrieved from http://ec.europa.eu/eurostat/statistics-

explained/index.php/Acquisition_of_citizenship_statistics

Fagerlund, J., \& Brander, S. (2013). Country Report: Finland. Badio Fiesolana: European University Institute.

Faist, T, \& P. Kivisto. (2007). Dual Citizenship in Global Perspective. From Unitary to Multiple Citizenship. Basingstoke: Palgrave Macmillan.

Favell, A. (1998). Philosophies of Integration: Immigration and the Idea of Citizenship in France and Britain. London: Macmillan Press.

FitzGerald, D. S., Cook-Martín, D., García, A. S., \& Arar, R. (2018). Can you become one of us? A historical comparison of legal selection of "assimilable" immigrants in Europe and the Americas. Journal of Ethnic and Migration Studies, 44(1), 27-47.

Fox, J. E. (2017). The edges of the nation: a research agenda for uncovering the taken-for-granted foundations of everyday nationhood. Nations and Nationalism, 23(1), 26-47.

Gamlen, A. (2008). The emigration state and the modern geopolitical imagination. Political Geography, 27(8), 840-856.

Goodman, S. W. (2010). Integration Requirements for Integration's Sake? Identifying, Categorising and Comparing Civic Integration Policies. Journal of Ethnic and Migration Studies, 36(5), 753-772.

Goodman, S. W. (2012). Fortifying Citizenship: Policy Strategies for Civic Integration in Western Europe. World Politics, 64(4), 659-98.

Goodman, S. W. (2014). Immigration and Membership Politics in Western Europe. Cambridge: Cambridge University Press.

Gozdecka, D.A. (2013). Naturalisation Procedures for Immigrants. Finland. EUDO Citizenship Observatory. Badia Fiesolana: European University Institute.

Gustafson, P. (2008). Transnationalism in retirement migration: the case of North European retirees in Spain. Ethnic and Racial Studies, 31(3), 451-475.

Hainmueller, J., Hangartner, D., \& Pietrantuono, G. (2017). Catalyst or crown: does naturalization promote the long-term social integration of immigrants? American Political Science Review, $111(2), 256-276$.

Hagelund, A. \& Reegård, K. (2011). "Changing teams": a participant perspective on citizenship ceremonies. Citizenship Studies, 15(6-7), 735-748.

Hammar, T. (1990). Democracy and the Nation State: Aliens Denizens and Citizens in a World of International Migration. Aldershot: Avebury. 
Hansen, R., \& Weil, P. (2001). Introduction: Citizenship, Immigration and Nationality: Towards a Convergence in Europe? In R. Hansen \& P. Weil (Eds.), Towards a European Nationality: Citizenship, Immigration and Nationality Law in the EU. Basingstoke: Palgrave MacMillan.

Haug, B., Dann, G. M., \& Mehmetoglu, M. (2007). Little Norway in Spain: From tourism to migration. Annals of Tourism Research, 34(1), 202-222.

Hedetoft, U. (2006). Divergens eller konvergens? Perspektiver i den dansk-svenske sammenstilling [Divergence or Convergence? Perspectives in the Danish-Swedish Comparison]. In U. Hedetoft, B. Petersson, \& L. Sturfelt (Eds.), Bortom stereotyperna? Invandrare och integration i Danmark och Sverige (pp. 251-268). Göteborg: Makadam Förlag.

Hoekstra, M. (2015). Diverse cities and good citizenship: How local governments in the Netherlands recast national integration discourse. Ethnic and Racial Studies, 38(10), 1798-1814.

Institut for menneskerettigheder. (2016). Statsborgerskab. Status 2015-16 [Citizenship. Status 2015-16]. Copenhagen: Institut for menneskerettigheder.

Isin, E. \& P. Wood. (1999). Citizenship and identity. London: Sage.

Jensen, K.K., Fernández, C. \& Brochmann, G. (2017). Nationhood and Scandinavian naturalization politics: varieties of the civic turn. Citizenship Studies, 21(5), 606-624.

Jóhannesson, G. T., Pétursson, G.T. \& Björnsson, T. (2013). Country Report: Iceland. Badio Fiesolana: European University Institute.

Joppke, C. (2007). Transformation of Citizenship: Status, Rights, Identity. Citizenship Studies, 11(1), 37-48.

Joppke, C. (2010). Citizenship and Immigration. Cambridge \& Malden: Polity Press.

Justitsministeriet. (2013). Cirkulærebeskrivelse nr. 9253 af 6. juni 2013 om naturalisation [Circular Document no. 9253 of June 62013 on naturalization]. Retrieved from http://globalcit.eu/wpcontent/plugins/rscas-national-citizenship-law-

gcit/docs/DEN\%20CIS\%2ono\%209253\%202013_as\%2oenacted_ORIGINAL\%2oLANGUAGE.pdf

Kaufmann, E. (2017). Complexity and nationalism. Nations and Nationalism, 23(1), 6-25.

Knott, E. (2017). Quasi-citizenship as a category of practice: analyzing engagement with Russia's Compatriot policy in Crimea. Citizenship Studies, 21(1), 116-135.

Koch, N. (2015). Is nationalism just for nationals? Civic nationalism for noncitizens and celebrating National Day in Qatar and the UAE. Political Geography, 54, 43-53.

Koopmans, R. (2010). Trade-Offs between Equality and Difference: Immigrant Integration, Multiculturalism and the Welfare State in Cross-National Perspective. Journal of Ethnic and Migration Studies, 36(1), 1-26.

Kristinsson, A.P. (2012). Sprogtester og islandsk statsborgerskab [Language Tests and Icelandic Citizenship]. Sprog i Norden 2012, 47-64.

Kymlicka, W. (2015) Solidarity in diverse societies: beyond neoliberal multiculturalism and welfare chauvinism. Comparative Migration Studies, 3, 1-19.

Marshall, T. H. (1992 [1950]). Citizenship and Social Class. In T. H. Marshall \& T. Bottomore (Eds.), Citizenship and Social Class. London: Pluto Press.

Meissner, F. (2015). Migration in migration-related diversity? The nexus between superdiversity and migration studies. Ethnic and Racial Studies, 38(4), 556-567.

Midtbøen, A.H. (2008). Innvandringens ideologiske konsekvenser. Årsaker til og implikasjoner av statsborgerrettslig divergens $i$ de skandinaviske landene [The Ideological Consequences of Immigration. Causes and Implications of Citizenship Divergence in the Scandinavian Countries]. MA thesis. Department of Sociology and Human Geography, University of Oslo.

Midtbøen, A. H. (2009a). Statsborgerrettslig divergens i Skandinavia: En teoretisk utfordring [Divergence in Citizenship Rights in Scandinavia - A Theoretical Challenge]. Norsk Statsvitenskapelig Tidsskrift, 25(4), 307-329.

Midtbøen, A. H. (2009b). Statsborgerrettslig revisjon og integrasjonspolitisk variasjon i de skandinaviske landene [Nationality Reform and Divergent Conceptions of Integration in the Scandinavian Countries]. Tidsskrift for samfunnsforskning, 50(4), 523-550. 
Midtbøen, A. H. (2015). Citizenship, Integration and the Quest for Social Cohesion: Nationality Reform in the Scandinavian Countries. Comparative Migration Studies, 3(3), 1-15.

Midtbøen, A. H. (2017). Dual Citizenship in an Era of Securitization. Paper presented at the Eastern Sociological Society Annual Meeting, Philadelphia, February 242017.

Morales, L., \& Giugni, M. (Eds.). (2016). Social capital, political participation and migration in Europe: making multicultural democracy work? Basingstoke: Palgrave Macmillan.

Mouritsen, P. (2013). The resilience of citizenship traditions: Civic integration in Germany, Great Britain and Denmark. Ethnicities, 13(1), 86-109.

Myhre, J. E. (2003): Det liberale innvandringsregimet, 1860-1901 [The Liberal Immigration Regime, 1860-1901]. In: K. Kjeldstadli (Ed): Norsk innvandringshistorie 2: I nasjonalstatens tid 1814-1940 (pp. 196-222). Oslo: Pax Forlag.

Nordhaug, S. (2000). Tilknytning og privilegier: En studie i fremveksten av norsk statsborgerrett [Belonging and Privileges: The Emergence of Citizenship Rights in Norway]. Department of History, Norwegian University of Science and Technology.

NOU 2000:32. Lov om erverv og tap av norsk statsborgerskap (Statsborgerloven) [Law on Acquisition and Loss of Citizenship (The Citizenship Law)]. Oslo: Norwegian Ministry of Justice and the Police.

Ot.prp. nr. 41. (2004-2005). Om lov om norsk statsborgerskap (Statsborgerloven). [Proposition to the Norwegian Storting regarding the Citizenship Act]. Oslo: Norwegian Ministry of Local Government and Regional Development.

Palmgren, S., \& Wetterberg, G. (2017). Nordens tid är nu. Förutsättningar och möjligheter med ett nordiskt medborgarskap [The Time of the Nordic Countries is Now. Preconditions and Possibilities of a Nordic Citizenship]. Tankesmedjan Agenda.

Perchinig, B., \& Bauböck, R. (2006). Preface. In R. Bauböck, E. Ersbøll, K. Groenendijk, \& H. Waldrauch (Eds.), Acquisition and Loss of Nationality: Policies and Trends in 15 European Countries. Volume 2: Country Analysis. Amsterdam: Amsterdam University Press.

Pettersen, S.V. (2012). Overgang til norsk statsborgerskap 1977-2011 [Transititon to Norwegian Citizenship 1977-2011]. Report 2012/25. Oslo: Statistics Norway.

Prop. 146 L (2016-2017). Endringer i statsborgerloven mv. (tap av statsborgerskap ved straffbare forhold eller av hensyn til grunnleggende nasjonale interesser) [Changes in the Citizenship Act. (Loss of Citizenship by Criminal Acts or for the Sake of Fundamental National Interests)]. Oslo: The Norwegian Ministry of Justice and Public Security.

Raj, D. S. (2015). The overseas citizen of India and emigrant infrastructure: tracing the deterritorializations of diaspora strategies. Geoforum, 59, 159-168.

Reeskens, T., \& Hooghe, M. (2010). Beyond the civic-ethnic dichotomy: investigating the structure of citizenship concepts across thirty-three countries. Nations and nationalism, 16(4), 579-597.

Schlenker, A., (2016). Divided loyalty? Identification and political participation of dual citizens in Switzerland. European Political Science Review, 8(4), 517-546.

Schuck, P. (1998). Citizens Strangers and In-Betweens: Essays on Immigration and Citizenship. Boulder: Westview Press.

Sejersen, T. B. (2008). "I Vow to Thee My Countries" - The Expansion of Dual Citizenship in the 21st Century. International Migration Review, 42(3), 523-49.

Skey, M. (2010). "A sense of where you belong in the world:" national belonging, ontological security and the status of the ethnic majority in England. Nations and Nationalism, 16(4), 71533 .

Smith, M.P. (2003). Transnationalism, the state, and the extraterritorial citizen. Politics \& Society, 31(4), 467-502.

SOU 1999:34. Svenskt medborgarskap. Slutbetänkande av 1997 års medborgarskapskommitté [Swedish Citizenship. Report from the Citizenship Commitee of 1997]. Stockholm: Swedish Ministry of Culture.

SOU 2013:29. Det svenska medborgarskapet [The Swedish Citizenship]. Stockholm: Swedish Ministry of Justice. 
Staeheli, L. A. (2010). Political Geography: Where's Citizenship? Progress in Human Geography, 35(3), 393-400.

Statistics Iceland (2017). Foreign citizens gaining Icelandic citizenship by former citizenship, sex and age 1991-2016. Retrieved from http://px.hagstofa.is/pxen/pxweb/en/lbuar/lbuar_mannfjoldi_3_bakgrunnur_Rikisfbr/MAN 04119.px

Stokke, K. (2013). Conceptualizing the politics of citizenship. Publication on Power, Conflict and Democracy in South \& Southeast Asia, 5(1).

Stokke, K., \& Erdal, M.B. (2017) Political geographies of citizenship. Norwegian Journal of Geography, 71 (4): 189-192.

Street, A. (2014). My child will be a citizen: Intergenerational motives for naturalization. World Politics, 66(2), 264-292.

Suárez-Orozco, C., Hernández, M. G., \& Casanova, S. (2015). "It's sort of my calling": The civic engagement and social responsibility of Latino immigrant-origin young adults. Research in Human Development, 12(1-2), 84-99.

Talleraas, C. (2017). Reconciling transnational mobility and national social security: what say the welfare state bureaucrats? Journal of Ethnic and Migration Studies, 1-19.

Torpey, J. (2000). The Invention of the Passport: Surveillance, Citizenship and the State. Cambridge: Cambridge University Press.

UDI (2018a). Clarified identity in citizenship cases. Retrieved from https://www.udi.no/en/worddefinitions/clarified-identity-in-citizenship-cases/

UDI (2018b). Guide to case processing times for applications for Norwegian citizenship. Retrieved from: https://www.udi.no/en/word-definitions/guide-to-case-processing-times-for-applicationsfor-norwegian-citizenship/?h=1\&c=som

Udlændinge-, Integrations- og Boligministeriet. (2015). Cirkulærebeskrivelse om naturalisation nr. 10873 af 13.10.2015 [Circular Document no. 10873 of 13.10.2015 on Naturalization]. Retrieved from https://www.retsinformation.dk/Forms/Ro710.aspx?id=174789

van Bochove, M. \& Rusinovic K. (2008). Transnationalism and Dimensions of Citizenship. Journal of Ethnic and Migration Studies, 34(8), 1337-43.

Vassbotn, V.P. (2006). Nasjonalstatlige prinsipper I en transnasjonal tid - en analyse av den nye statsborgerloven [Nation-state Principles in a Transnational Time - an Analysis of the new Citizenship Law]. MA thesis. Department of Political Science, University of Oslo.

Vertovec, S., \& Wessendorf, S. (Eds.). (2010). The Multiculturalism Backlash: European Discourses, Policies and Practices. London: Routledge.

Vink, M. P. \& Bauböck, R. (2013). Citizenship configurations: Analysing the multiple purposes of citizenship regimes in Europe. Comparative European Politics, 11(5), 621-48.

Vink, M.P., Breuer, T. P. \& Dronkers, J. (2012). Immigrant Naturalization in the Context of Institutional Diversity: Policy Matters, but to Whom? International Migration, 51(5), 1-20.

Wickström, M. (2017). Nordic brothers before strange others: pan-national boundary making in the post-war naturalization policies of the Nordic countries. Ethnic and Racial Studies, 40(4), 675-693.

Zimmer, O. (2003). Boundary mechanisms and symbolic resources: towards a process-oriented approach to national identity. Nations and Nationalism, 9(2), 173-93. 


\section{Appendix: Literature overview}

In this appendix, we have compiled a range of relevant documents - reports, theses, and scientific contributions - which considers citizenship law and policies in the Nordic countries. The list is not comprehensive, but includes the most important texts. We distinguish between different types of documents to make it easier for the reader to get an overview of the relevant literature.

\section{EUDOCIT country reports 39}

Bernitz, H. (2012). Country Report: Sweden. EUDO Citizenship Observatory. Badia Fiesolana: European University Institute.

Bernitz, H. (2013). Naturalisation Procedures for Immigrants. Sweden. EUDO Citizenship Observatory. Badia Fiesolana: European University Institute.

Björnsson, T. \& Pétursson, G.T. (2013). Naturalisation Procedures for Immigrants. Iceland. EUDO Citizenship Observatory. Badia Fiesolana: European University Institute.

Brochmann, G. (2013). Country Report: Norway. EUDO Citizenship Observatory. Badia Fiesolana: European University Institute.

Ersbøll, E. (2013). Naturalization Procedures for Immigrants. Denmark. EUDO Citizenship Observatory. Badia Fiesolana: European University Institute.

Ersbøll, E. (2015a). Country Report: Denmark. EUDO Citizenship Observatory. Badia Fiesolana: European University Institute.

Fagerlund, J. \& Brander, S. (2013). Country Report: Finland. EUDO Citizenship Observatory. Badia Fiesolana: European University Institute.

Gozdecka, D.A. (2013). Naturalisation Procedures for Immigrants. Finland. EUDO Citizenship Observatory. Badia Fiesolana: European University Institute.

Jóhannesson, G. T., Pétursson G.T., \& Björnsson, T. (2013). Country Report: Iceland. EUDO Citizenship Observatory. Badia Fiesolana: European University Institute.

\section{Policy evaluations}

Hagelund, A., Kavli, H.C. \& Reegård, K. (2009). "Jeg følte det var min dag". Om deltakere og deltakelse i statsborgerseremonier 2006-2008 ["I felt it was my day". On Participants and Participation in Citizenship Ceremonies 2000-2008]. FAFO-report 2009:18. Oslo: FAFO.

Institut for menneskerettigheder. (2016). Statsborgerskab. Status 2015-16 [Citizenship. Status 2015-16]. Copenhagen: Institut for menneskerettigheder.

\footnotetext{
39 The EUDOCIT country reports are published by the European University Institute as part of the broader project EUDO Citizenship Observatory, which started up in 2008 and have mapped the historical development of citizenship laws in a range of European countries. Since 1 January 2017, the project's new name has been GLOBALCIT. The new name reflects what now is the Observatory's worldwide coverage is. See the project's webpage for more information: http://globalcit.eu/
} 
Viblemo, T.E., Gustafsson, M., Ersbøll, E., Damsholt, T., Aagedal, O., Slottved, M. \& Salomonsen, J. (2010). Rettigheter og tilhørighet. Evaluering av statsborgerregelverket [Rights and Belonging. Evaluation of the Citizenship Legislation]. Oslo: Oxford Research.

\section{Master's and doctoral theses}

Bevelander, P. (2000). Immigrant Employment Integration and Structural Change in Sweden, 19701995. Doctoral Thesis. Lund University.

Birkvad, S.R. (2017). The Meanings of Citizenship: Mobility, Legal Attachment and Recognition. MA thesis. Department of Sociology and Human Geography, University of Oslo.

Brixen, U. (2009). Dansk Statsborgerskab i et indvandrerperspektiv: hvilken betydning kan en policyændring iform af skærpede krav til opnåelse af dansk statsborgerskab forventes at have for følelsen af inklusion i samfundet hos indvandrere fra ikke-vestlige lande? [Danish Citizenship in an Immigrant Perspective: How Can a Restrictive Policy Change Affect Feelings of Inclusion in Society Among Immigrants from non-Western Countries?]. MA thesis. Department of Political Science, Aarhus University.

Florén, A. (2010). Dubbelt statsborgarskap. Ett hot mot det norske fellesskapet och en realitet i det pragmatiske Sverige [Dual Citizenship. A Threat against the Norwegian Community and a Reality in Pragmatic Sweden]. MA thesis. Department of Political Science, University of Oslo.

Hammari, K. (2004). Bør man kunne norsk for å være norsk? Prinsipper for tildeling av statsborgerskap til immigranter [Should one know Norwegian to be Norwegian? Principles of Granting Citizenship to Immigrants]. MA thesis. Department of Political Science, University of Oslo.

Hansen, K. K. (2011). Naturalisering I Norge. En studie av innvandrergruppers overgang til norsk statsborgerskap [Naturalization in Norway. A Study of Immigrant Groups Transition to Norwegian Citizenship]. MA thesis. Department of Political Science, University of Oslo.

Hjellum, I. (2009). Velkommen som ny norsk statsborger. En kvalitativ studie av statsborgerskapets innhold og betydning i det flerkulturelle Norge [Welcome as a new Citizen. A Qualitative Study of the Content and Significance of Citizenship in Multicultural Norway]. MA thesis. Department of Sociology and Human Geography, University of Oslo.

Jensen, C.H. (2014). Motivation eller frustration? Et kvalitativt studie af dansk statsborgerlovgivnings integrationseffekt [Motivation or Frustration? A Qualitative Study of Danish Citizenship Legislation's Integration Effects]. MA thesis. Department of Political Science, Aarhus University.

Midtbøen, A.H. (2008). Innvandringens ideologiske konsekvenser. Årsaker til og implikasjoner av statsborgerrettslig divergens $i$ de skandinaviske landene [The Ideological Consequences of Immigration. Causes and Implications of Citizenship Divergence in the Scandinavian Countries]. MA thesis. Department of Sociology and Human Geography, University of Oslo.

Møller, C.M. (2013). "Til et folk de alle høre..." En komparativ analyse af de parlamentariske debatter vedrørende dobbelt statsborgerskab i Tyskland og Danmark 1998-2011 ["To a People Everyone Belongs..." A Comparative Analysis of Parliamentary Debates on Dual Citizenship in Germany and Denmark 1998-2011]. MA thesis. Department of History, Copenhagen University.

Nordhaug, S. (2000). Tilknytning og privilegier: En studie i fremveksten av norsk statsborgerrett [Belonging and Privileges: The Emergence of Citizenship Rights in Norway]. Doctoral thesis. Department of History, Norwegian University of Science and Technology.

Olsen, E.D.H. (2004). Mellom rettigheter, kultur og cosmopolis: en teoretisk og empirisk analyse av europeisering og statsborgerskap [Between Rights, Culture and Cosmopolis: a Theoretical and Empirical Analysis of Europeanization and Citizenship]. Doctoral thesis. Department of Political Science, University of Oslo.

Stenhammer, G.K. (2015). Statsborgerskapets røtter og føtter. En rettssosiologisk studie av statsborgerskapets betydning i lys av nasjonale og globale samfunnsutviklinger [The Roots and Feet of Citizenship. A Sociology of Law Analysis of the Significance of Citizenship in Light of 
National and Global Developments]. MA thesis. Department of Criminology and Sociology of Law, University of Oslo.

Vassbotn, V.P. (2006). Nasjonalstatlige prinsipper I en transnasjonal tid - en analyse av den nye statsborgerloven [Nation state Principles in a Transnational Time - an Analysis of the New Citizenship Law]. MA thesis. Department of Political Science, University of Oslo.

Wickström, M. (2015). The Multicultural Moment. The History of the Idea and Politics of Multiculturalism in Sweden in Comparative, Transnational and Biographical Context, 1964-1975. Doctoral Thesis in General History. Åbo: Åbo Akademi University.

\section{Reports}

Bevelander, P., Helgertz, J. (Eds.) (2015). Vem blir medborgare och vad händer sen? Naturalisering i Danmark, Norge och Sverige [Who Becomes Citizens and What Happens Later? Naturalization in Denmark, Norway and Sweden]. Delmi report 2015:6. Stockholm: Delegationen för migrationsstudier.

Pettersen, S.V. (2012). Overgang til norsk statsborgerskap 1977-2011 [Transititon to Norwegian Citizenship 1977-2011]. Report 2012/25. Oslo: Statistics Norway.

Spång, M. (2015). Svenskt medborgarskap: reglering och förändring i skandinaviskt perspektiv [Swedish Citizenship: Regulation and Change in a Scandinavian Perspective]. Delmi report 2015:4. Stockholm: Delegationen för migrationsstudier.

Vrålstad, S. \& Wiggen, K.S. (Eds.) (2017). Levekår blant innvandrere i Norge 2016 [Living Conditions Among Immigrants in Norway 2016]. Report 2017/13. Oslo: Statistics Norway.

\section{Policy Briefs}

Erdal, M. B. \& Talleraas, C. (2015) Becoming One of Us?, PRIO Policy Brief, 11. Oslo: PRIO.

Fangen, K., Paasche, E., Lynnebakke, B. (2012) Citizenship Regimes: Consequences for Inclusion and Exclusion of Young Adult Immigrants in Europe, EUMARGINS Policy Brief 2, Oslo: University of Oslo.

\section{Academic publications}

Bauböck, R., Ersbøll, E., Groenendijk, K. \& Waldrauch, H. (Eds.). (2006a). Acquisition and Loss of Nationality: Policies and Trends in 15 European Countries. Volume 1: Comparative Analysis. Amsterdam: Amsterdam University Press.

Bauböck, R., Ersbøll, E., Groenendijk, K. \& Waldrauch, H. (Eds.). (2006b). Acquisition and Loss of Nationality: Policies and Trends in 15 European Countries. Volume 2: Country Analyses. Amsterdam: Amsterdam University Press.

Bech, E.C., Jensen, K.K., Mouritsen, P. \& Olsen, T.C. (2017). Hvem er folket? Flygtninge og adgangen til dansk statsborgerskab [Who is the People? Refugees and Access to Danish Citizenship]. Politica, 49(3), 227-448.

Bevelander, P. (2011). Naturalization and Inclusion. In OECD (Ed.), Naturalization: A Passport for the Better Integration of Immigrants? (pp. 2010: 230). Paris: OECD Publishing.

Bevelander, P. \& DeVoretz, D.J. (2008). The Economics of Citizenship. Malmö: Malmö University (MiM).

Bevelander, P., Fernández, C. \& Hellström, A. (Eds.). (2011). Vägar till medborgarskap [Paths to Citizenship]. Arkiv förlag. 
Bevelander, P. \& Pendakur, R. (2011). Voting and Social Inclusion in Sweden. International Migration 49(4), 67-92.

Bevelander, P. \& Spång, M. (2014). From Aliens to Citizens: The Political Incorporation of Immigrants. In B. Chiswick \& P. Miller (Eds.), Handbook of the Economics of International Migration, 1A: The Immigrants (pp. 443-82). Amsterdam: North-Holland.

Bernitz, H.L. (2004). Medborgarskapet i Sverige och Europa: Räckvidd och rättigheter [Citizenship in Sweden and Europe: Range and Rights]. Uppsala: lustus förlag.

Borevi, K., Jensen, K.K. \& Mouritsen, P. (2017). The civic turn of immigrant integration policies in the Scandinavian welfare states. Comparative Migration Studies, 5(9), 1-17.

Borevi, K. (2017). Diversity and solidarity in Denmark and Sweden. In K. Banting and W. Kymlicka (Eds.), The Strains of Commitment: The Political Sources of Solidarity in Diverse Societies (pp. 364388). Oxford: Oxford University Press.

Bremdal, P. (2016). Rätt til medborgarskap? Om de svenska naturalisationsreglerna [Right to Citizenship? On the Swedish Naturalization Rules]. Uppsala: Iustus förlag.

Brochmann, G. (2002). Statsborgerskap, medborgerskap og tilhørighet [Citizenship and Belonging]. In G. Brochmann, T.J. Rogstad (Eds.), Sand i maskineriet. Makt og demokrati i det flerkulturelle Norge (pp. 56-84). Oslo: Gyldendal.

Brochmann, G. (2007). Til Dovre faller. Å bli norsk - å være norsk - troskapsløfte og statsborgerskap i den foranderlige nasjonen [Until Dovre falls: Becoming Norwegian - being Norwegian - pledges of allegiance and citizenship in a changing nation]. In G. Alsmark, T. Kallehave \& B. Moldenhawer (Eds.), Migration och tillhörighet. Inklusions- och exclusionsprocesser i Skandinavien (pp. 99-126). Gøteborg: Makadam förlag.

Brochmann, G. \& Seland, I. (2010). Citizenship policies and ideas of nationhood in Scandinavia. Citizenship Studies, 14(4), 429-443.

Brochmann, G. \& Hagelund, A. (2012). Immigration Policy and the Scandinavian Welfare State 1945-2010. Houndmills: Palgrave Macmillan.

Damsholt, T.(2008). Statsborgerskabets materialiseringer: Vestlige statsborgerskabsceremonier i et nyt årtusind årtusind [The Materializations of Citizenship: Western Citizenship Ceremonies in a new Millennium]. Tidsskrift for Kulturforskning, 7(1), 5-27.

Damsholt, T. (2017). "I didn't think I would be emotional until I started saying the oath" emotionalising and ritualising citizenship. Journal of Ethnic and Migration Studies, 1-16.

Erdal, M. B., \& Sagmo, T. H. (2017). Descent, birthplace and residence: Aligning principles of citizenship with realities of migrant transnationalism. Norsk Geografisk Tidsskrift-Norwegian Journal of Geography, 71(4), 208-219.

Ersbøll, E. (2003a). Statsborgerskab - medborgerskab - europæisk konvergens - nordisk divergens [Citizenship - European Convergence - Nordic Divergence]. Nordisk tidsskrift for menneskerettigheter, 21(2-3), 147-163.

Ersbøll, E. (2003b). Nationality Law in Denmark, Finland and Sweden. In R. Hansen \& P. Weil (Eds.), Towards a European Nationality: Citizenship, Immigration and Nationality Law in the EU (pp. 230-254). Basingstoke: Palgrave MacMillan.

Ersbøll, E. (2014). Nationality and Identity Issues. German Law Journal, 15(5), 835-866.

Ersbøll. E. (2015b). Loss of Nationality in the Nordic Countries. In S.C. Nuñez \& G.R. de Groot (Eds.), European Citizenship at the Crossroads: The Role of the European Union on Loss and Acquisition of Nationality (pp. 185-216). Oisterwijk: Wolf Legal Publishers.

Gustafson, P. (2005). International Migration and National Belonging in the Swedish Debate on Dual Citizenship. Acta Sociologica, 48(1), 5-19.

Hagelund, A. \& Reegård, K. (2011). "Changing teams:" a participant perspective on citizenship ceremonies. Citizenship Studies, 15(6-7), 735-748.

Holm, L.K. (2006). Migration, nationalt tilhørsforhold og statsborgerskab: Forskelligt syn på dobbelt statsborgerskab i Danmark og Sverige [Migration, National Belonging and Citizenship. Divergent Views on Dual Citizenship in Denmark and Sweden]. In U. Hedetoft, B. Petersson, \& L. Sturfelt (Eds.), Bortom stereotyperna? Invandrare och integration i Danmark och Sverige (pp.145-173). Göteborg: Makadam Förlag. 
Jensen, K.K., Fernández, C. \& Brochmann, G. (2017). Nationhood and Scandinavian naturalization politics: varieties of the civic turn. Citizenship Studies, 21(5), 606-624.

Jensen, K. K., \& Mouritsen, P. (2017). Nationalism in a Liberal Register: Beyond the "Paradox of Universalism" in Immigrant Integration Politics. British Journal of Political Science, 1-20.

Kristinsson, A.P. (2012). Sprogtester og islandsk statsborgerskab [Language Tests and Icelandic Citizenship]. Sprog i Norden 2012, 47-64.

Midtbøen, A.H. (2009a). Statsborgerrettslig divergens I Skandinavia - En teoretisk utfordring [Divergence in Citizenship Rights in Scandinavia - A Theoretical Challenge]. Norsk statsvitenskapelig tidsskrift, 25, 307-329.

Midtbøen, A.H. (200gb). Statsborgerrettslig revisjon og integrasjonspolitisk variasjon i de skandinaviske landene [Nationality Reform and Divergent Conceptions of Integration in the Scandinavian Countries]. Tidsskrift for samfunnsforskning, 50(4), 523-550.

Midtbøen, A. H. (2011). Postnasjonal nødvendighet eller nasjonens retur? Holdninger til dobbelt statsborgerskap i de skandinaviske landene [Postnational Necessity or the Return of the Nation? Attitudes Towards Dual Citizenship in the Scandinavian Countries]. In T. H. Eriksen \& H. E. Næss (Eds.), Kulturell kompleksitet i det nye Norge. Oslo: Unipub.

Midtbøen, A.H. (2015). Citizenship, integration and the quest for social cohesion: nationality reform in the Scandinavian countries. Comparative Migration Studies, 3(3), 1-15.

Mouritsen, P. \& Olsen, T.V. (2013). Denmark between liberalism and nationalism. Ethnic and Racial Studies, 36(4), 691-710.

Mouritsen, P. (2013). The resilience of citizenship traditions: Civic integration in Germany, Great Britain and Denmark. Ethnicities, 13(1), 86-109.

Mouritsen, P. (2015). En plads i verden. Det moderne medborgerskab [A Place in the World. The Modern Citizenship]. København: Gyldendal.

Ronkainen, J. K. (2011). Mononationals, hyphenationals, and shadow-nationals: multiple citizenship as practice. Citizenship Studies, 15(2), 247-263.

Takle, M. (2006). Statsborgerskapsdebatt i Norge og Tyskland [Citizenship Debates in Norway and Germany]. Internasjonal politikk, 64(2), 199-212.

Simonsen, K. B. (2017). Does citizenship always further Immigrants' feeling of belonging to the host nation? A study of policies and public attitudes in 14 Western democracies. Comparative Migration Studies, 5(3), 1-17.

Stokes-DuPass, N. (2015). Integration and New Limits on Citizenship Rights: Denmark and Beyond. New York: Palgrave Macmillan.

Spång, M. (2007). Pragmatism All the Way Down? The Politics of Dual Citizenship in Sweden. In T. Faist (Ed.), Dual Citizenship in Europe. From Nationhood to Societal Integration (pp. 103-127). Cornwall: Ashgate.

Wickström, M. (2017). Nordic brothers before strange others: pan-national boundary making in the post-war naturalization policies of the Nordic countries. Ethnic and Racial Studies, 40(4), 675-693.

Aagedal, O. (Ed.) (2012). Statsborgarseremonier i Skandinavia [Citizenship ceremonies in Scandinavia]. Oslo: Unipub forlag. 
Nordic Council of Ministers

Nordens Hus

Ved Stranden 18

DK-1061 Copenhagen K

www.norden.org

\section{Citizenship in the Nordic Countries}

The Nordic countries have a century-long tradition for cooperation within the area of citizenship law. Since the mid-1970s, however, the Nordic countries have moved in different directions. Today, the Nordic countries represent the entire continuum in European citizenship policies - from liberal Sweden to restrictive Denmark, with the other Nordic neighbors in between. This report reviews the historical development and the current citizenship regime in the five Nordic countries, it provides statistics on the acquisition and loss of citizenship in each country over the past 10-15 years, and it offers a comparative analysis of the divergent development of citizenship law in the 2000s. The concluding chapter discusses possible consequences of the different citizenship regimes and the prospects for strengthened cooperation between the Nordic countries in the area of citizenship law. 